Portland State University

PDXScholar

$5-5-1994$

\title{
Planning for Academic Success: Survey of University Professors' Assessments of Non-native Students' Language Skill Needs
}

Carol BonDurant Sloan

Portland State University

Follow this and additional works at: https://pdxscholar.library.pdx.edu/open_access_etds

Part of the Speech and Rhetorical Studies Commons

Let us know how access to this document benefits you.

Recommended Citation

Sloan, Carol BonDurant, "Planning for Academic Success: Survey of University Professors' Assessments of Non-native Students' Language Skill Needs" (1994). Dissertations and Theses. Paper 4777.

https://doi.org/10.15760/etd.6661

This Thesis is brought to you for free and open access. It has been accepted for inclusion in Dissertations and Theses by an authorized administrator of PDXScholar. Please contact us if we can make this document more accessible: pdxscholar@pdx.edu. 


\section{THESIS APPROVAL}

The abstract and thesis of Carol BonDurant Sloan for the Master of Arts in TESOL were presented May 5, 1994, and accepted by the thesis committee and the department.

COMMITTEE APPROVALS:
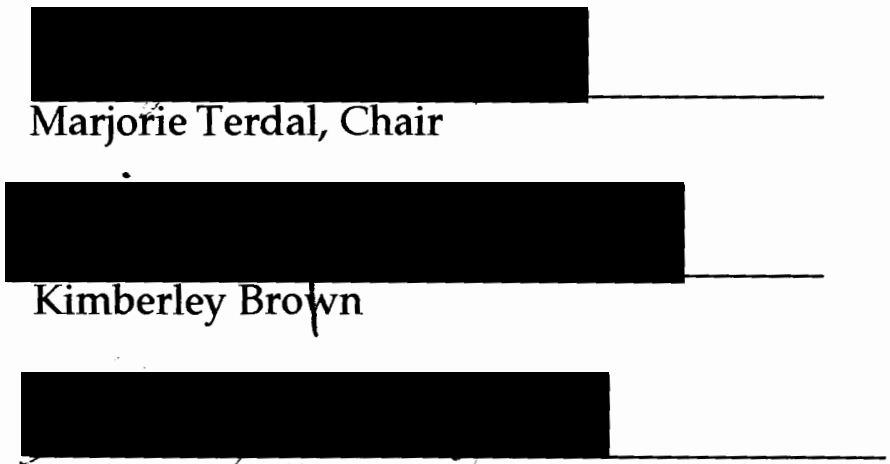

Shirley Morrell

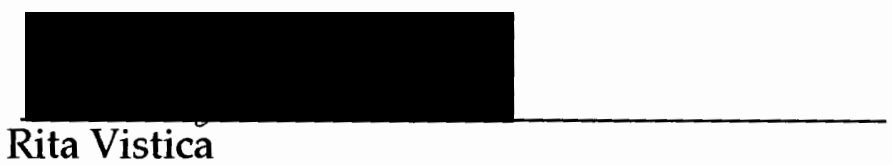

Representative of the Office of Graduate Studies

DEPARTMENT APPROVAL:
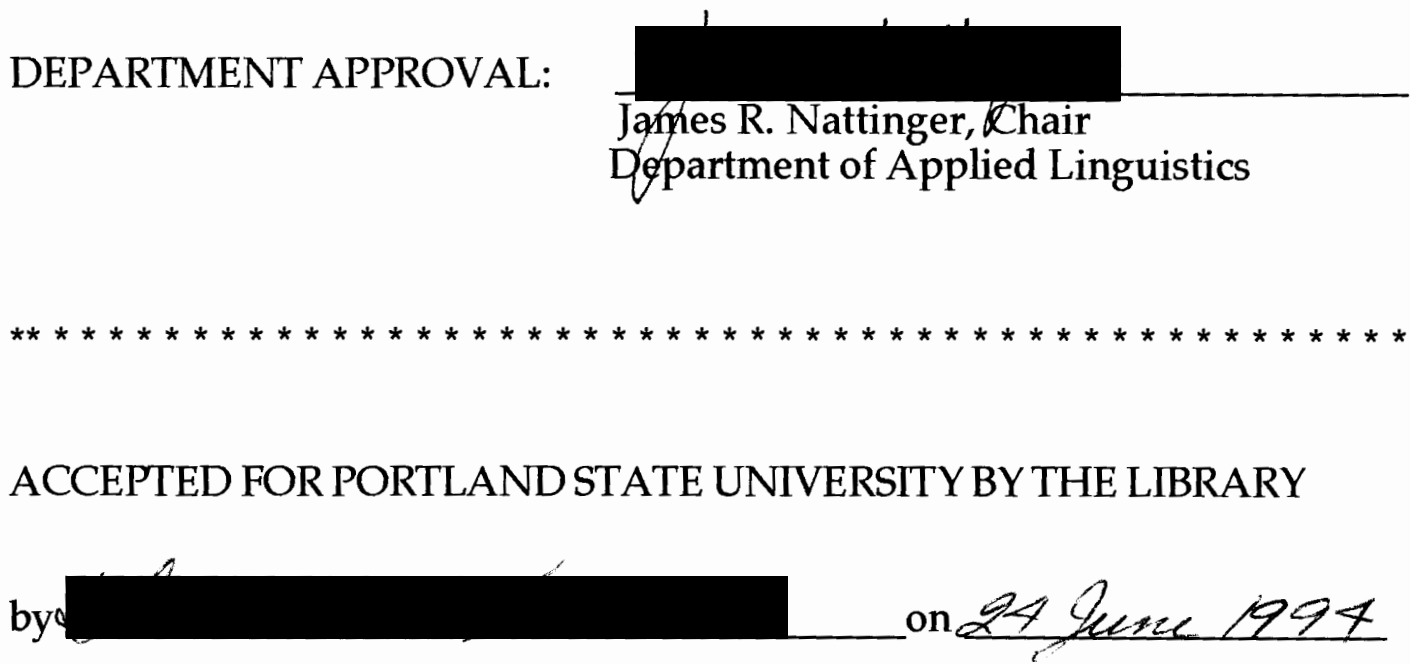


\section{ABSTRACT}

An abstract of the thesis of Carol BonDurant Sloan for the Master of Arts in TESOL presented May 5, 1994.

Title: Planning for Academic Success: Survey of University Professors' Assessments of Non-native Students' Language Skill Needs

The purpose of this study is to examine which language skills university professors believe are most essential for academic success in Portland State University classes. The study can shed light on a question for future research: Do current academic ESL classes at Portland State University teach the necessary skills to help international students maximize their second-language learning potential in university-level courses.

Enrollment statistics for 1993/94 show 53 percent of the 815 international students declared majors in two programs: the school of Business Administration and the school of Engineering and Applied Science. This study asked 31 instructors from business and engineering to assess which language skills--reading, writing, listening or speaking--were most important to success in their undergraduate and graduate classes; how they used the language skills; how international students performed in their classes compared with nativespeaking students; and to describe any critical incidents which appeared to have been caused by lack of comprehension of orally-presented materials.

Interview questions were designed to establish a profile of each class and assess the relationship between the amount of culturally-embedded vocabulary and the degree of difficulty experienced by non-native speaking students. 
Three patterns emerged from the research. First, the ranking of language skills followed results of earlier national surveys showing the importance of reading and listening. All faculty ranked reading the "most important" language skill; reading and listening were ranked equally "most important" by engineering faculty; and writing varied by level and discipline; and speaking was ranked "least important" by all faculty.

Second, all faculty ranked textbooks the preferred use of reading skills; note taking was the most-used listening skill; and class discussion was the mostused speaking skill. Writing activities varied by level and discipline, although reports and essay answers were the most frequently mentioned uses.

Third, faculty said international students performed better in quantitative than qualitative classes. Within both disciplines, classes which manipulated numbers were less problematic than those which manipulated language with culturally-embedded context or vocabulary.

Implications for ESL curriculum design suggest emphasis on skills considered most important by academic faculty. 
PLANNING FOR ACADEMIC SUCCESS:

SURVEY OF UNIVERSITY PROFESSORS' ASSESSMENTS

OF NON-NATIVE STUDENTS' LANGUAGE SKILL NEEDS

by

CAROL BONDURANT SLOAN

A thesis submitted in partial fulfillment of the requirements for the degree of

\section{MASTER OF ARTS}

in

TESOL

Portland State University

1994 


\section{ACKNOWLEDGMENTS}

I would like to thank my advisor, Dr. Marjorie Terdal, for her support, understanding, and effort on my behalf; my committee, Dr. Kimberley Brown, Shirley Morrell, and Sister Rita Vistica, for their valuable time; and Jane Dresser for her professional encouragement and support of me as a teacher. My grateful thanks go also to my children, Mara and Ryan, and friends for believing in me.

This work is dedicated to the memory of my mother, whose unfailing vision made me believe I could accomplish this goal, and to my husband, Steve, whose love and support made it possible to do so. 
TABLE OF CONTENTS

PAGE

ACKNOWLEDGMENTS $\ldots \ldots \ldots \ldots \ldots \ldots \ldots \ldots \ldots \ldots \ldots \ldots \ldots$ i

LIST OF TABLES $\ldots \ldots \ldots \ldots \ldots \ldots \ldots \ldots \ldots \ldots \ldots \ldots, \quad \mathbf{v}$

LIST OF FIGURES $\ldots \ldots \ldots \ldots \ldots \ldots \ldots \ldots \ldots \ldots \ldots \ldots \ldots \ldots$ vi

CHAPTER

I INTRODUCTION $\ldots \ldots \ldots \ldots \ldots \ldots \ldots \ldots \ldots \ldots \ldots$

Research Questions............... 4

II REVIEW OF THE LITERATURE $\ldots \ldots \ldots \ldots \ldots \ldots$

Traditional ESL Goals ................ 6

Reading Skills................. 8

Listening Skills ................. 10

Writing Skills ................... 15

Speaking Skills ................. 16

Non-Traditional ESL Goals ............. $\quad 17$

Summary .................... 19

III METHODOLOGY $\ldots \ldots \ldots \ldots \ldots \ldots \ldots \ldots \ldots \ldots \ldots$

Rationale ..................... 21

Subjects $\ldots \ldots \ldots \ldots \ldots \ldots \ldots \ldots \ldots \ldots \ldots \ldots \ldots \ldots$

Pilot Study $\ldots \ldots \ldots \ldots \ldots \ldots \ldots \ldots \ldots \ldots \ldots \ldots \ldots$

Skills Survey $\ldots \ldots \ldots \ldots \ldots \ldots \ldots \ldots \ldots \ldots$ 
IV ANALYSIS OF SURVEY QUESTIONNAIRE ...... 28

Part One: Language Skill Importance . . . . . . . 29

Part Two: Language Skill Differences. ........ 34

Part Three: Language Skill Uses . . . . . . . . . . 39

Summary of Findings ............. 60

V ANALYSIS OF SURVEY INTERVIEWS ......... 62

Analysis Factors . . . . . . . . . . 62

Individual Language Skill Importance . . . . . . 65

Faculty Assessments . . . . . . . . . . . . 67

Summary .................. 84

VI CONCLUSIONS ................... 86

Purpose of the Study ............. 86

Cultural Factors of Language . . . . . . . . 87

Answers to Research Questions .......... 89

Implications of the Study . . . . . . . . . . . 100

Implications for Teachers of ESL . . . . . . . 101

Limitations . . . . . . . . . . . . . . . 107

Conclusion .................. 108

Recommendations ............... 110

BIBLIOGRAPHY ....................... 113

APPENDICES

A

FACULTY FORMS ............... 116

Interview Request Letter $\quad 117$

Faculty Informed Consent Form 118 
APPENDICES

B

B

C

D

E

F

G

$\mathrm{H}$

I
INTERVIEW QUESTIONNAIRES ......... 119

Questionnaire

120

Interview Questions

TABLES OF NUMBER OF RESPONSES AND

RANKINGS OF ALL DISCIPLINES AND LEVELS

122

SCORES OF COMPARATIVE RANKINGS OF LANGUAGE SKILLS ...............

SCORES OF COMPARATIVE RANKINGS OF LANGUAGE SKILLS USES BY

DISCIPLINE AND LEVEL . . . . . . . . . . .

Reading

133

137

Speaking

141

Listening

TABLES OF HIGHEST AND LOWEST LANGUAGE SKILLS BY FACULTY AVERAGES

TABLES OF HIGHEST AND LOWEST LANGUAGE SKILLS USES BY FACULTY AVERAGES .....

COMPARISON OF MOST IMPORTANT LANGUAGE SKILLS AND USES BY AVERAGE SCORE OF ALL FACULTY . . . . . . . . . . . . . .

GOALS OF PORTLAND STATE UNIVERSTTY'S ENGLISH AS A SECOND LANGUAGE PROGRAM 


\section{LIST OFTABLES}

TABLE

\section{PAGE}

I. Results of Survey Question F: Types of English Important to Success by Discipline and Level

II Language Continuum of Courses 


\section{LIST OF FIGURES}

1. Comparative Importance of Language Skills for Undergraduate Business Faculty

2. Comparative Importance of Language Skills for Graduate Business Faculty

3. Comparative Importance of Language Skills for Undergraduate Engineering Faculty

4. Comparative Importance of Language Skills for Graduate Engineering Faculty

5. Comparative Rankings for Reading Skills 34

6. Comparative Rankings for Listening Skills 35

7 Comparative Rankings for Writing Skills 36

8 Comparative Rankings for Speaking Skills 38

9. Undergraduate Business Faculty: Uses of Reading Skills 41

10. Graduate Business Faculty: Uses of Reading Skills 42

11. Undergraduate Engineering Faculty: Uses of Reading Skills 43

12. Graduate Engineering Faculty: Uses of Reading Skills 44

13. Undergraduate Business Faculty: Uses of Writing Skills 46

14. Graduate Business Faculty: Uses of Writing Skills 47

15. Undergraduate Engineering Faculty: Uses of Writing Skills 48

16 Graduate Engineering Faculty: Uses of Writing Skills 49 
17. Undergraduate Business Faculty: Uses of Speaking Skills 51

18. Graduate Business Faculty: Uses of Speaking Skills 52

19. Undergraduate Engineering Faculty: Uses of Speaking Skills

20 Graduate Engineering Faculty: Uses of Speaking Skills 54

21 Undergraduate Business Faculty: Uses of Listening Skills 56

22 Graduate Business Faculty: Uses of Listening Skills 57

23. Undergraduate Engineering Faculty: Uses of Listening Skills

24 Graduate Engineering Faculty: Uses of Listening Skills 


\section{CHAPTER I}

\section{INTRODUCTION}

The education of international students, especially graduate students, has become a major activity of U.S. universities. According to the U.S. Department of Commerce (1993) over 420,000 students were enrolled in U.S. higher education institutions in the academic year 1993-94.

Portland State University (PSU) statistics show a 9\% increase in foreign student enrollment in the four year period between 1989 and 1993 (PSU Office of Institutional Research and Planning). In order for international students to succeed in their academic programs they must possess English language proficiency beyond the communicative dimension of language needed to successfully engage in social and economic transactions. They must be able to master subject matter in a second-language.

International students' lack of comprehension of academic lectures is mentioned as a major problem in second-language literature. In a pilot study at Portland State University (PSU), this concern was voiced by faculty from business and engineering departments. Non-native students from English as a Second Language (ESL) classes at PSU report difficulty listening to lectures, taking notes in classes, and participating in small group discussions once they have transitioned into university content classes. 
Richards (1983) notes a general lack of direct research on listening comprehension in a second language. He reports that most of what we know about listening ability is derived from studies with native speakers.

The development of "academic language skills," reading, writing, listening, and speaking focused on the school environment rather than on social communication, is advocated as a necessary step for successful academic progress for international students in an American university setting. However, a review of the literature reveals few faculty assessments of the ranked importance of academic language skills and the preferred uses for each of them within the undergraduate/graduate levels and among various disciplines.

Successful transition for non-native language learners to content university-level classes is an area of concern for language professionals who teach English as a Second Language (ESL) classes. Of special concern is the move to comprehension and note-taking in university lectures after their experience in sheltered ESL classes. National research by Johns (1981) and Powers (1986) among interdisciplinary academic faculty supports this concern.

Considerations of how best to prepare students for their transition to learning content in a second language led to this study. At the heart of the matter was the question, "what refinements to the basic language skills--reading, writing, listening, and speaking--would contribute most directly to their academic success in university classes?" To answer this question it was necessary to test the perceptions university professors held regarding the skills most important to non-native speakers' academic success.

In two studies by Johns (1981) and Powers (1986), faculty were surveyed and professors from every discipline cited incidents involving non-native students' misunderstanding of lectures. Frequently mentioned were difficulties 
in taking examinations due to misinterpreting questions, failure to understand assignments, lack of understanding of idioms and technical terms, and a tendency to interpret non-literal language literally. In addition, faculty cited the tendency of non-native students not to ask questions in class, a fact which was generally interpreted as a lack of understanding. Only a few faculty saw this as more of a cultural phenomenon than a lack of comprehension.

In Johns' survey of 100 San Diego State University faculty members, nearly all disciplines ranked the receptive skills of reading and listening first in importance. Writing was ranked as most important only by faculty in the English department. Speaking was considered least important by faculty in all disciplines.

Johns asked faculty members if general English or discipline-specific English was more important to success in their classes. Only the majority of Engineering faculty chose specific-purposes English over general English, whereas other departments chose general English as first in importance.

Powers (1986) analyzed survey responses from graduate faculties in civil and electrical engineering, psychology, chemistry, computer science, and business, and undergraduate faculty in English. The faculty, from twenty-eight institutions in the United States and Canada, concluded that non-native speakers of English have disproportionately greater difficulty with nine listening-related activities, including: following lectures given with different speeds, understanding informally structured lectures, deducing the meaning of words from the context, identifying the role of discourse cues, and recognizing irrelevant matter.

Powers names reading as the skill most important to academic success, and listening as either the second or third most important ability. As in Johns' 
study, only the English department faculty ranked writing as the most important ability. Speaking ability was rated as the least important in all disciplines, although speaking ability was rated higher in business than in other disciplines.

Concerns expressed by Portland State University faculty echo results found in the studies by Johns and Powers. In an unpublished 1992 pilot questionnaire with professors from the engineering and business departments, general problems of non-native students' comprehension were discussed. The difficulties described ranged in seriousness from students' inability to understand and participate in classroom humor to their tendency to read academic materials too slowly, using a "word-for-word" approach.

The need for additional research to examine the actual perceptions of faculty regarding the study skills needed by ESL students for optimal academic success in university classes at PSU led to this study.

\section{RESEARCHQUESTIONS}

The purpose of this study is to examine which language skills university professors believe to be most essential for academic success in classes at Portland State University.

1. a. Which of the four language skills, reading, writing, listening and speaking, are considered most important by faculty in the schools of Business Administration and Engineering and Applied Science?

b. Is there a difference in how these skills are ranked between the two divisions?

c. Is there a difference in how these skills are ranked between undergraduate and graduate levels? 
2. a. For what functions are reading, writing, listening and speaking actually used.

b. Are these skills used similarly by both the schools of Business Administration and Engineering and Applied Science?

c. Are these skills used similarly by both undergraduate and graduate levels?

In order to answer these questions, an academic skills survey, modeled closely after the study by Johns (1981), was given to a total of 31 faculty members from Engineering and Business Administration. Faculty members were contacted by letter [see Appendix A] and assured of confidentiality.

A balanced perspective was sought among all departments: fifteen faculty from Engineering--Civil Engineering (CE), Electrical Engineering (EE), Mechanical Engineering (ME), Computer Engineering (CMPS), Engineering Management Program (EMP); and sixteen from Business Administration-Information Systems and Quantitative Analysis (ISQA), Accounting (ACTG), Management (MGMT), Marketing (MKTG). Graduate faculty from the Master's of Business Administration Program (MBA) faculty were represented within each of the Business Administration departments.

The following chapter summarizes research on the question of the appropriateness of the type of language skills needed by second-language learners for success within an academic environment. Chapter III describes the survey participants and the methodology. Chapter IV details the survey results from the questionnaire, while Chapter $\mathrm{V}$ presents results from the interviews with 31 faculty members. Chapter VI discusses the findings, relates the implications to teachers of ESL, and offers recommendations to designers of ESL curricula. 


\section{CHAPTER II \\ REVIEW OF THE LITERATURE}

The post-secondary international students who want to succeed in American university-level classes, will need to know what is expected of them by university professors. This chapter examines the traditional goals of ESL; literature which questions how best to prepare non-native speakers to succeed in an academic environment; and research on teaching strategies for the specific language skills of reading, writing, listening, and speaking.

\section{TRADITIONAL ESL GOALS}

Much evidence exists that indicates the traditional goals of ESL programs--general English proficiency and the ability to interact effectively in social situations--do not equate with academic success.

Saville-Troike (1984) reached this conclusion regarding elementary school students, whose scores on English proficiency tests did not correlate with their scores on achievement tests in content subjects. In addition, SavilleTroike found no correlation between the amount of time her subjects spent interacting in English and their achievement test scores.

In a study of Hispanic students in Texas, Apodaca (1985) found that the needs of this limited English, secondary school population were better met if the ESL curriculum included subject area courses at all levels. In recommending 
a High Intensity Language Training (HILT) curriculum to serve un-met needs, Apodaca states:

The content of most ESOL courses is not adequate for the proper preparation of ESOL students to go into regular content area and English courses. . . Our students need to be prepared beyond the interpersonal communication skills level to the academic language proficiency level.... (p. 5)

Cummins (1983) distinguishes between basic interpersonal communication skills and cognitive academic language proficiency in discussing the language skills necessary for academic success. Cummins theorizes that a second-language learner's linguistic encounters move along a continuum of language that is at one end context-embedded with cognitive clues and the other end context-reduced without cognitive clues. The stronger the clues from the language environment, the less demanding the search for meaning. This is the area where language responses can be learned and automatized. This often describes a social situation.

The academic environment moves the second-language learner along the continuum to the cognitively demanding area of context-reduced language clues. Here the learner must search for clues of meaning and use a creative, non-automatized response to language. In other words, the linguistic demands of a university classroom are different from those encountered in face-to-face social situations outside of class. He estimates that it takes between 5 and 7 years for students to approach grade-level norms in second language academic skills, versus about 2 years for immigrant students to master personal communication skills upon arrival in a host country. Cummins argues,

The strong relationships between language proficiency and academic and cognitive variables exist across all four of the general language skills (listening, speaking, reading, and writing). (p. 112) 
Studies by Adamson (1990) at the secondary-school level repeat this finding. Adamson reports that a study of the Science Research Associates (SRA) test scores of 1,547 ESL secondary-school students which found that ESL students fell significantly behind their native English speaking peers at all levels in all sections except math. After they were mainstreamed, post-elementary ESL students did not catch up with native speakers but fell further behind.

Adamson further reports that ESL students who got high scores on an English language test did not necessarily get high scores on content area tests. This finding suggests that although the students' proficiency in general English was adequate, their proficiency in academic English was not. The alarming implication is that the students' lack of academic language proficiency puts them significantly behind in mastery of the complex material required for high school students.

\section{READING SKILLS}

Teaching students how to guess meaning from context is an effective strategy for eliminating the "word-for-word" approach to reading that a faculty member in the Portland State University pilot questionnaire cited as an impediment to success in the business program.

The Adamson case studies of 15 ESL students in content classes suggest that a lack of academic success may be the result of a lack of effective academic skills, including the specific skills of reading and listening. The academic skills examined were note-taking, reading and dictionary use, oral participation, organization, copying, and memorization. An experimental pre-course was set up in which college students in a theme-based ESL course attended an undergraduate linguistics course for three weeks. 
Strategies used by students in the Adamson study involved guessing meaning of unknown words from context while missing part of the lecture, writing down in English whatever the lecturer said and translating it with help later, transcribing unknown words in their native language and asking for help later, and taping the lecture and translating later.

All of the subjects used the dictionary in connection with their reading assignments. Students who had a low tolerance for ambiguity tended to overuse the dictionary, looking up every unknown word, even very easy words. Others used the dictionary sparingly and looked up only the words that were important.

Adamson says that note-taking is a complex linguistic task in which even the best students often have to make a choice between understanding what the teacher is saying and taking notes. Adamson concludes that appropriate academic skills should be taught explicitly, and content-based courses provide an effective way to teach academic skills. Note-taking and reading should be taught in connection with real academic material in a setting with native English speakers, such as an adjunct course or a pre-course.

Ostler (1980) reports students' concerns over their inability to read complex academic material. Students also mentioned difficulty in note-taking and poor performance on some types of exams. In a needs analysis according to major and class standing among advanced ESL classes at the University of Southern California's American Language Institute, Ostler found that the greatest needs overall were the abilities to read text books $(90 \%)$, take notes in class $(84 \%)$, and ask questions in class $(68 \%)$. The study points out the need to develop reading strategies in students for understanding the rhetoric found in academic journals and papers. 
Ostler found a difference in academic skill need according to undergraduate and graduate class level. While both levels reported equivalent scores for reading text books and taking notes, undergraduates indicated a greater need for taking multiple choice exams, and graduate students indicated a need for reading academic journals and writing research papers.

\section{LISTENING SKILLS}

A study by Feyten (1989) investigated the relationship between native language listening skills and foreign language learning. Results suggest a positive relationship between listening ability and second-language acquisition, as demonstrated in both listening and oral skills. Feyten concludes that native language listening ability appears to be a previously unidentified factor contributing to the second-language learning process. She suggests that since listening ability can be improved through training, an important goal would be to investigate the effect of listening training on future second-language research.

Anderson-Mejias (1986) says the non-native learner experiences a great deal of difficulty in listening, and that often the required ESL classes do not prepare him or her for the specific skills associated with following a university lecture.

Surveys by Johns (1981) and Powers (1986) discuss lack of comprehension of academic lectures by international students. Difficulties in taking examinations due to misinterpreting questions, failure to understand assignments, lack of understanding of idioms and technical terms, and a tendency to interpret non-literal language literally were high on the list of major "listening" deficiencies. In addition, faculty cited the tendency of non- 
native students to not ask questions in class, which was generally interpreted as a lack of understanding.

In both Johns' and Powers' surveys, faculty members ranked reading and listening skills as most important in contributing to academic success. Writing was third in importance, and was ranked as first by only the English department faculties. Speaking was last in all disciplines.

Powers (1986) further analyzed survey responses from graduate faculties in civil and electrical engineering, psychology, chemistry, computer science, and business, and undergraduate faculty in English for perceptions about the importance of listening skills. The faculty, from twenty-eight institutions in the United States and Canada, concluded that non-native speakers of English have disproportionately greater difficulty with the following activities:

Following lectures given with different speeds

Comprehending key vocabulary related to the topic of a lecture

Deducing the meaning of words from the context in which they appear

Understanding informally structured lectures

Identifying the role of discourse cues

Following different modes of audio lectures

Recognizing irrelevant matter

Recognizing the function of such features as change of pitch and sentence stress.

Powers borrowed from studies of listening comprehension by Richards (1983), who identified 18 skills important to academic listening. Powers examined which of these specific listening features were shared across 
disciplines. All faculty members in Powers' study agreed that answering questions involving recall of details and involving inferences and deductions was viewed as somewhat more appropriate to descriptions of their disciplines than were other tasks mentioned, as was condensing (being able to reduce what is heard to an outline of main points).

Business faculty, however, rated skills of identifying the role of discourse cues, retaining information through note-taking, and retrieving information from notes as less important than did other faculty.

"Scanning" (listening for selected specific pieces of information) and "extending" (going beyond what was said) were seen as somewhat less appropriate to discipline-related tasks by faculty in the sciences. Scanning was viewed as inappropriate because course material in their disciplines needs to be considered "in detail and in depth" and scanning results in ignoring important details. Another concern was that scanning may imply that students know beforehand what relevant information is to be presented in lectures and that is not often the case.

"Extending" was viewed as inappropriate because it requires abilities beyond or other than listening skills, such as synthesis and critical thinking skills.

"Number questions" (questions involving the comprehension of numbers and numerical concepts) received the highest overall rating of appropriateness among disciplines. These high ratings were especially prominent in the quantitative fields of chemistry and engineering, but were mentioned even in less quantitative fields like English.

"Paraphrase answer" questions (selecting the best paraphrase of a statement), "appropriate response" questions (selecting the most logical answer 
from several available choices), and "conversation" questions (dialogues, or comprehending a conversation between speakers) were the question types rated as the next most appropriate in Powers' survey.

One of the ways that ESL classes can address faculty concerns about comprehension issues in university classes is to analyze the skill sets involved in understanding the organization and flow of the lecture. According to Adamson (1990), note-taking involves the ability to

. . comprehend the stream of speech, separate important from unimportant information, provide a logical framework for the important information, ... and write down the important information in its logical framework in the target language. (p. 71)

Lebauer (1984) says that good lecture comprehension involves specific skills of synthesizing discourse to extract information, predicting future information, and relating background knowledge to new information. Many students who have little difficulty in apparent fluency, find that these skills are not sufficiently developed to support their ease of lecture comprehension and note-taking. Lebauer says that listening involves recreation of text, consolidating, deleting, and generalizing information. Students need to be taught how to formulate correct hypotheses about the incoming information in order to correctly process it.

In addition to learning predictive skills, non-native speakers need an awareness of the lecturer's verbal and non-verbal markers and cohesive devices. Deciphering the flow of words in a lecture involves listening for discourse cues and understanding verbal, directional markers. In a study by DeCarrico and Nattinger (1988), lexical phrases that occurred in several academic lectures were examined and categorized for the discourse function 
they perform. DeCarrico and Nattinger see the comprehension problem as one related to the function of language rather than the form of language units.

DeCarrico and Nattinger offer the "lexical phrase approach", or "chunks" of language, as a new direction for solving many of these problems. They describe the standard lecture "formula" as consisting of many phrases which serve as directional signals for indicating how the information is to be organized and evaluated.

Three varieties of lectures were examined--reading style, rhetorical style, and conversational style--and categorized into topic markers, topic shifters, summarizers, exemplifiers, relators, evaluators, qualifiers, and aside markers. These lexical organizers serve to help students mentally organize and process the lecture by initiating expectations and predictions about it.

Traditionally, ESL classes teach students to recognize and understand formal markers of discourse like moreover, in addition, however. Global categories such as, Let me suggest some ways, my point is that, you might say that, that would go not only for $X$ but also for $Y$ are found in all three varieties of lectures, but not specifically taught in ESL classes, and therefore, students would not be expected to know that they signal important functions in the lecture.

DeCarrico and Nattinger offer the suggestion of teaching lexical phrases as vocabulary items, analyzing them in pieces the same way that first language learners do. Pattern practice drills could provide a way of gaining fluency and confidence. Eventually, students could learn to segment and construct their own phrases, as a bridge to understanding the phrases of others. 


\section{WRITING SKILLS}

Previous academic writing surveys have not answered the question of just what kinds of academic writing tasks students are called upon to do in U.S .universities. Horowitz (1986) says in creative writing, literature, and ESL classes, much attention is paid to organizing written material around invention and personal meaning rather than practice skills of academic information processing.

Bridgeman and Carlson's (1984) survey of frequency of academic writing topic types concluded that students would best be prepared for crossdisciplinary academic writing by tasks that require them to organize arguments from several sources, to analyze and critique ideas, and to focus on "paper organization [and] quality of content [rather] than on ... punctuation/spelling, sentence structure, vocabulary size." (p.278)

Horowitz (1986) suggests that writing teachers can create tasks which simulate the essential characteristics of real university writing assignments. In light of his survey of university writing assignment tasks, Horowitz advises that the ESL writing syllabus be aimed at teaching language skills within the context of the tasks which they will eventually serve:

....the main thrust [of the academic writing task] is to emphasize recognition and reorganization of data and to de-emphasize invention and personal discovery. . . the academic writer's task is not to create personal meaning, but to find, organize, and present data according to fairly explicit instructions.(p. 455) 


\section{SPEAKING SKILLS}

Of all language-based problems, students often report the most difficulty with speaking skills. Correspondingly, faculty report this skill as the most "problematic area" with international students.

Some research in this area recommends teaching speaking skills aimed specifically at academic environments, rather than just social interaction. Ostler (1980) evaluated students on their perception of being understood in social and academic settings. She reports that each situation requires a different type of language skill: formulaic for the socially familiar, and creative for the academic environment. Formulaic language skills involve limited topics, finite number of expressions which can be memorized, and are used for social transactions at restaurants, banks and grocery stores. Creative language skills involve topic initiation, topic extension, and no memorization of sentence patterns. The scores from Ostler's study show that students were less confident with their speaking skills in academic settings than in social ones. The study indicates that methods need to be developed to promote the use of creative language skills for ESL students to feel successful in university classes and professor's offices.

Tarvin and Al-Arishi (1991) believe that activities in the ESL classroom need to consider the dimension of reflective, deliberative thinking rather than reactive communicative responses alone.

In the language classroom, we believe that activities which allow for introspection before interaction will enhance a student's selfimage because the student will have achieved a private fruition through intrapersonal testing, thereby eliminating certain firstnotion responses. Consequently, s/ he will approach the valuable public negotiation of meaning with greater confidence. (p. 17) 


\section{NON-TRADITIONAL ESL GOALS}

Two non-traditional models for facilitating international students' successful transition to university content classes are the adjunct model and the language intervention model. Much has been written on the adjunct model. Only a small sample is discussed here.

The case for an adjunct model (linking ESL courses with content courses to integrate reading, writing, and study skills) is made by Snow (1988), who advocates using this approach to better prepare non-native students to succeed in university classes. Echoing Johns' (1981) finding that undergraduate students ty pically lack the ability to recognize relevant data, Snow says that a focus on critical thinking skills, rather than on the personal essay, appears to be a top priority in the university language curriculum.

The case for an adjunct model of instruction for academic ESL is firmly stated in studies by Saville-Troike (1976). She suggests that courses for international students at the university level do not provide students with adequate skills for coping with university-level instruction in English.

The need is for early and stronger emphasis on reading processes, and for teaching the more formal style required by textbooks and lectures rather than the conversational style often found in audiolingual materials. (p. 77).

Saville-Troike recommends a shift in priorities to reading and writing; teaching subject-specific vocabulary; dictionary instruction; auditing university courses concurrently with ESL programs; and graduate courses in research methods and writing style appropriate for American theses, dissertations, and comprehensive examinations. 
ESL classes, whether adjunct models or traditional, help prepare the international student before acceptance into university classes. Some researchers, however, have suggested the need for English language training after acceptance to university classes. Research has consistently cited inadequate language proficiency as a major problem for negative academic performance. Once international students are enrolled in content classes, most of the onus of academic adjustment must fall on the students themselves. Some of it, however, falls on the academic staff, including faculty and administration. Wan, Chapman and Biggs (1992) investigated factors associated with the academic stress experienced by international graduate students in the U.S. Results of the study suggest that successful academic adjustment is influenced by students' perceived confidence in their functional language skills. Conversing with faculty, taking notes in lectures and participating in classroom discussions were all positive factors contributing to successful academic adjustment. Additional factors included students' beliefs that they had a strong social support network. The study suggests the importance of university intervention in encouraging social networks for international students.

$\mathrm{Xu}$ (1991) also cites extenuating circumstances other than language proficiency which impact international students' academic performance. Factors include social problems, such as making friends and being accepted by social groups, and anxiety factors, such as getting to know the American academic norms and expectations. The findings of the study suggest that the students who believed that their English was adequate encountered less academic difficulties than those who believed it to be inadequate. $\mathrm{Xu}$ notes that English proficiency can be improved after students are admitted into the 
academic program through language intervention programs. Some of the students' social concerns and anxiety levels can be addressed by the university. To the extent that part of the international students' academic coping mechanism is their perceived language proficiencies, this study highlights the necessity for institutional services for international students.

\section{SUMMARY}

Studies of university level, international students reveal that communicative-based approaches alone are not sufficient for the specialized use of language skills in an academic university environment (see, for example, Saville-Troike, 1976; Apodaca, 1985; Adamson, 1990 ).

Cummins (1980) distinguishes between basic interpersonal communication skills and cognitive academic language proficiency in discussing the language skills necessary for academic success. Light, $\mathrm{Xu}$, and Mossup (1987) say that academic achievement in the hard sciences, requiring quantitative skills, is less affected by English language proficiency than is academic achievement in the humanities, arts, and social sciences.

In national surveys, faculty members ranked reading and listening as the most important language skills contributing to academic success (Johns, 1981; Powers, 1986). Listening skills of non-native students are often faulty and need to be trained to follow the discourse style of university lectures (see Richards, 1983; Lebauer, 1984; Anderson-Mejias, 1986; DeCarrico \& Nattinger, 1988 ).

A survey among advanced ESL students by Ostler (1980) focused attention on the need to teach specialized skills such as reading academic journals and papers and writing critiques. The importance of addressing 
undergraduate and graduate students' academic needs differently was indicated by the study.

Teaching language skills within the context of the tasks which they will eventually serve is recommended by some scholars (Bridgeman \& Carson, 1984; Horowitz 1986; Anderson-Mejias, 1986); while others advocate integrating reading, writing and study skills within an adjunct ESL model (Saville-Troike, 1976; Snow \& Brinton, 1988; and Adamson, 1990). Still others suggest designing language intervention programs even after students are admitted into the academic program ( Xu, 1991; Wan, Chapman, \& Biggs, 1992). 


\section{CHAPTER III}

\section{METHODOLOGY}

This chapter will outline the rationale for the choice of the schools of Business Administration and Engineering and Applied Science; describe the procedure for selection of the faculty subjects; discuss the method used in the needs analysis; and define the skills survey used in the faculty interviews.

\section{RATIONALE}

Enrollment statistics from Portland State University's 1993/94 census of foreign students show that 815 international students comprise 5.4 percent of the total student population of 14,486 . Fifty-two percent of the total number of international students enroll in two programs: the school of Business Administration (203 undergraduates and graduates), and the school of Engineering and Applied Science (167 undergraduates and graduates). Although Computer and Information Sciences is included in the school of Engineering and Applied Science, a separate enrollment figure of 58 is provided. That makes a combined total of 428 students within these two disciplines. Furthermore, Fall, 1993 enrollment figures from the department of Applied Linguistics show 47 international students from 11 countries enrolled in academic ESL classes. Thirty-six of these students were admitted and thus are included in the figures for international students (part of the 815). Eleven of the 
students were nonadmitted and that number is in addition to the 815 . Chosen majors of the 47 ESL students reflect the same distribution of Business Administration and Engineering and Applied Science as the overall international student statistics. Because Business and Engineering total the largest percentage of non-native student majors, this survey focuses on faculty opinions within these two disciplines.

\section{SUBJECTS}

The School of Engineering and Applied Science includes 54 full-time and many part-time faculty members who teach classes in the following five fields: Civil Engineering, Electrical Engineering, Mechanical Engineering, Computer Science, and the graduate Engineering Management Program. The School of Business Administration includes fifty full-time and many part-time faculty members who teach classes in ten fields: Accounting, Advertising Management, Business Education, Finance-Law, General Business Administration, General Management, Human Resource Management, Information Systems and Quantitative Analysis, Marketing, and International Business.

An academic skills survey [see Appendix A], modeled closely after the study by Johns (1981), was given to a total of 31 faculty members from these two departments, 15 from Engineering and 16 from Business Administration. Representatives from the offices of Institutional Research and Planning, International Student and Faculty Services, and Business Administration Student Services were consulted to establish appropriate interviewees within each discipline. Faculty members were suggested based on their degree of contact with international students. Other considerations for their inclusion in 
the survey were the number of required core classes they teach, the percentage of international students in their classes, their willingness to participate in the survey, and a desire to obtain a balance among divisions within each discipline.

To achieve as much balance, and therefore as much breadth of perspective as possible, the 15 faculty members from Engineering were selected from the following divisions: 3 from Civil Engineering (CE), 5 from Electrical Engineering (EE), 3 from Mechanical Engineering (ME), 3 from Computer Engineering (CMPS), and 1 from the Engineering Management Program (EMP).

A similar balance was attempted among the 16 Business Administration faculty: 2 from Information Systems and Quantitative Analysis (ISQA), 4 from Accounting (ACTG), 6 from Management (MGMT), and 4 from Marketing (MKTG). Graduate faculty from the Master's of Business Administration Program (MBA) faculty were represented within each of these divisions.

All faculty members were contacted by letter [see Appendix A] at their offices and told that they would be called by the interviewer within the next ten days. They were asked if they would take part in a thirty-minute language skills analysis survey of international students at PSU. They were told that their participation would increase knowledge that might influence curricular decisions in English as a Second Language (ESL) classes currently taught at PSU. They were assured that their identities would be kept confidential, which they have been and will be. All faculty were interviewed in their offices. After an examination of the survey questionnaire [see Appendix B], the interview took place. 


\section{PILOTSTUDY}

A pilot study was conducted in 1992 using the ranked questionnaire modeled after Ann Johns'. Two PSU. faculty members, one from engineering and one from business, were selected randomly and a thirty-minute personal interview was conducted with each in their offices. Questions in the current interview portion of the survey were derived from results of the pilot interviews and from the literature discussing language skills already reviewed in Chapter II.

Results of the pilot study repeated Johns' findings that reading and listening were ranked first in importance of the four language skills. Writing was ranked third and speaking last. Both business and engineering faculty chose general English over specific English as most important. The language status of the faculty members was suspected to play a part in their assessment of the academic performance of international students. The business professor was a native speaker who gave a critical assessment of the role of international students' accents in her discipline. The engineering professor was a non-native speaker who said accent played no part at all in students' academic success.

\section{SKILLS SURVEY}

Permission was granted by Ann Johns to replicate the focus of her survey. While Johns surveyed faculty in all disciplines at San Diego State University by means of a written questionnaire, this study was conducted in person with thirty-one faculty members from only two divisions at Portland State University. 
The skills survey consists of a thirty minute interview, with two types of questions: ranked responses to six questions (questionnaire) and verbal descriptions of problematic areas (interview questions). Interviewees were assured of complete confidentiality and anonymity in their responses. The questionnaire was designed to elicit the following information:

1). The importance of listening, reading, speaking and writing skills.

2). The importance of various listening, reading, speaking and writing activities to academic success within the class.

3). Features of typical courses, especially the characteristics of lectures.

4). The importance of general English versus discipline-specific English to understanding class materials.

Instructors were given a copy of the six questions to follow and asked to respond to each as it was read. They were asked to rank order the questions on a scale of 1 to 4 , with 1 as "most important" and 4 as "least important." To insure faculty confidentiality and encourage comfort with the interview process, their oral responses were not taped, but were recorded by hand by the interviewer.

Question (A) asked instructors to rank the importance of four major skill categories to success in their classes: reading, writing, speaking, and listening. Question (B) asked which reading skills were most necessary: textbooks, multiple choice examination questions, essay examination questions, or non textbook assignments. Question (C) asked which writing skills were most necessary: reports, term papers, essay answers, or short critiques or analyses of author's work. Question (D) asked which speaking skills were most necessary: abilities to participate in class discussion, formulate questions, organize and present oral reports, or pronounce words clearly. Question (E) asked which 
listening skills were most important: abilities to follow spoken directions, understand and restate orally-presented material, understand and take notes on lectures, or understand student talk. Question (F) asked which was more important for success in class: general knowledge of English or knowledge of English specific to the discipline.

Responses to survey questions A through E were rank ordered. Question F was tallied. No statistical test was performed for any survey question.

In addition to the survey questions, interview questions were designed to establish a profile of each discipline. The interview portion of the survey included the following questions to each faculty member:

-What is the relationship between communicative tasks versus independent tasks in classes in your discipline?

- Compared with native-speaking students, how do international students perform in your classes?

-Do any areas tend to be problematic for international students in your classes?

- Describe any incidents involving non-native students' misunderstanding of orally-presented material.

-Does a student's "foreign accent" impact academic success in your discipline?

-In addition to language skills, what social skills do you believe would be most helpful to non-native students' academic success in your discipline?

- Are you familiar with the language skills taught in academic ESL classes at Portland State University? 
Responses to the above interview questions will be discussed in the analysis of faculty members' perceptions about non-native students and academic success. The information was analyzed to see if meaningful patterns exist between levels and/or disciplines. 


\section{CHAPTER IV}

\section{ANALYSIS OF SURVEY QUESTIONNAIRE}

The purpose of the study was to conduct a needs analysis of international students' language skills at Portland State University by use of a two-part faculty questionnaire. Business Administration and Engineering professors were asked two major questions: first, which of four language skills-reading, writing, speaking, or listening-- did they believe were most important to academic success in their classes at PSU; and second, what were the most important uses for each of the four skills.

The results of the interviews are described in this chapter in three parts by means of text and bar graphs. Each part uses the format of comparison between levels and divisions: undergraduate and graduate business, and undergraduate and graduate engineering. Part one shows the comparative importance of language skills. In other words, compared with each other, how do faculty levels and disciplines rank the importance of each of the four skills. Tables showing number of responses and rankings by percentage for all are listed in Appendix (D).

Part two shows the comparative ranking of each of the four skills. In other words, what was the difference in importance of each skill between faculty by level and discipline. Complete scores are listed in Appendix (E). 
Part three shows the comparative ranking of uses of reading skills for each level and discipline. In other words, what are the preferred uses of each skill. Complete scores are listed in Appendix (F).

\section{PART ONE: LANGUAGE SKILL IMPORTANCE}

For each question asked, a response from 1 to 4 was given. A ranking of 1 indicated that the skill was the "most important"; 2 , that it was second in importance; 3, third; and 4, that it was "least important" to success in the class. Faculty members were encouraged to give a single ranking to each of the four skill sets, but occasionally, members could not differentiate the level of importance and gave more than one " 1 " to the four listed skills. These extra rankings, usually number 1 or 2 , were counted as part of the overall score. Because skills were "ranked" ( a comparison of skills against each other) and not "rated" (a comparison of the importance of the skills with themselves), there was no numerical way for faculty to comment on the importance of each skill within the skill set. Therefore, the extra importance that was attached to the skill was allowed for those few faculty who said "I simply cannot differentiate in importance between these skills."

A fifth ranking, non applicable (NA), was used for those skills which either did not apply or were not appropriate to class format or teaching style. For the reasons above, percentages do not total $100 \%$.

Survey Question A. Of the four major language skills--reading, writing, listening, or speaking--which is most essential to success in your classes?

The survey responses to the above question were converted to percentages and are listed by department and level: The total percentage of responses varies for each ranking, so a comparison of skills by level and 
discipline cannot be made in the same way they could if the total percentage for each skill was a constant 100 percent. In this study, the maximum percentage is different for each skill.

Undergraduate school of Business Administration faculty:

As figure 1 shows, $56 \%$ of the faculty surveyed say that reading is the most important language skill; $31 \%$ say writing and listening are equally most important; and only $6 \%$ say speaking is most important. Listening is considered to be the second most important language skill by $44 \%$ of the undergraduate faculty.

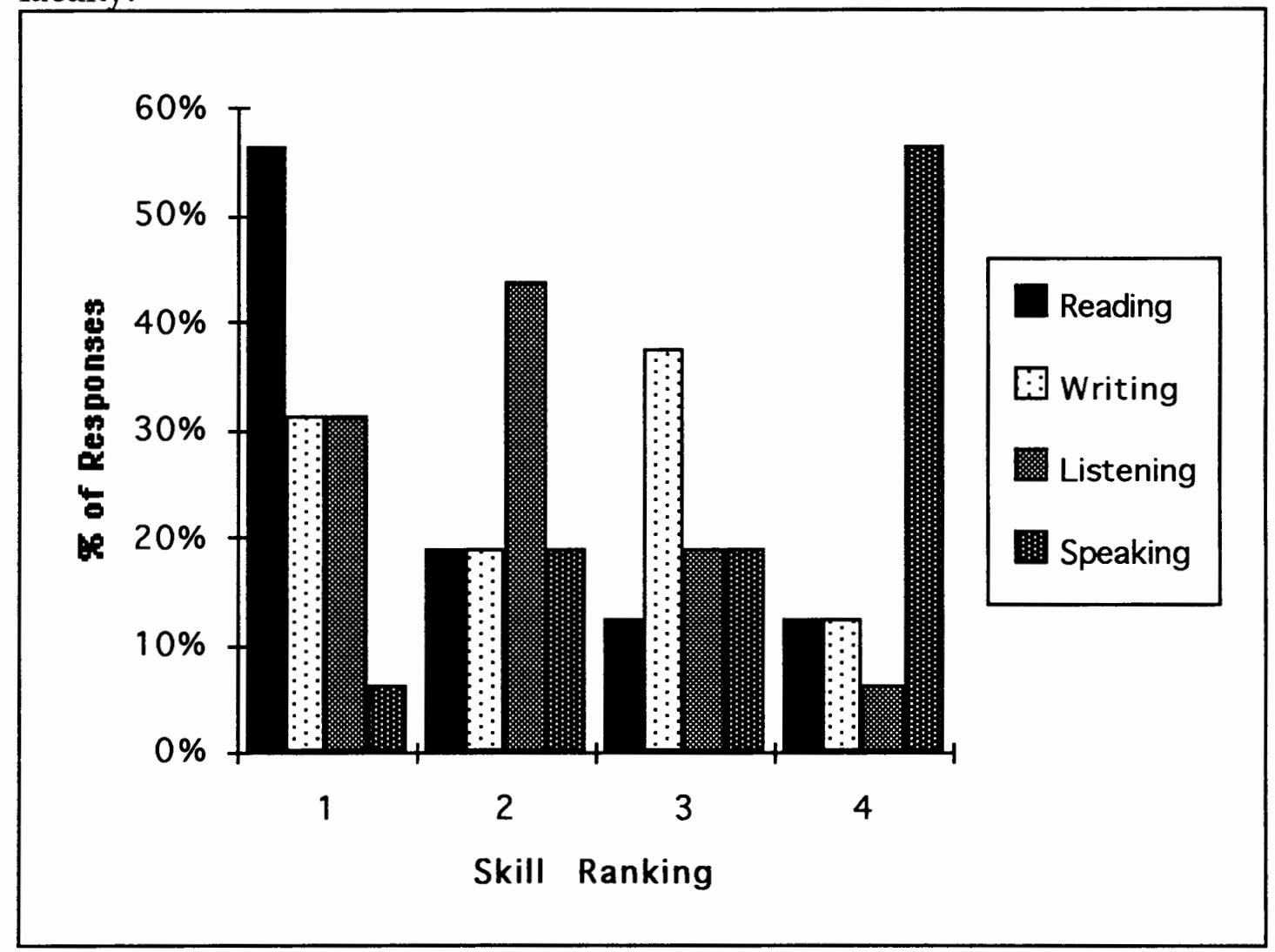

Figure 1. Comparative importance of language skills for undergraduate business faculty

Graduate school of Business Administration faculty:

As shown in figure $2,58 \%$ of the faculty say reading is the most important language skill; $33 \%$ say listening is most important; $25 \%$ say writing is 
most important; and 8\% say speaking is most important. Writing and speaking are considered second most important by $33 \%$ of the graduate faculty.

While undergraduate and graduate business administration faculty consider reading by far the most important language skill, listening and writing receive a high and nearly equal number of "most important" responses. Speaking skill varies in significance according to the level of classes. It appears to be considered as less significant by undergraduate faculty (56\% give it a "least important" ranking). Yet, one-third of the graduate faculty rank it second in importance. The difference in reported significance for speaking within the two levels of business classes is mentioned by faculty in their discussions about the importance of small group participation in proportion to class lectures for students in the MBA program.

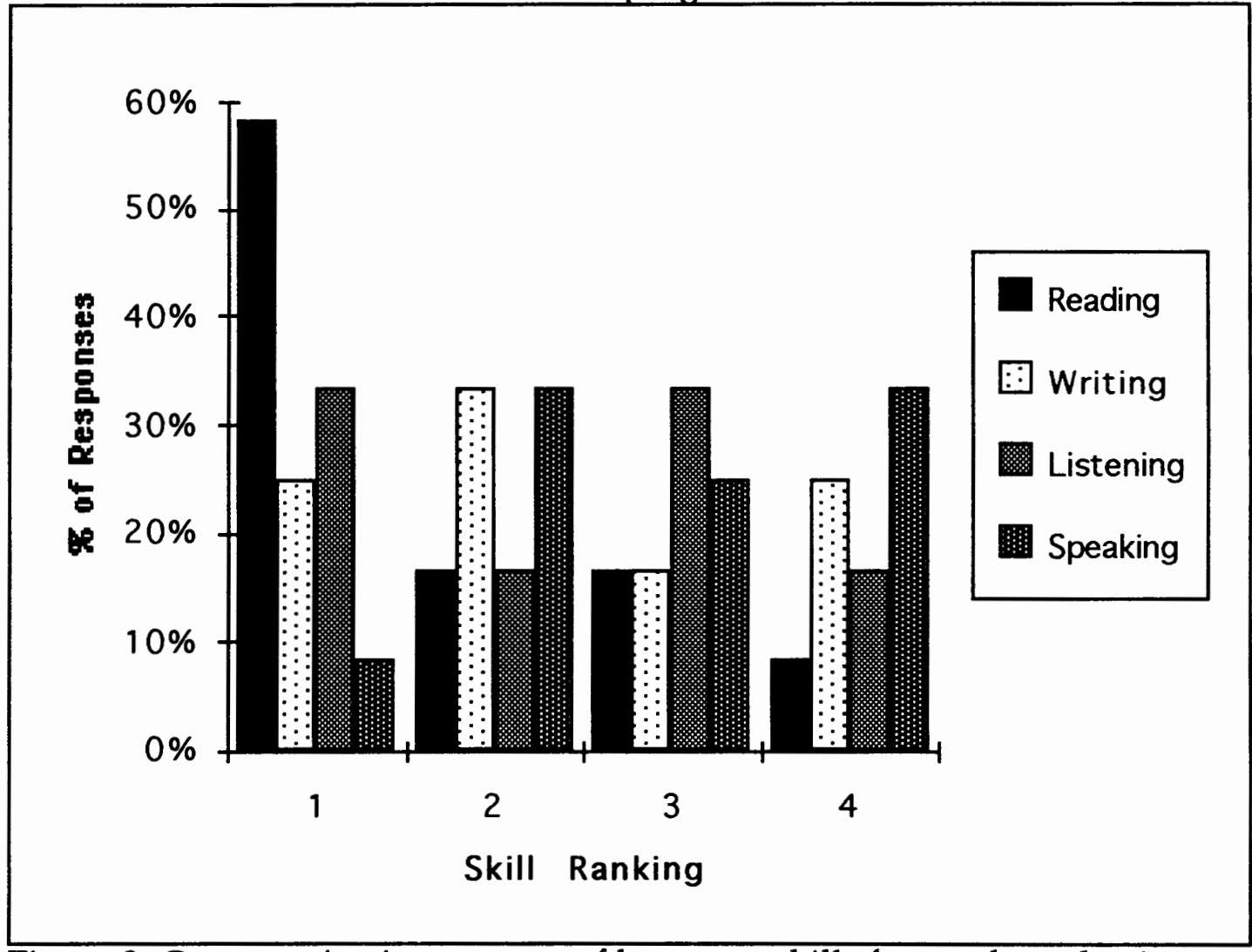

Figure 2. Comparative importance of language skills for graduate business faculty 
First rankings results for the school of Engineering and Applied Science differ slightly from those for the school of Business Administration. Survey results for this discipline show a heavy reliance on two language skills, reading and listening. Percentage results by level follow:

Undergraduate Engineering and Applied Science faculty:

Of all faculty in the study, the highest number $(71 \%)$ who report that reading is the most important language skill are instructors in the undergraduate engineering classes (see figure 3). The second highest percentage $(57 \%)$ say listening is most important. Only $7 \%$ say writing is most important; and no faculty at all rank speaking most important. In fact, $50 \%$ say this skill is "least important", and 7\% say it is non applicable (NA).

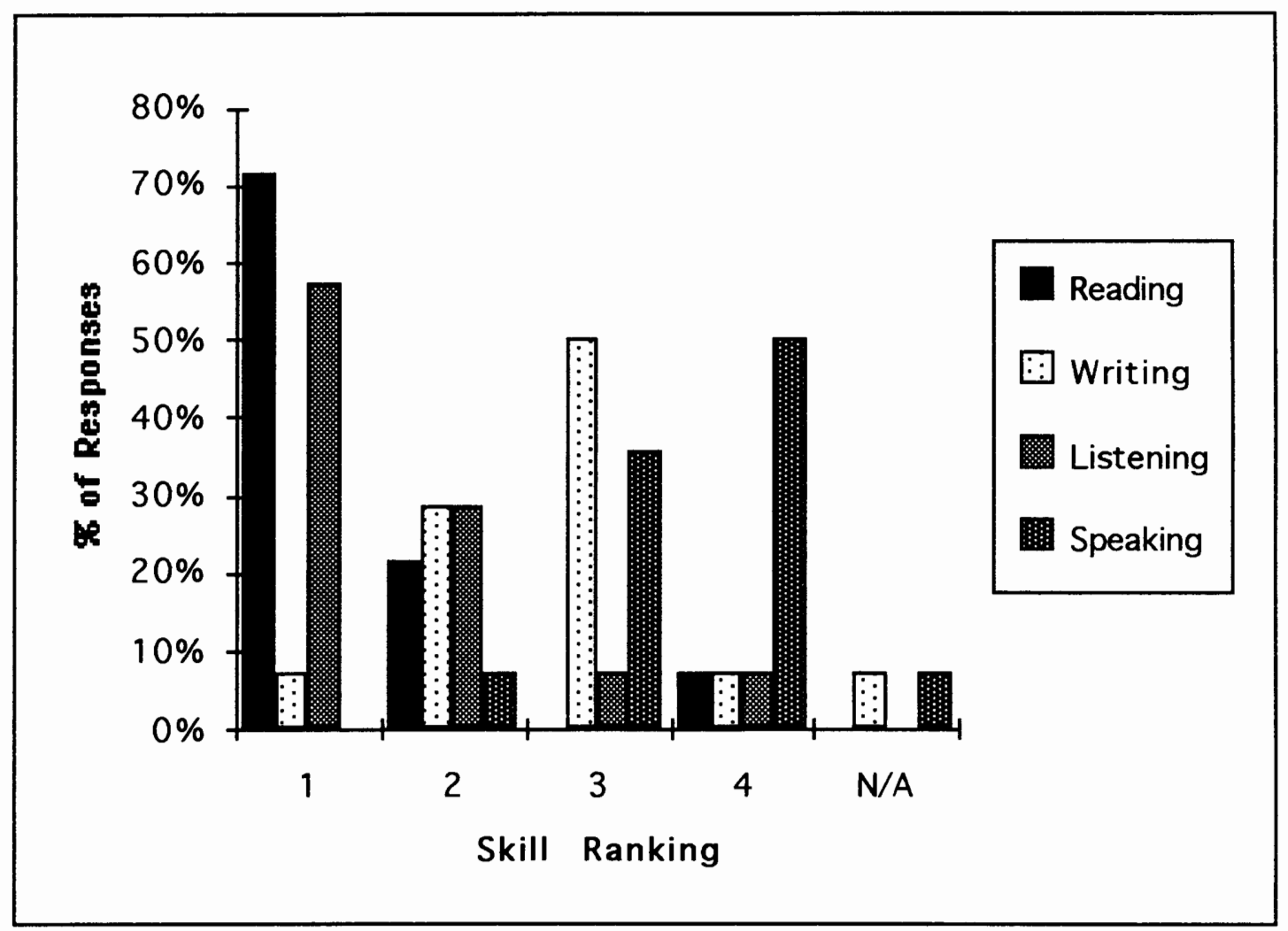

Figure 3. Comparative importance of language skills for undergraduate engineering faculty 
Graduate Engineering and Applied Science faculty:

Evidence of the importance of the listening skill to this discipline is shown in figure 4 by the results from graduate engineering faculty. Sixty-two percent respond that reading and listening were equally "most important." The increased importance of writing to students in graduate classes is shown by the fact that twice as many graduate faculty $(15 \%)$ as undergraduate $(7 \%)$ claim writing as most important. Thirty-one percent rank writing as second most important. Like the undergraduate faculty, no graduate faculty rank speaking as most important; in fact 54\% say it is the "least important." language skill.

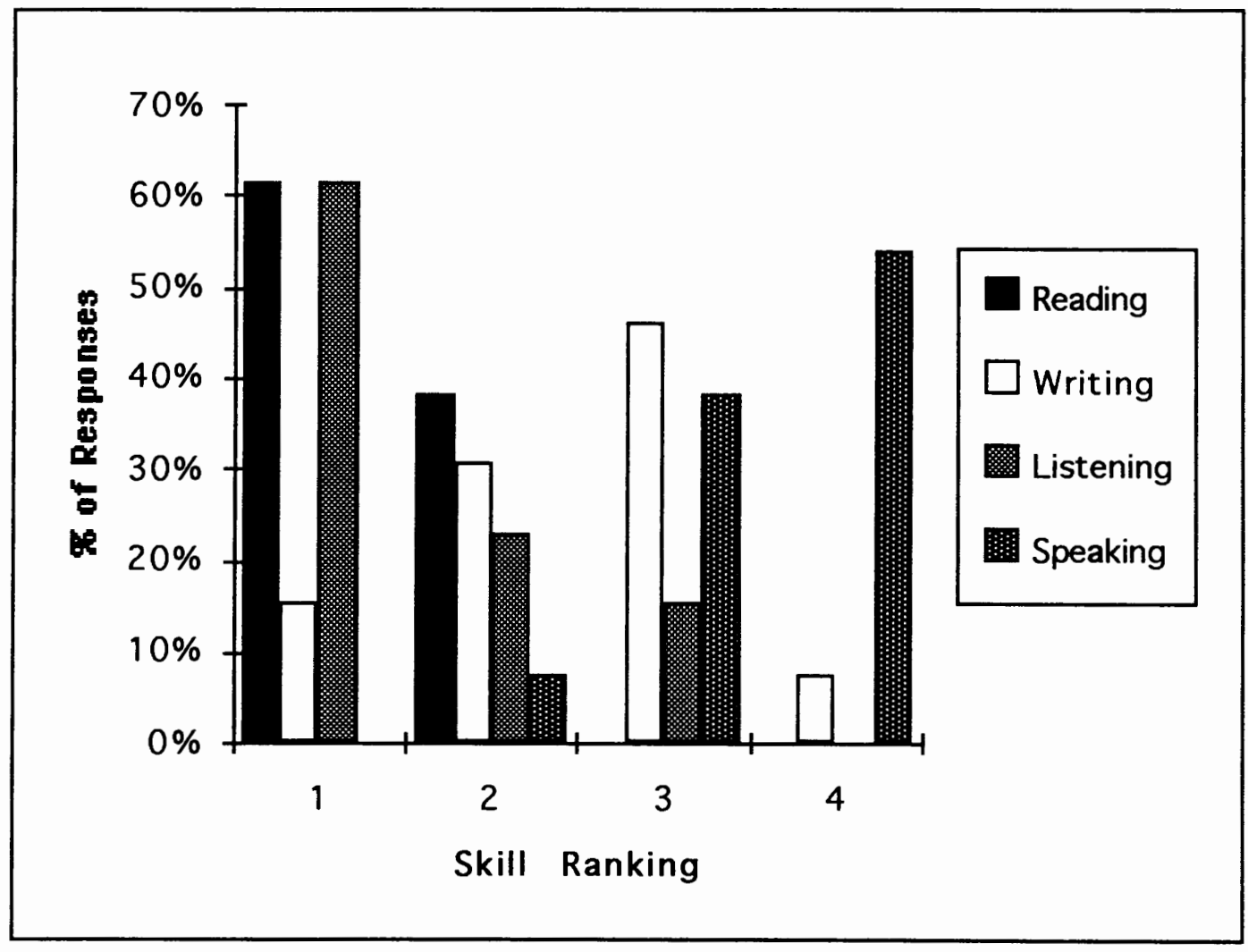

Figure 4. Comparative importance of language skills for graduate engineering faculty 


\section{PART TWO: LANGUAGE SKILL DIFFERENCES}

In this section, the skills will be compared by first rankings of all faculty. They will be discussed in the order of their ranked importance by all faculty: reading, listening, writing, and speaking.

Reading:

Because reading is considered the most important language skill by all faculty, it is worthwhile to look at differences between first rankings by division and level. The bar graph in Figure 5 shows the comparative ranking of reading skills among faculty. The school of Engineering and Applied Science rank reading higher than does the school of Business Administration, but neither discipline ranks it lower than $56 \%$.

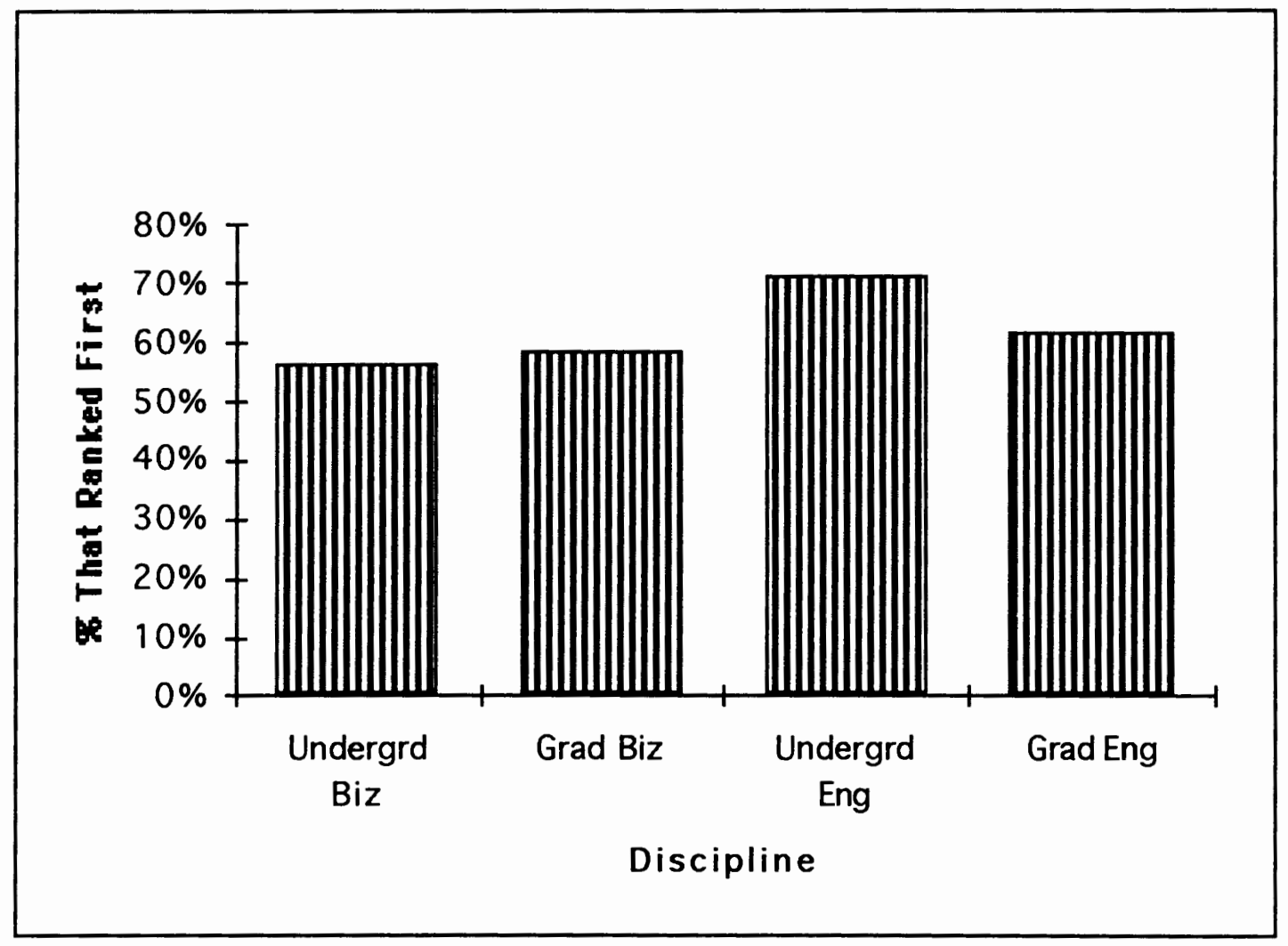

Figure 5: Comparative rankings for reading skill 
Listening:

The importance of the listening skill is evident from the statistics as shown in Figure 6. It is ranked no lower than second to reading by all faculty. In fact, listening is ranked equally as important as reading by graduate engineering faculty; nearly as important as reading by undergraduate engineering faculty; and as the second most important language skill by undergraduate and graduate business faculties. The interesting comparison, however, is between divisions. On the average, nearly twice as many engineering (60\%) as business (32\%) faculty at both levels rank listening first.

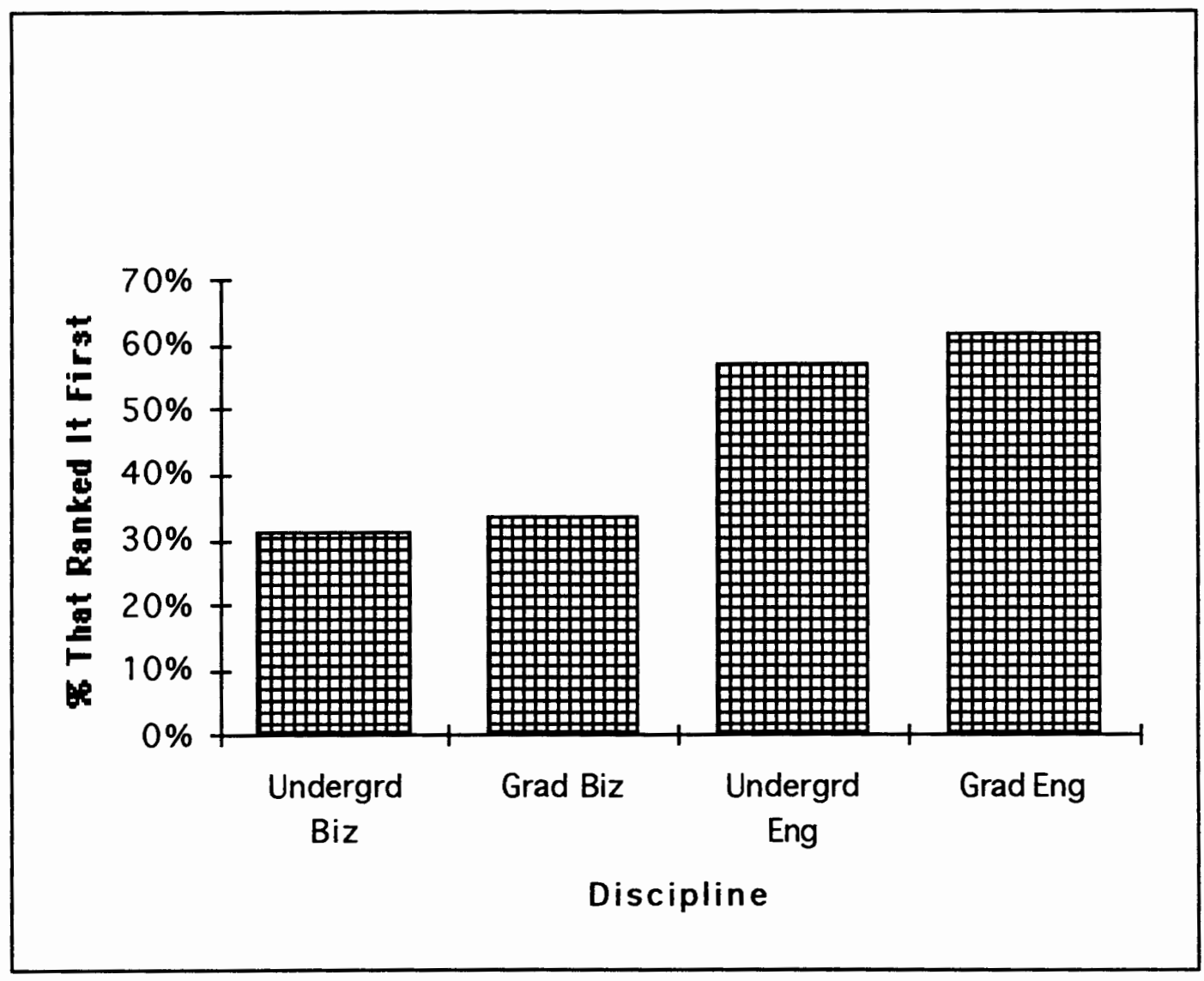

Figure 6: Comparative ranking for listening skill 
Writing:

Overall, the writing skill is ranked much higher by business faculty than by engineering (see Figure 7). It is ranked highest by undergraduate business $(31 \%)$, with graduate business $(25 \%)$ close behind. Of the faculty surveyed, undergraduate engineering instructors consider writing least important (7\%), although instructors for graduate engineering classes ranked it twice as important as undergraduate (15\%).

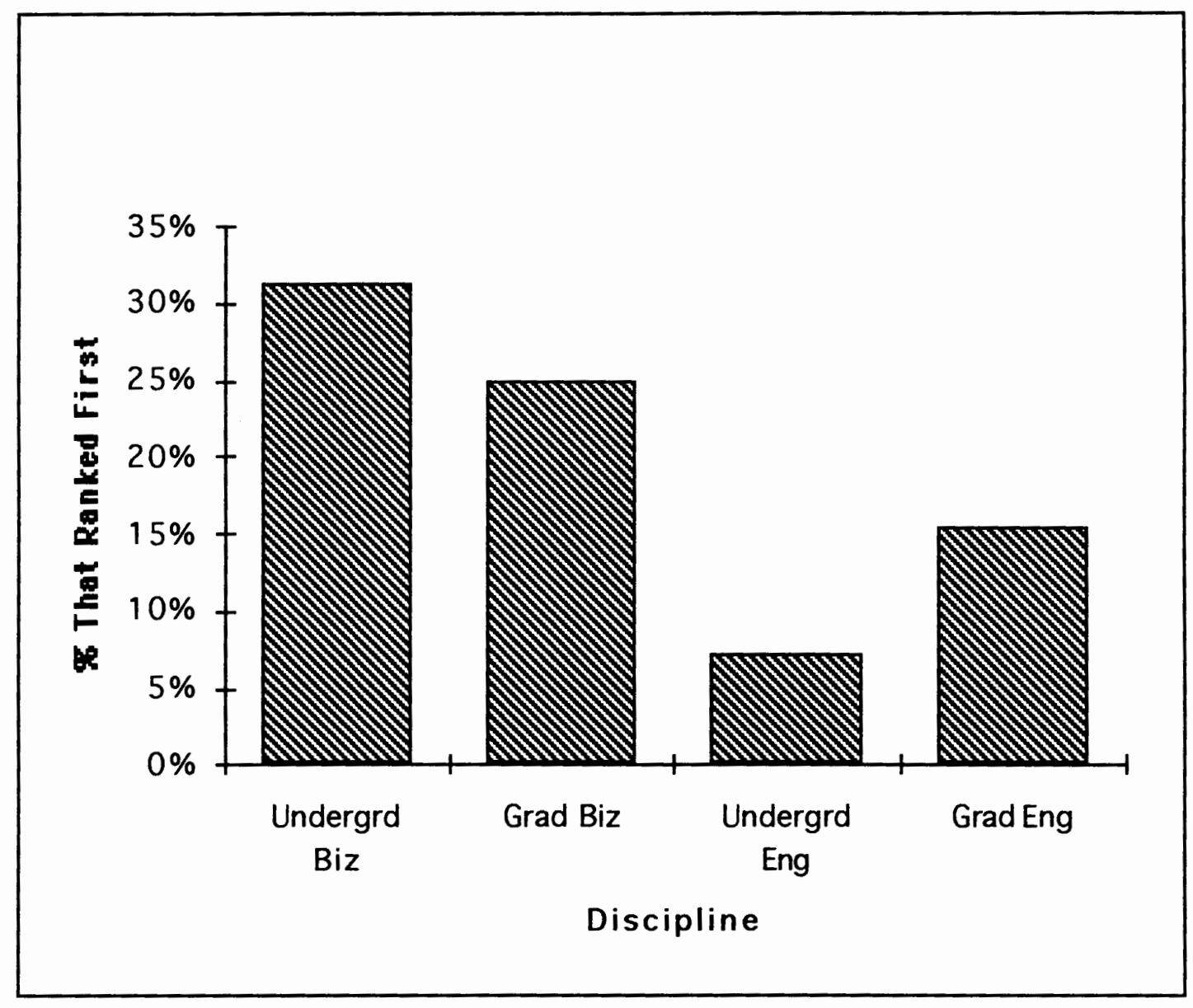

Figure 7: Comparative ranking for writing skill 
Speaking:

Speaking is judged the "least important" language skill by all faculty. It received such low rankings that in order to show any difference in percentages among the levels and disciplines, it is necessary to combine the first and second responses to this question. Charting only the "number 1 " responses does not show enough results to make a comparison.

When responses 1 and 2--the number of first and second choices--are combined, however, there is a marked difference in importance in speaking between the academic disciplines (see Figure 8). Business faculties (undergraduate $25 \%$ and graduate $42 \%$ ) rank the speaking skill as substantially more important to academic success than do engineering faculties (undergraduate $7 \%$ and graduate $8 \%$ ).

Even though this skill is ranked as last in importance by all faculty, the size of this classification is worth examining. During the faculty interviews, nearly all instructors mentioned the "speaking skill" as a factor in their assessment of international students' academic progress. Many said it was a source of frustration to them as teachers. This was especially common in remarks by graduate business faculty. Statistics show that the highest use of the speaking skill in graduate business classes is class discussion. Most business faculty mentioned the lack of international students' spontaneous class discussion skills as critical to their success or lack of success in classes. 


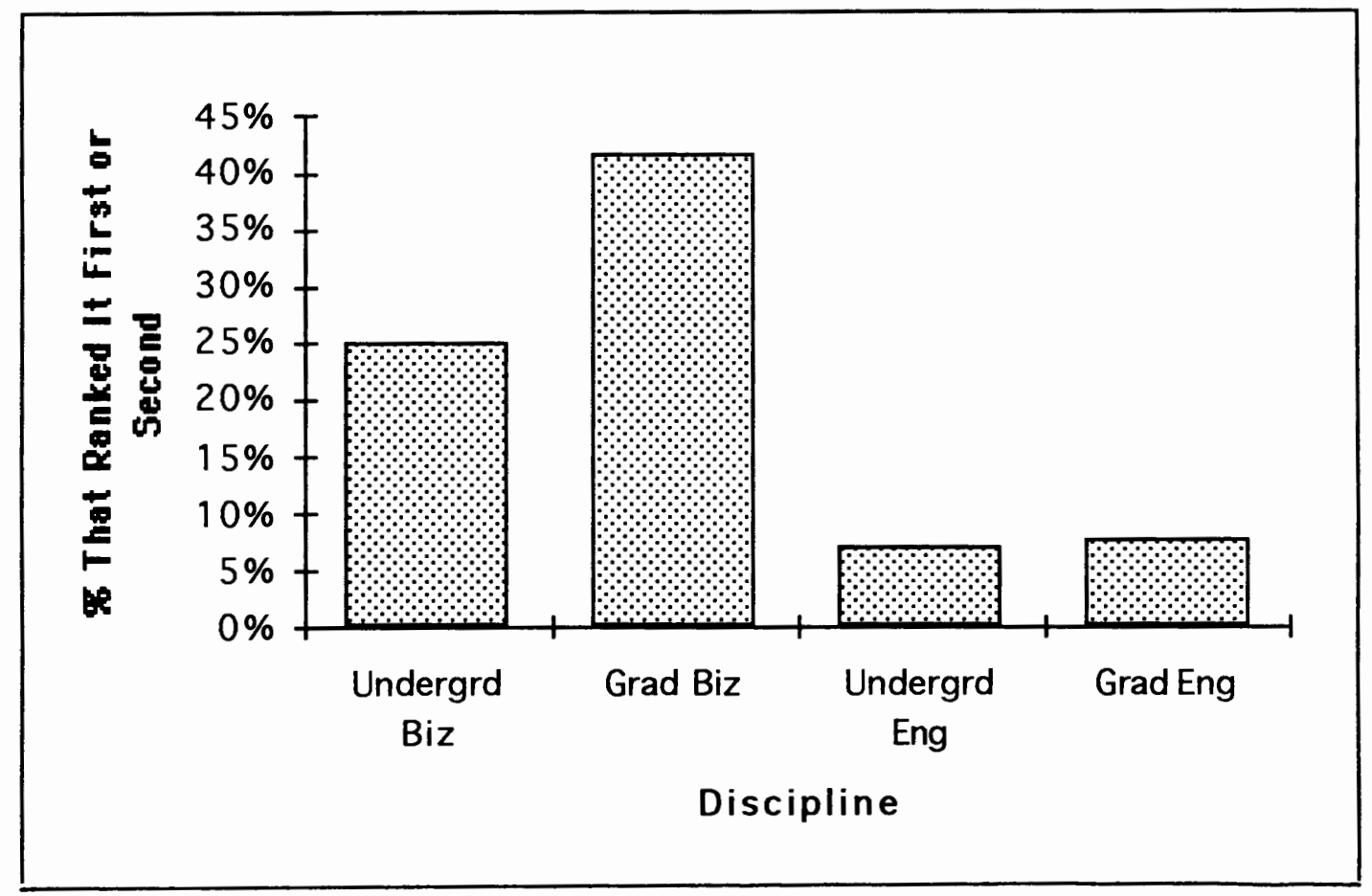

Figure 8: Comparative ranking for speaking skill 


\section{PART THREE: LANGUAGE SKILL USES}

In this section, how faculty said they use reading, writing, listening and speaking in classes will be examined.

Survey questions B through E asked faculty to rank subsets of skills' uses for each of the four language skills. The category non applicable (NA) was an option for responding to uses which were either inappropriate to the subject matter or not compatible with teaching style. Space was provided for ranking alternative uses of the skill (Other). Responses listed under "Other" were generated by the instructors, not the interviewer, and are listed as closely as possible to the original concept. Results for this section do not total $100 \%$. The complete number of responses and percentage rankings are presented in Appendix C. Skills are discussed in the order in which they appear on the survey. The following responses were converted to percentages for comparison between levels and disciplines:

Survey Question B. Which reading skills--textbooks, multiple choice examination questions, essay examination questions, or non textbook assignments --are most necessary?

The overall first choice for uses of the reading skill by all faculty is textbooks, with an average $74 \%$ ranking it first. The interesting breakdown for the use of textbooks is not between divisions, but rather between levels: undergraduate ranking it higher than graduate, and engineering ranking it higher than business.

Specifically, textbooks are ranked as first choice by $86 \%$ of the undergraduate engineering faculty and by $81 \%$ of the undergraduate business 
faculty; while $69 \%$ of the graduate engineering and $58 \%$ of graduate business rank them first. The reliance on non-textbooks as the second most preferred employment of reading skills is apparent from the statistics in both disciplines as students progress in their academic careers. Interestingly, this preference again is by level and not discipline, with graduate business ( $42 \%$ ) and graduate engineering (46\%) ranking non-textbooks first, versus undergraduate business (19\%) and undergraduate engineering (21\%).

Undergraduate school of Business Administration faculty:

As Figure 9 shows, $81 \%$ of the faculty rank textbooks as the most important use of reading in their classes; $19 \%$ rank non-textbooks as the most important use for the reading skill; $13 \%$ rank both multiple choice and essay questions on examinations as most important, but several faculty conversely note that both (19\% multiple choice) and (13\% essay) are non applicable (NA) to their classes. No alternative choices are mentioned under "Other." 


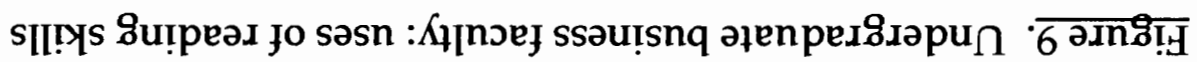

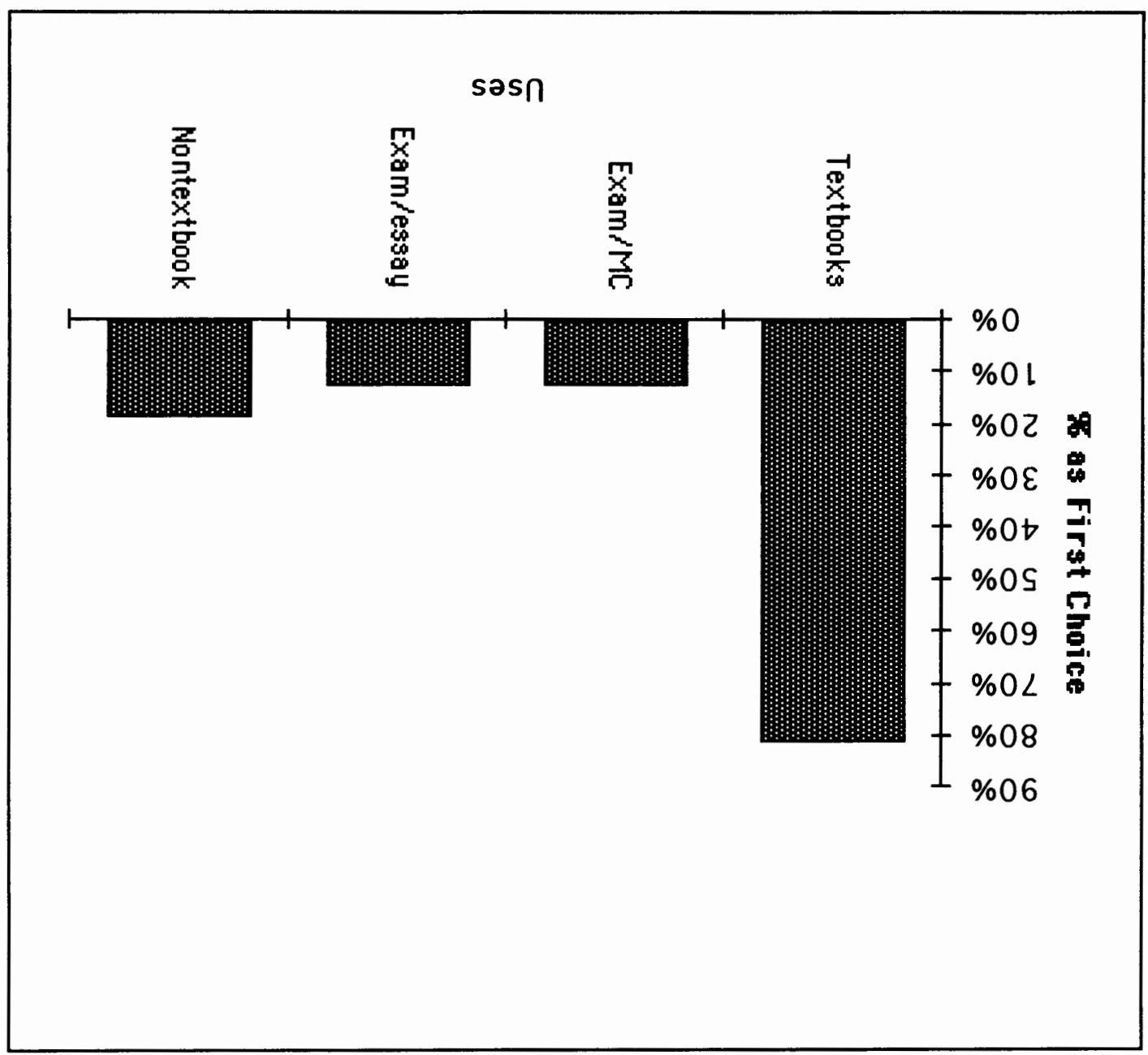


Graduate school of Business Administration faculty:

Only two uses for the reading skill are ranked as "most important" by graduate faculty in business. Figure 10 shows that $58 \%$ of the faculty ranked textbooks as the most important use of reading in their classes, and $42 \%$ ranked non-textbooks as most important. Both types of examination questions, multiple choice $(42 \%)$ and essay (25\%), are considered non applicable (NA). No alternative choices for reading are mentioned under "Other."

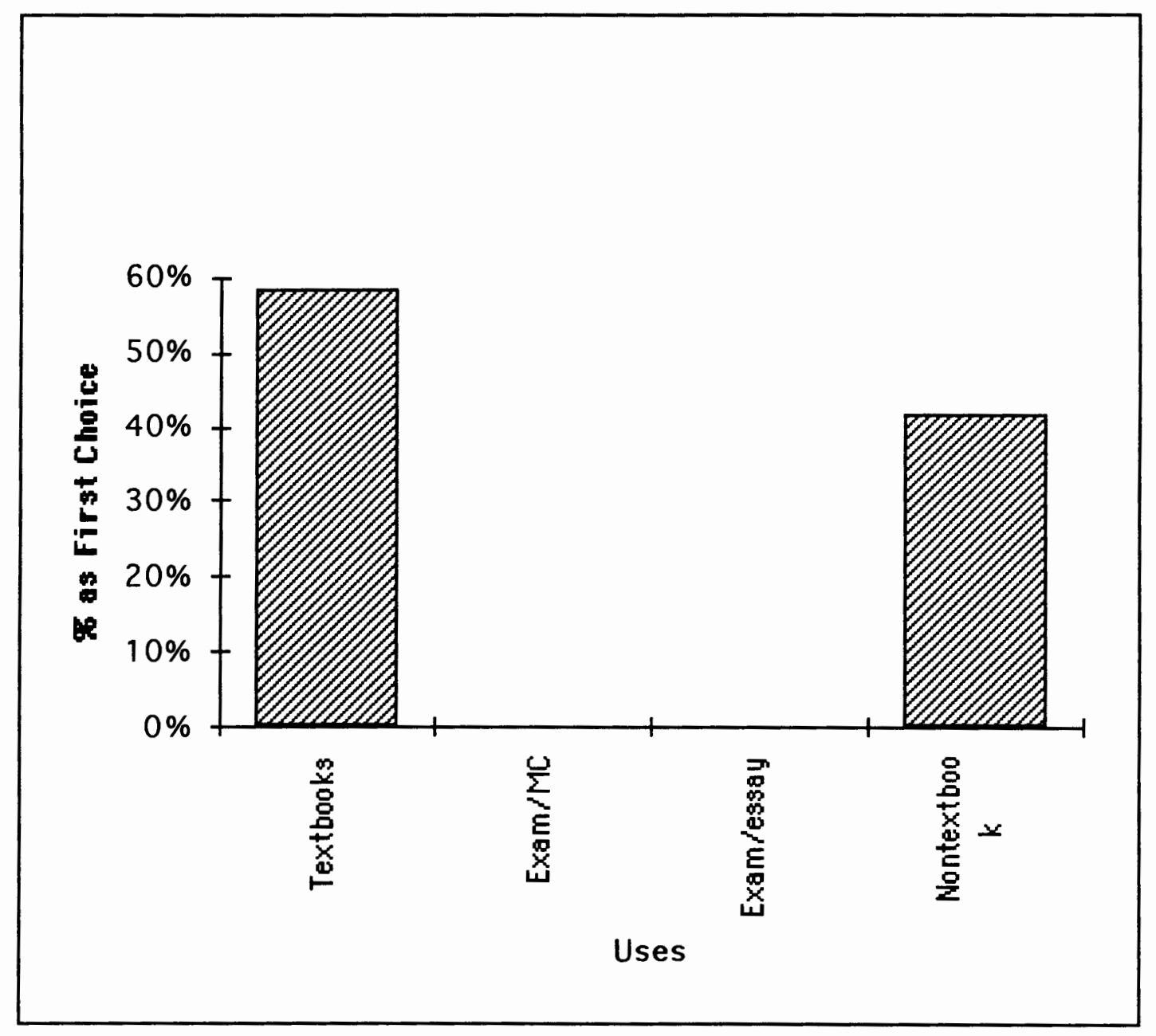

Figure 10. Graduate business faculty: uses of reading skills 
Undergraduate Engineering and Applied Science faculty:

Figure 11 shows that $86 \%$ of the faculty rank textbooks as the most important use of reading in their classes. This is the highest use for any skill in the survey An equal number of faculty (29\%) rank essay questions as "most important" and as non applicable (NA). A quarter of the faculty (25\%) rank non-textbooks as most important. Only $8 \%$ rank multiple choice questions on exams as important and $57 \%$ rank that category as NA. Faculty offer two choices for "Other" uses of reading skills. As second-(7\%) and third-most important (7\%), faculty offer problem solving as pertinent uses of reading skills.

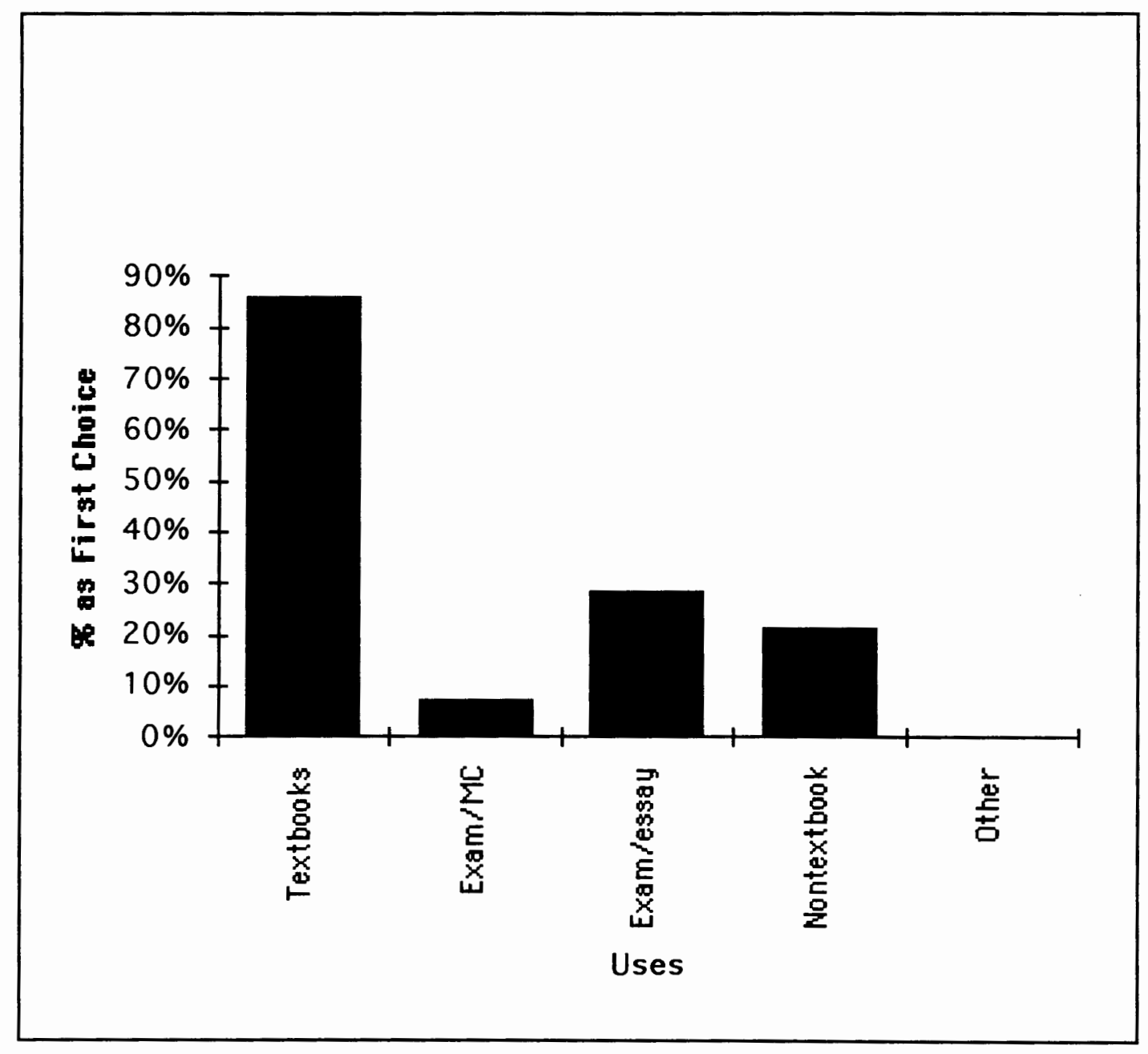

Figure 11. Undergraduate engineering faculty: uses of reading skills 
Graduate Engineering and Applied Science faculty:

The distribution and relationship of rankings between undergraduate and graduate engineering are very similar. As is shown in Figure 12,69\% of the graduate faculty say textbooks are the most important use of the reading skill for their classes, while $46 \%$ say non-textbooks are most important. Twentythree percent rank essay answers as most important, and only $8 \%$ rank multiple choice first. Like all other faculty, a very high percentage, $62 \%$, rank multiple choice NA. Instructors offer alternative reading skill uses of problem solving (8\%) and critical thinking and interpretation (8\%) as first choices.

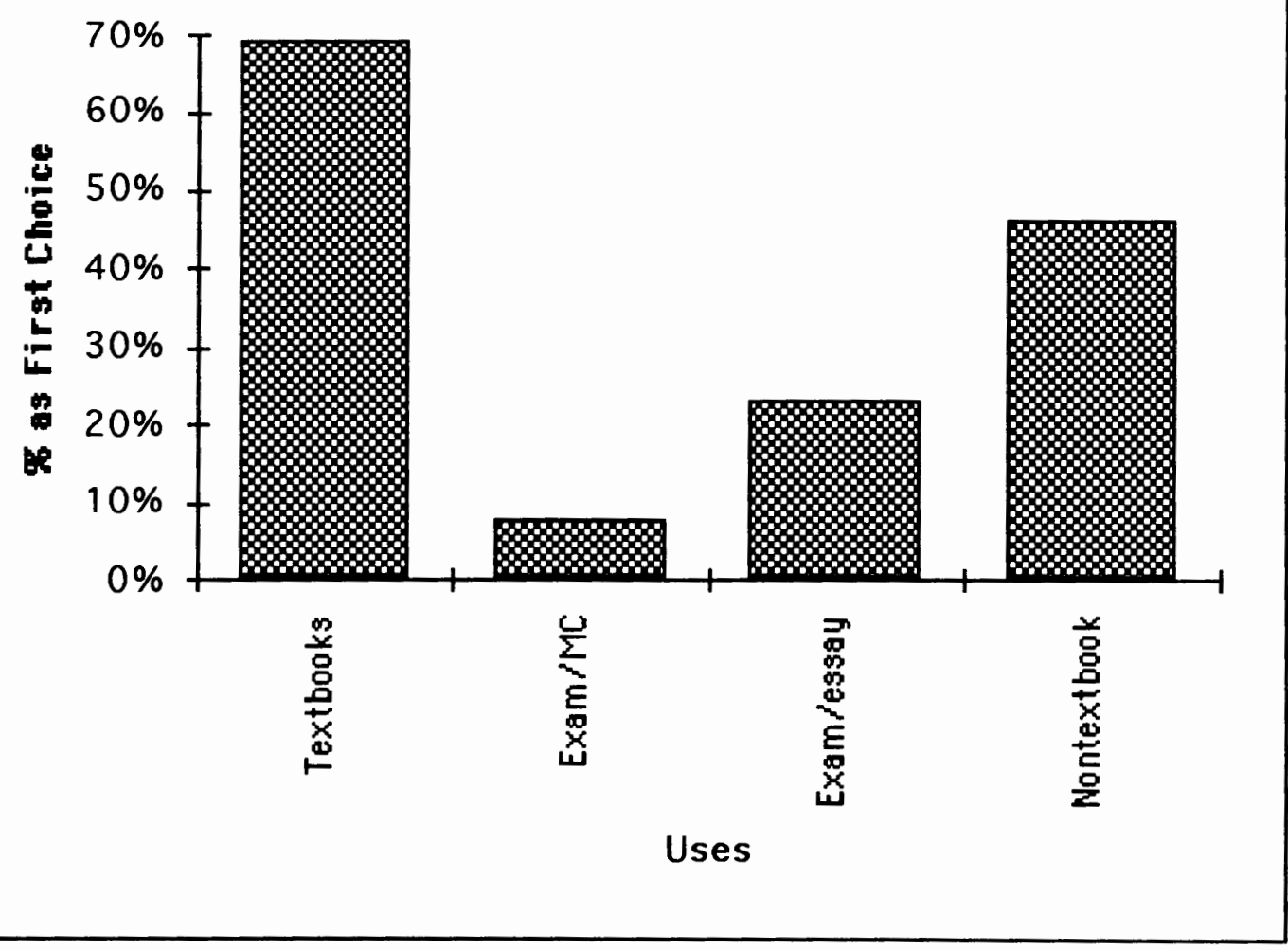

Figure 12. Graduate engineering faculty: uses of reading skills 
Survey Question C. Which writing skills--reports, term papers, essay answers, or short critiques or analyses of author's works--are most necessary?

This question provoked the most response and discussion from faculty in both disciplines. Many wanted to know the difference between a report and a term paper. For the purposes of the survey, a report was described as a response to a proposed question which was used as a homework assignment or an in-class project. A term paper was defined as a longer body of work which involved research and used references or library sources and was prepared over a longer period of time. Short critiques or analyses of others' works were defined as analysis genre.

The category non-applicable (NA) was very high for this question. The use which received the highest NA rankings, in other words the use least recognized as pertinent to the discipline, was short critiques or analyses, Scores ranged from undergraduate business $(69 \%)$ to graduate engineering (46\%).

This question received the most "Other" responses, with graduate engineering faculty offering the largest number of alternative uses of writing skills.

\section{Undergraduate school of Business Administration faculty:}

Fifty percent of the faculty rank essay answers on examinations as the most important use of writing in their classes (see Figure 13). Forty-four percent rank term papers as most important. Thirty-one percent of the faculty rank reports as most important Only $6 \%$ rank short critiques or analyses of others' works as most important and 69\% list that category as NA Many faculty considered this as not representative of the form of analysis they actually use in class; therefore, $19 \%$ list case analyses as second, third, and fourth most 
important responses under "Other." Memo or business letter was an additional listing in the "Other" category as the second most important use of writing.

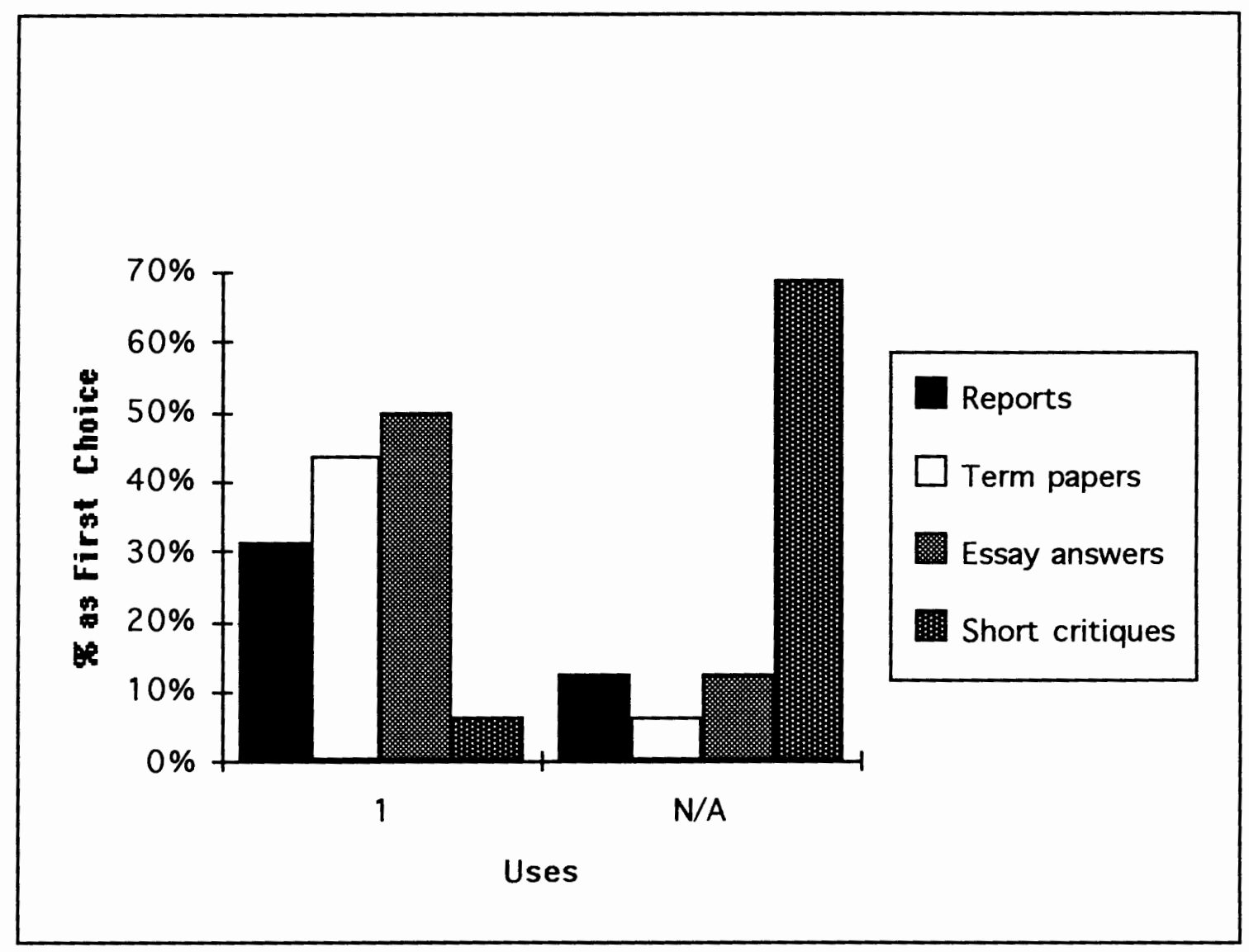

Figure 13. Undergraduate business faculty: uses of writing skills 
Graduate school of Business Administration faculty:

Reports are ranked by $50 \%$ of the faculty as the most important use of the writing skill in their classes (see Figure 14). Thirty-three percent of the graduate faculty rank essay answers as most important. A quarter of the faculty (25\%) rank term papers as most important. Only $8 \%$ said short critiques or analyses are most important. Like the undergraduate faculty, a high percentage $(67 \%)$ list short critiques as NA, but cite no alternative responses for "Other."

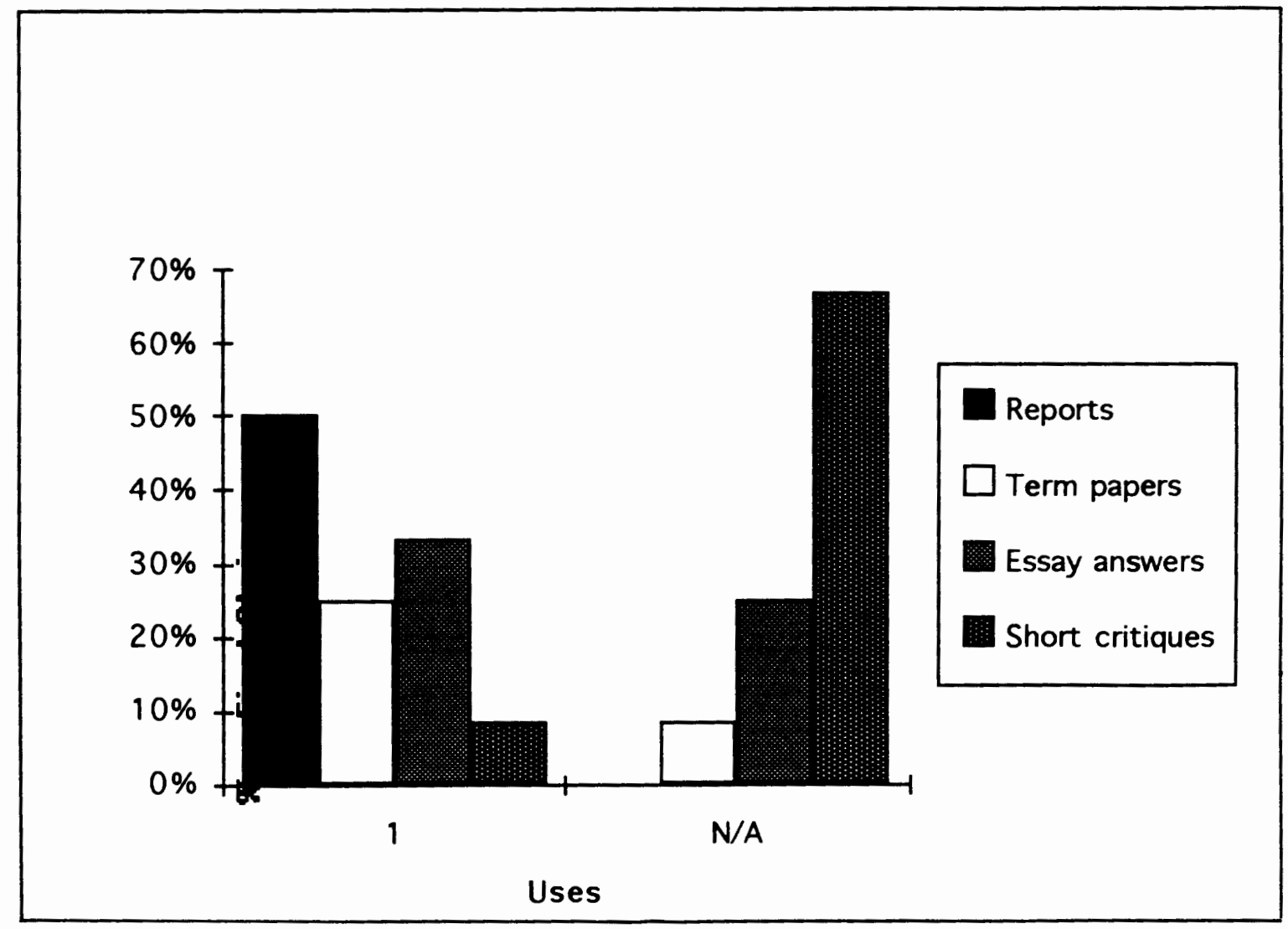

Figure 14. Graduate business faculty: uses of writing skills 
Undergraduate Engineering and Applied Science faculty:

PSU engineering faculty, as business faculty, show a similar use by level of reports ( $31 \% / 50 \%$ business to $36 \% / 45 \%$ engineering); and a lower use of essay answers, (50\% / 33\% business to $29 \% / 23 \%$ engineering).

Figure 15 shows that $36 \%$ of the undergraduate engineering faculty rank reports as the most important use of writing in their classes, while $57 \%$ rank it as second most important. Essay answers are ranked equally "most important" and NA by $29 \%$. Term papers are considered most important by $21 \%$, while $36 \%$ rank them NA. No one ranks short critiques first, and $57 \%$ say they were NA. Such a high occurrence of NA categories indicates that the engineering faculty must rely on "Other" forms for written communication. This is validated by the mention of such items as problem solving ( $14 \%$ most important), and claritu and grammar ( $7 \%$ most and second-most important).

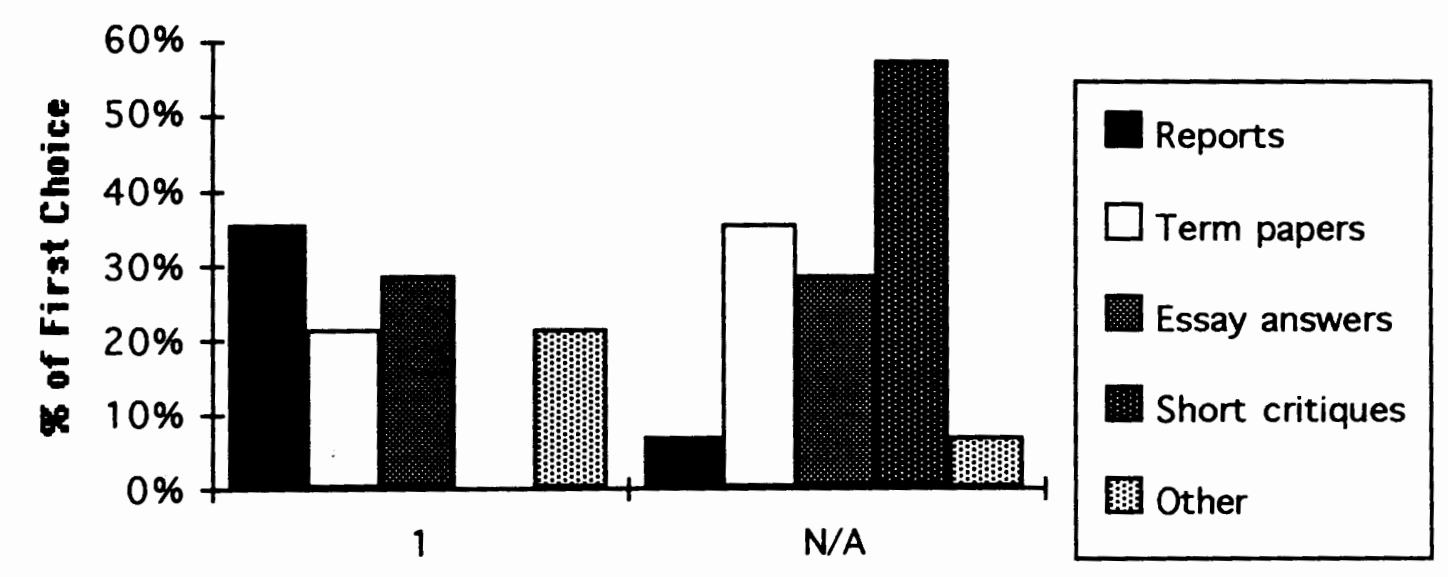

Uses

Figure 15. Undergraduate engineering faculty: uses of writing skills 
Graduate Engineering and Applied Science faculty:

Reports receive the highest ranking of writing skill use for graduate engineering classes (46\%), as shown by Figure 16 . Term papers are the next highest use of the skill (31\%). Essay answers (23\%) are ranked third. No faculty cite short critiques as "most important," with $46 \%$ mentioning them as NA. Instructors offer the most alternative uses of writing in the "Other" category. Clarity of presentation and grammar is ranked first by $7 \%$ and second by $14 \%$ of the faculty. Problem solving is third-most important (14\%), and publication $(7 \%)$ is fourth .

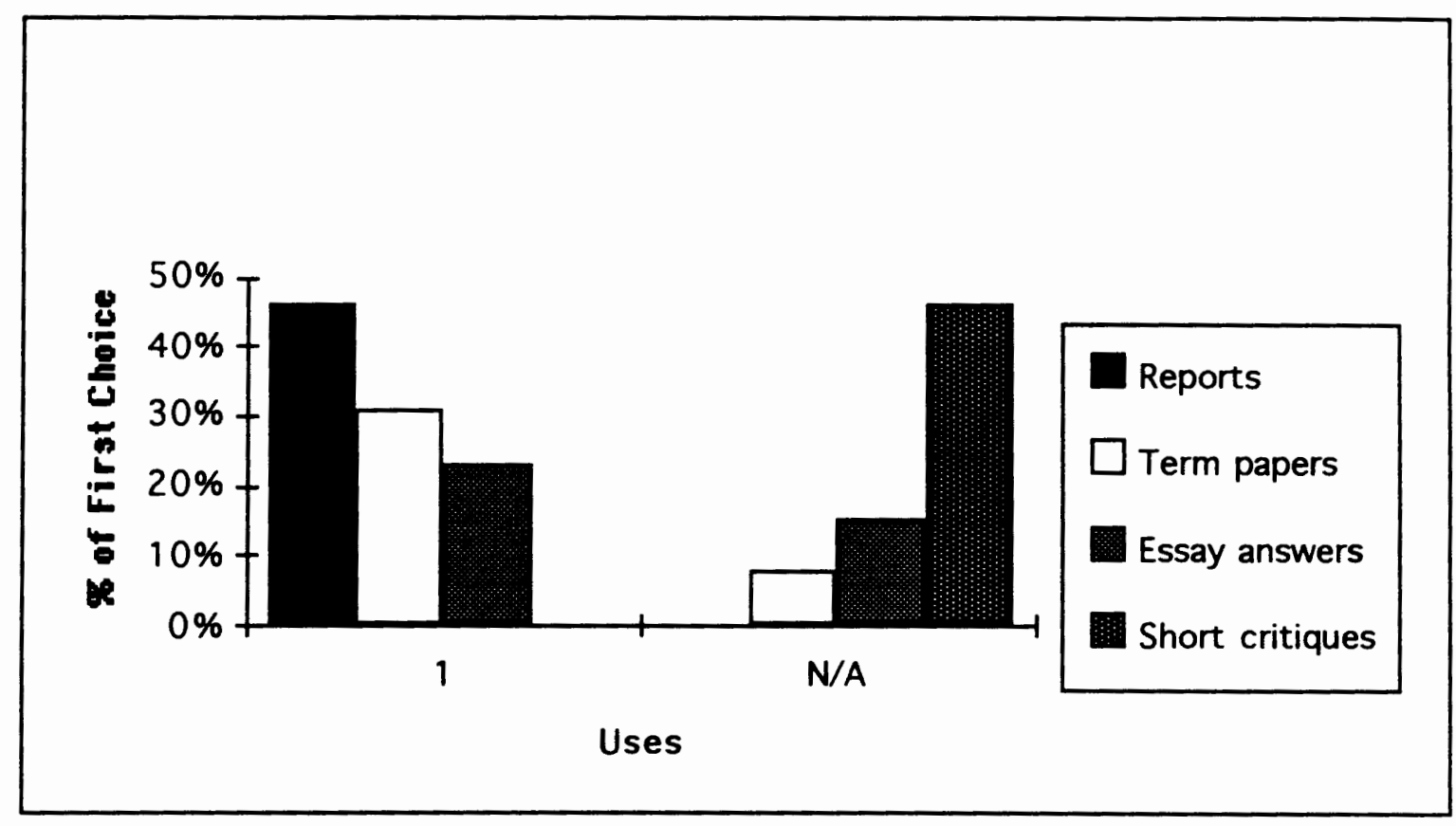

Figure 16. Graduate engineering faculty: uses of writing skills 
Survey Question D. Which speaking skills--ability to participate in class discussion, ability to formulate questions, ability to organize and present an oral report, or ability to pronounce words clearly--are most important?

In Survey Question A, the language skill speaking was ranked last by all faculty [see Appendix C]. It received the least number of $1 \mathrm{~s}$ of the four major language skills, and two NA rankings. However, speaking skill uses are fairly consistent within disciplines. Most faculty rank class discussion as most important to academic success in their classes, with the highest score coming from the graduate business faculty $(67 \%)$ and the lowest score undergraduate engineering ( $36 \%)$.

\section{Undergraduate school of Business Administration faculty:}

The importance of class discussion to academic success for this level and discipline is shown in the substantial difference between this use (63\%) and the next "most important" selection, formulating questions (25\%) as shown in Figure 17. Faculty seem to place equal importance on oral reports and pronunciation (both 13\%). However, the NA category shows a higher ranking for pronunciation (19\%) than for oral reports $(13 \%)$, indicating the former is considered less relevant to academic performance than the latter in this discipline.

The category "Other" receives no first choices. However, for secondmost important, 6\% rank small group communication skills and for fourth-most important, $6 \%$ say staying on track in order to further discussion is a necessary use of speaking skills to successful participation in classes in business classes. 


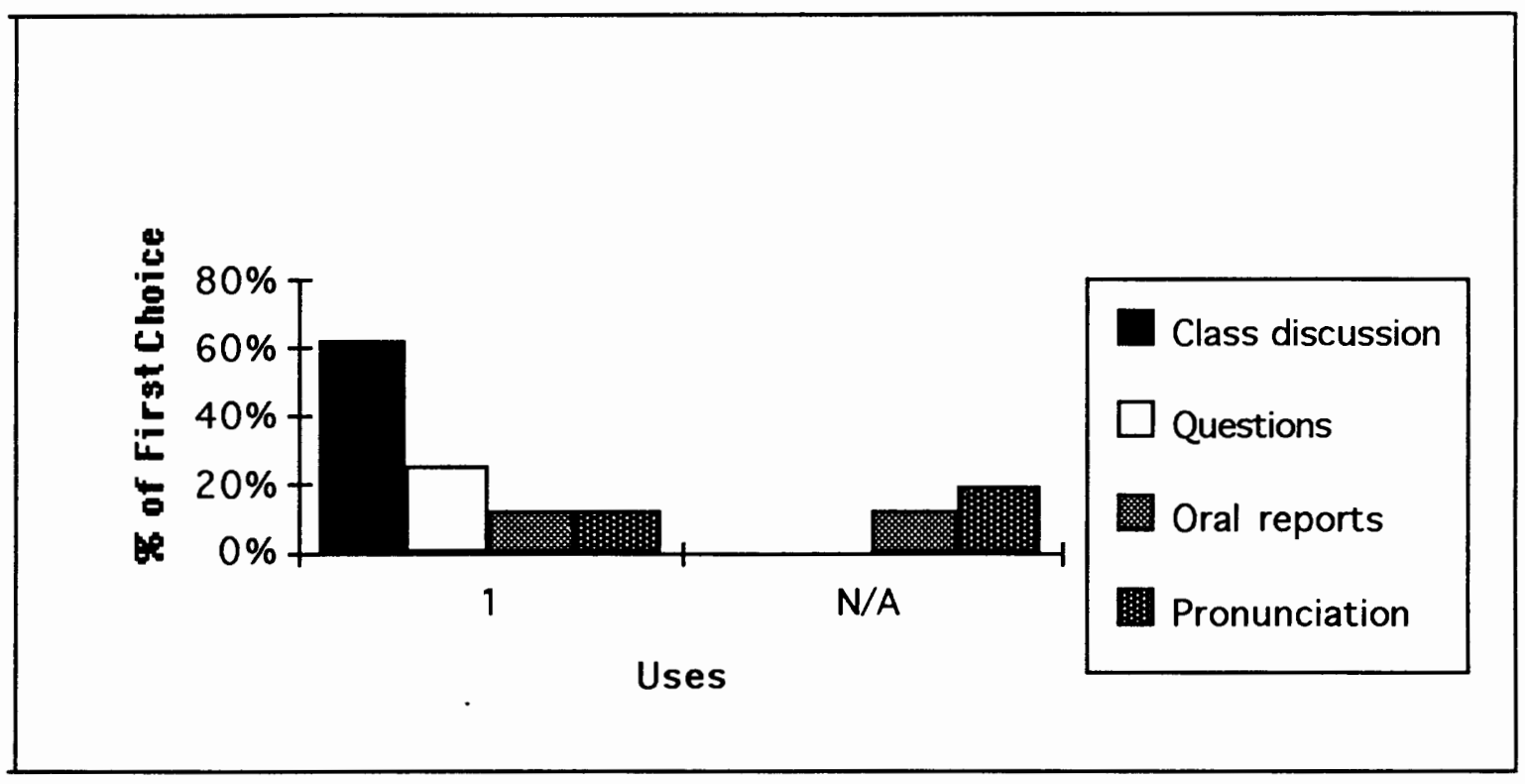

Figure 17: Undergraduate business faculty: uses of speaking skill 
Graduate school of Business Administration faculty:

The profile of speaking skill uses for this level looks very similar to the undergraduate level (see Figure 18). There is a strong reliance on the use of class discussion and a large gap between the next most important skill, formulating questions. The biggest difference is the absence of oral reports as a first choice response. Class discussion is ranked first by $67 \%$, formulating questions by $33 \%$, pronunciation by $17 \%$, and oral reports by no one. Again, pronunciation has the highest NA ranking (17\%). Eight percent rank oral reports as NA.

No responses for "Other" are ranked first, but it is worth noting that for second- and fourth-most important, the same two skills are mentioned as for undergraduate faculty: small group communication skills (8\%) and stay on track in order to further discussion ( $8 \%$ ).

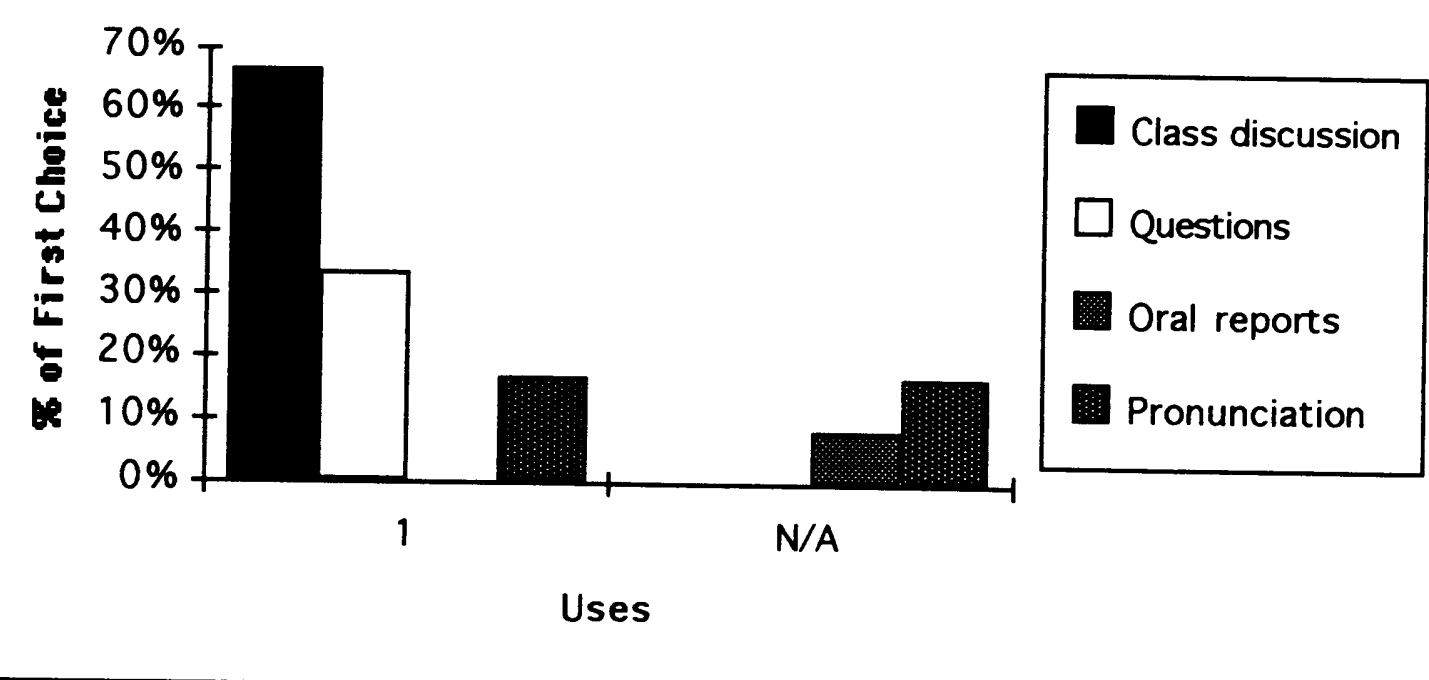

Figure 18: Graduate business faculty: uses of speaking skill 
Undergraduate Engineering and Applied Science faculty:

Results from this group show the lowest score for class discussion of all faculty (see Figure 19). It receives an equal ranking with formulating questions $(36 \%)$, nearly half the score from school of Business Administration instructors: undergraduate $(63 \%)$ and graduate $(67 \%)$. Another interesting result is the $21 \%$ ranking given to oral reports in both "most important" and "NA" categories. Results show that pronunciation matters little to this group of instructors (7\%). Seven percent say it is "most important" to utilize the speaking skills for small group communication in the "Other" category.

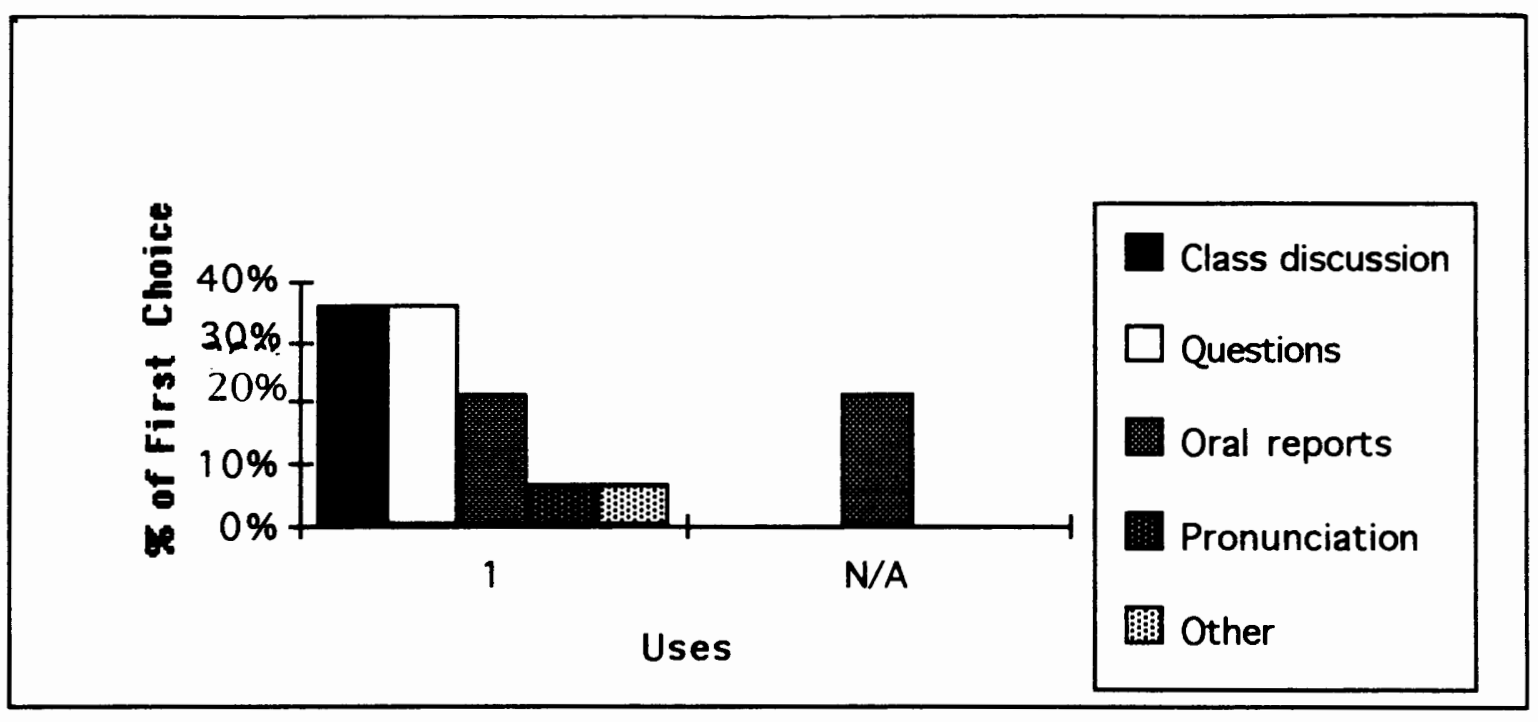

Figure 19: Undergraduate engineering faculty: uses of speaking skill 
Graduate Engineering and Applied Science faculty:

As shown in Figure 20, the primary difference between levels in engineering is in the increased importance of class discussion (46\% versus $36 \%$ ) and oral reports ( $31 \%$ versus $21 \%$ ) Only $15 \%$ say the latter skill is NA, compared with $21 \%$ of the instructors for the lower level classes.

Pronunciation has the lowest "first" ranking (8\%) of any speaking skill use from all faculty in the survey. It is ranked fourth in importance by $67 \%$, and $8 \%$ say it is NA to the discipline.

No alternative usage is listed in "Other."

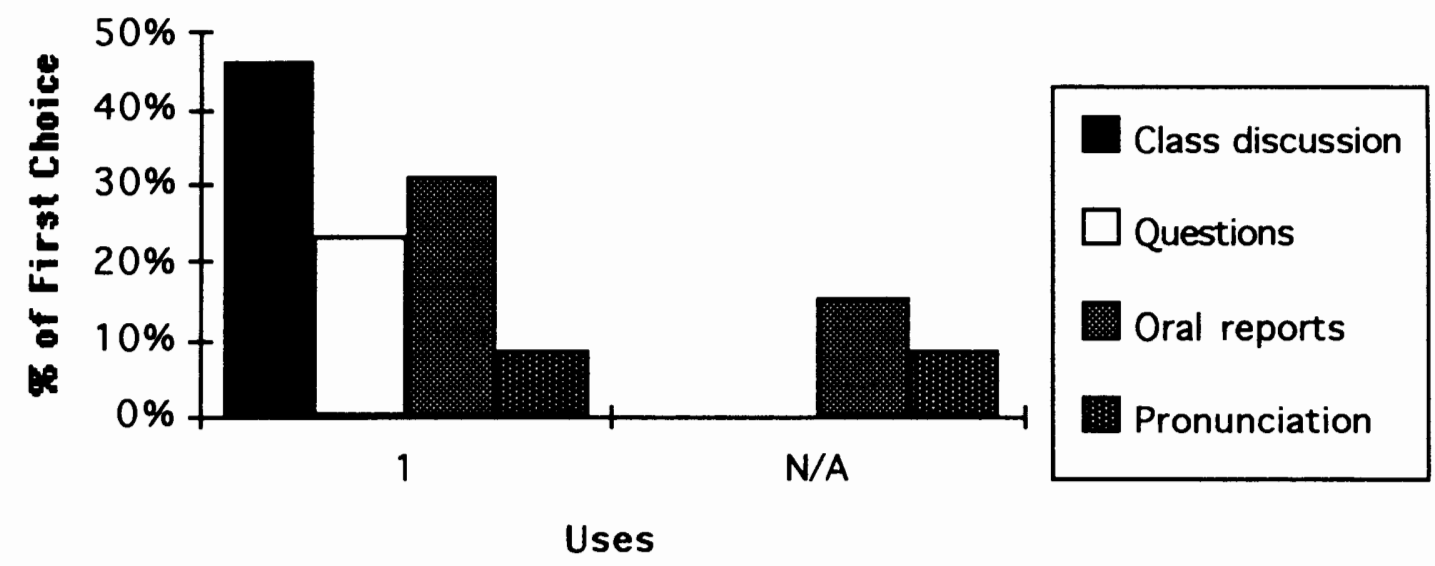

Figure 20: Graduate engineering faculty: uses of speaking skill 
Survey Question E. Which listening skills--ability to follow spoken directions, ability to understand and restate orally-presented classroom material, ability to understand and take adequate notes on lectures, or ability to understand student talk--are most important?

The subset of listening skills follows closely the nature of the language skills themselves--receptive skills and productive skills. Brown (1987) says listening and reading are often equated with comprehension. Speaking and writing, on the other hand, are productive skills equated with performance. Just as children may understand more than they actually produce, adults understand more vocabulary than they use in speech ( p. 27).

Similarly, following spoken directions and taking notes on lectures are slightly more receptive in character than either understanding and restating orallypresented material, which utilizes the skill of synthesizing ideas, or understanding student talk, which implies responding to and engaging in small group communication.

Overall, the differences between disciplines in how listening is used are in the subsets following directions and understanding student talk. Three faculty groups rank taking notes on lectures as the most important use of the listening skill, although the degree of importance seems to vary slightly by discipline. Graduate business faculty rank it very low; both engineering faculty rank it very high. The average business score for this manner of using the listening skill is $46 \%$ and for engineering, $58 \%$.

Although every faculty except undergraduate business lists certain subsets of the listening skill as NA, no one offers alternative uses for "Other." 
Undergraduate school of Business Administration faculty:

Results from the question on uses of listening skills among undergraduate business faculty show the complete absence of following directions as a first choice for classes (see Figure 21). The overall selection for this group is taking notes on lectures (50\%), followed by restating material (38\%). Understanding student talk is ranked first by only 19\%. Neither NA nor Other are mentioned.

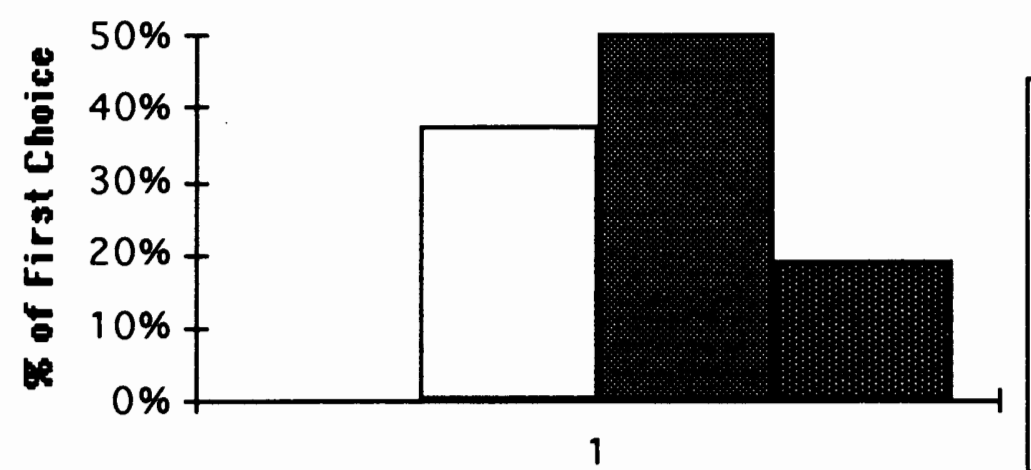

Follow direction

$\square$ Restate mater.

Takenotes

Student talk

Uses

Figure 21: Undergraduate business faculty: uses of listening skill 
Graduate school of Business Administration faculty:

Following directions is of little value as a use of listening, according to faculty at this level in business classes (see Figure 22). Only 5\% rank it "most important" and $8 \%$ say it is NA. The first choice $(50 \%)$ is restating orallypresented classroom material. Taking notes is the next most preferred choice (42\%), although $8 \%$ say it is NA. A quarter of this faculty rank understanding student talk the most important use of listening, the highest ranking by all faculty for this subset.

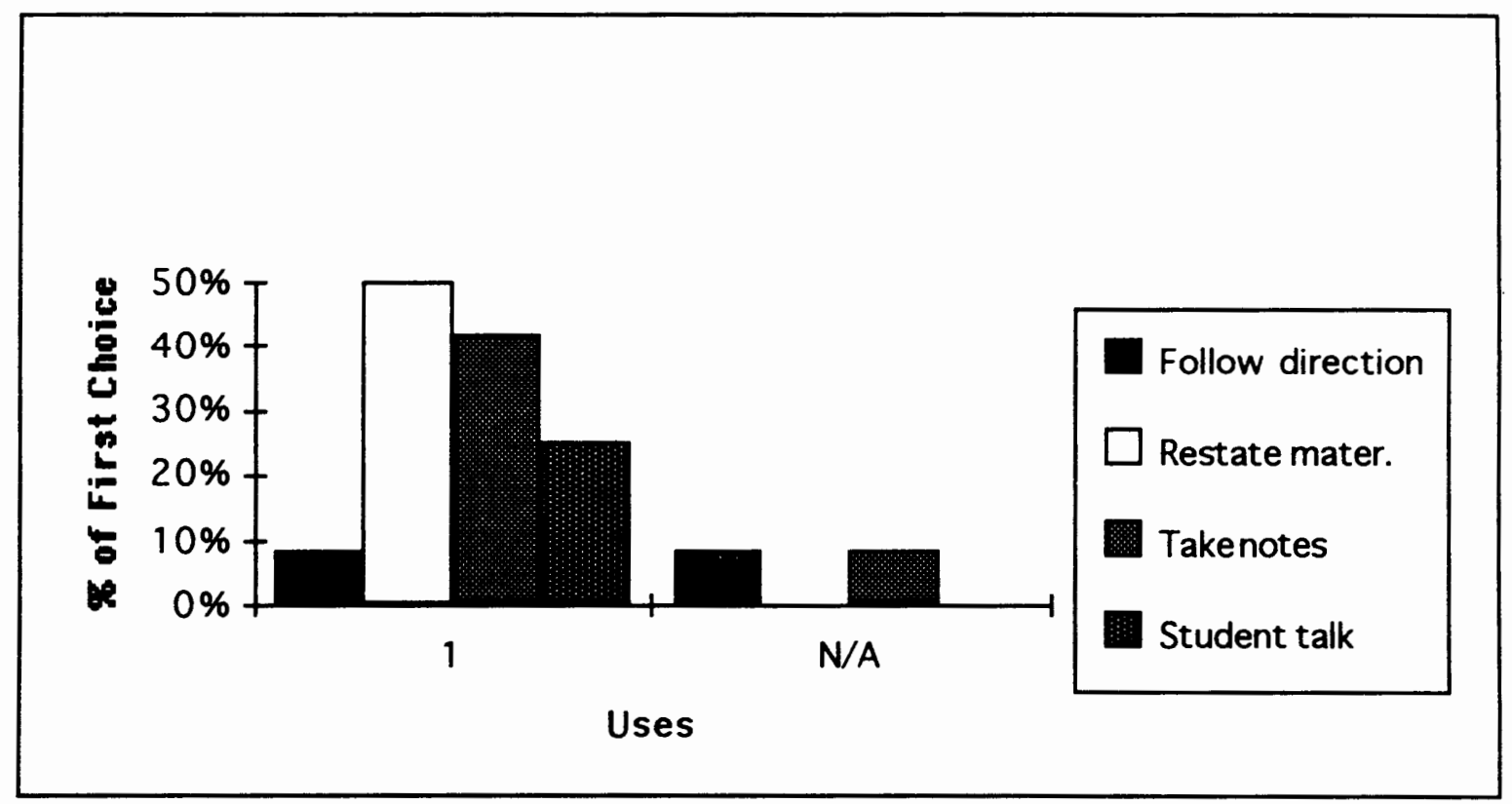

Figure 22: Graduate business faculty: uses of listening skill 
Undergraduate Engineering and Applied Science faculty:

As shown in Figure 21, 57\% of the engineering instructors for this level say that taking notes is the most important use of the listening skill for their classes. Twenty-nine percent say following directions and restating orallypresented classroom material are of equal importance. Seven percent of the instructors rank three separate uses of listening--following directions, restating material and understanding student talk--as NA.

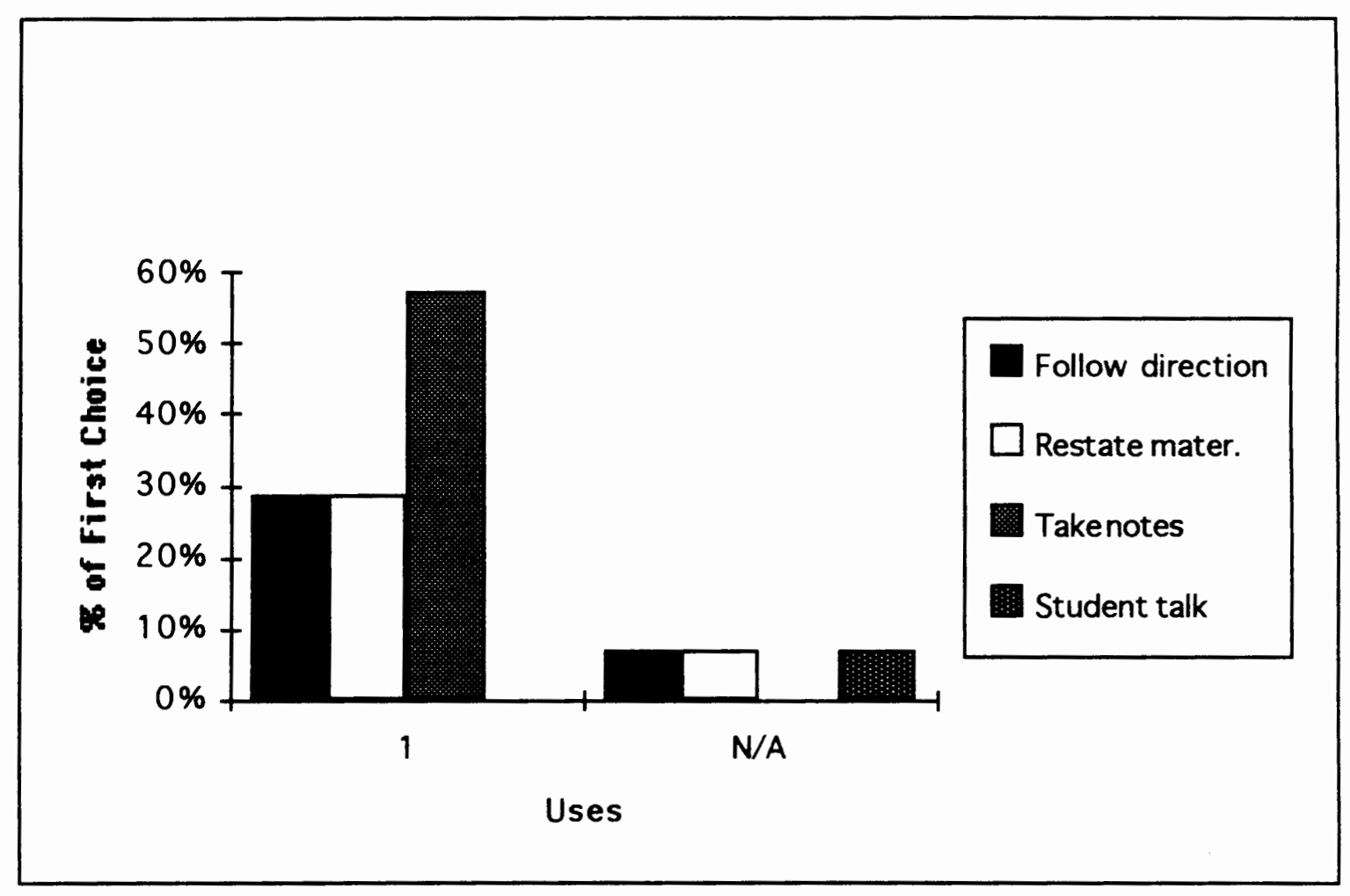

Figure 23: Undergraduate engineering faculty: uses of listening skill 
Graduate Engineering and Applied Science faculty:

Figure 24 shows that $62 \%$, the highest percentage of all faculty, say taking notes on lectures is the most important use of the listening skill for success in their classes. The importance of this subset for graduate faculty is shown by the fact that $38 \%$ rank it second-most important, and no ranking is given below that level. Twenty-three percent choose following directions. No one ranks understanding student talk as most important; $8 \%$ of the instructors rank it NA.

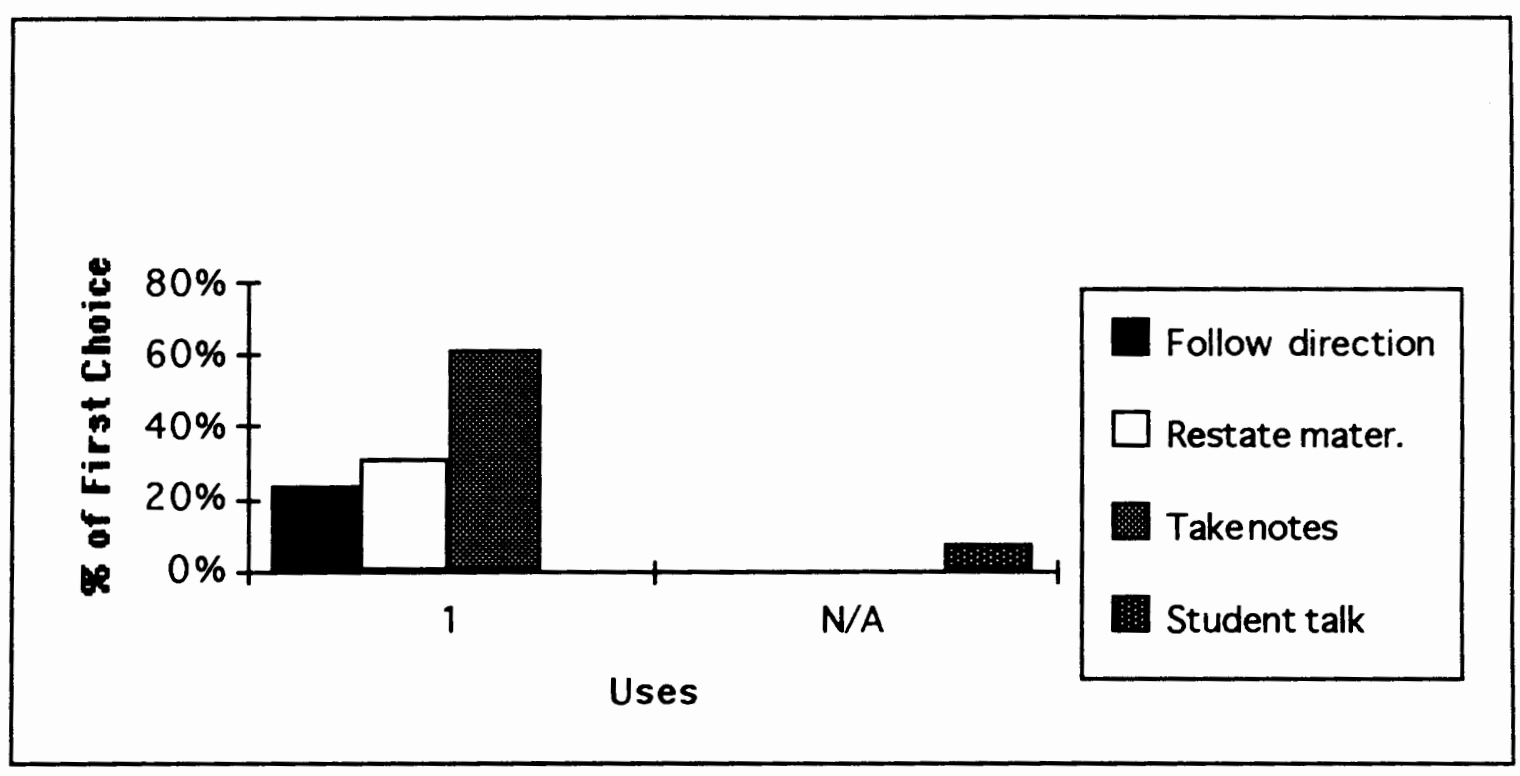

Figure 24: Graduate business faculty: uses of listening skill 
Survey Question F. Which is more important for success in your classes, a general knowledge of English or a knowledge of the English specific to the discipline?

Overwhelmingly, business faculty say that a general knowledge of English is more important for success in their classes. The strongest case for discipline-specific English comes from graduate engineering faculty. Results are listed in Table I:

\section{TABLE I}

\section{RESULTS OF SURVEY QUESTION F: TYPE OF ENGLISH IMPORTANT TO SUCCESS AS LISTED BY DISCIPLINE AND LEVEL}

\begin{tabular}{|c|c|c|c|c|}
\hline & $\begin{array}{c}\text { Undergraduate } \\
\text { Business }\end{array}$ & $\begin{array}{c}\text { Graduate } \\
\text { Business }\end{array}$ & $\begin{array}{c}\text { Undergraduate } \\
\text { Engineering }\end{array}$ & $\begin{array}{c}\text { Graduate } \\
\text { Engineering }\end{array}$ \\
\hline $\begin{array}{c}\text { General } \\
\text { English }\end{array}$ & $81 \%$ & $86 \%$ & $66 \%$ & $57 \%$ \\
\hline $\begin{array}{c}\text { Discipline- } \\
\text { Specific } \\
\text { English }\end{array}$ & $23 \%$ & $14 \%$ & $33 \%$ & $43 \%$ \\
\hline
\end{tabular}

\section{SUMMARY OF FINDINGS}

The results will be summarized by mean average scores. All faculty expressed difficulty ranking the four language skills according to which were most important to academic success in their classes. Several said that all were equally important. Nearly every faculty member ranked reading first, but most had difficulty choosing between reading and listening. The average first ranking for reading is $62 \%$, and listening, $46 \%$. 
Speaking and writing scored low in the preferred rankings. Speaking shows the greatest variance from low to high in percentage of "most important" rankings. Writing shows a similar variance, but its highest percentage is lower than that of speaking. By mean average score comparison, speaking $(21 \%)$ is ranked slightly higher than writing $(20 \%)$. Tables showing highest and lowest rankings for language skills by averages are presented in Appendix F.

Uses of skills vary by discipline and level. Textbooks are the preferred use of the reading skill. The average score is $74 \%$. Taking notes on lectures is the most important use of the listening skill (53\%). Class discussion is preferred by more than half of all faculty $(53 \%)$ as the most important use of the speaking skill. Reports (41\%) are slightly preferred over term papers and essay answers as the most important writing use. Tables showing highest and lowest rankings for language skill uses by averages are listed in Appendix G.

Tables showing the comparison of "most important" language skills and "most important" language skill uses by average score of all faculty are listed in Appendix $\mathrm{H}$. 


\section{CHAPTER V}

\section{ANALYSIS OF SURVEY INTERVIEWS}

This chapter examines faculty responses to the open-ended interview questions. Factors pertaining to the interpretation of the interview responses, language skill differences, and language skill uses are also discussed.

Six of the nine interview questions are discussed in Faculty Assessment section of this chapter in the order in which they were asked [see Appendix B]. Questions 7 through 9 are discussed in the Implications section of Chapter VI.

\section{ANALYSIS FACTORS}

Analysis of the latter part of the survey, the open-ended questions, provides information about how the verbal content of classes varies. Faculty interviews provided a glimpse at the nature of the content of classes in each discipline. The assumed dichotomy between business and engineering does not apply to the remarks in this portion of the study. Both disciplines share similarities as well as differences in language-orientation. For each discipline, there is a continuum of language use that includes the quantitative, or numberbased concepts, as well as the qualitative, or language-based concepts. Table II shows the language continuum found in Business Administration and Engineering and Applied Science courses. Some classes in engineering and business are both less verbal and more verbal than others. They each fall along 
TABLE II

LANGUAGE CONTINUUM OF COURSES

BUSINESS ADMINISTRATION

LESS VERBAL

MORE VERBAL

Accounting (ACTG)

Information Systems and Quantative Analysis (ISQA)

Management (MGMT)

Marketing (MKTG)

\section{ENGINEERING AND APPLIED SCIENCE}

LESS VERBAL

MORE VERBAL

Computer Science (CMPS)

CE Theory Classes

Electrical Engineering (EE) ME Industrial Design Classes

Civil Engineering (CE) Lab classes

Mechanical Engineering (ME) Lab classes

Engineering Management Program (EMP) 
a range defined by the amount of language as opposed to the amount of numbers they analyze and organize. At the lowest end of the continuum, fall the courses which are lecture-based, theory-driven, and numerically-focused. An example is this description of an electrical engineering (EE) instructor's class: "The language we all share is math." At the highest end are those which rely on small group interaction with an overlay of culturally-embedded language and concepts against a background of assumed contextual knowledge. An example is this marketing (MKTG) instructor's government class description: "Marketing nuances differ from political climate to political climate. . .terms and concepts that can be confusing to international students."

At the beginning of the interviews, faculty were asked to describe their classes in terms of the amount of culturally-intensive language or concepts involved. Most engineering classes fall at the low end of this spectrum and most business classes fall in the middle and upper end. Faculties' remarks will be analyzed with this factor in mind. All discussion pertaining to language skill and language skill use preferences in this chapter will take into account the degree to which international students are required by the nature of the class to manipulate culturally-intensive language or concepts.

Another important factor in looking at differences between faculty perceptions of academic success for non-native speakers in both disciplines is their country of origin. Professors who brought a cultural experience outside of the U.S. to their classrooms tended to view international students slightly differently in three areas particularly: academic performance, class participation, and accent. Of the fifteen instructors surveyed in engineering, eleven were born outside the United States. For them, second-language learning is the norm, not the exception. Ten of the eleven had completed some 
portion of their education at an American university, experiencing the same language adjustment problems as their students. Their remarks take on added dimension in the evaluation of "problematic areas" and "incidents of misunderstanding" for foreign students.

The number of foreign-born faculty in the school of Business Administration is much smaller. Fifteen of the sixteen instructors were born in the United States. Three of the U.S. born, plus the non-native instructor had some experience teaching abroad.

\section{INDIVIDUAL LANGUAGE SKILL IMPORTANCE}

Faculties' assessments of the amount of culturally-intensive language their courses contained figured into an arbitrary decision to group classes in both disciplines. Business classes on the less verbal end of the continuum include courses in Information Systems and Quantitative Analysis (ISQA) and Accounting (ACTG). These classes are numerically- and data-based, analytical, theoretical with more emphasis on lecture than group interaction, especially at the undergraduate level.

Engineering classes on the less verbal side include courses in Computer Science (CMPS), Electrical Engineering (EE), as well as lab classes in both $\mathrm{CE}$ and ME. In the words of one CE instructor, "Design classes with theory and application, and lab classes have little culture-intensive language. Symbols are more important than language. They speak for themselves." In these classes, in both disciplines, listening plays the strongest role, followed closely by reading. Analyses of data show a positive relationship between classes which manipulate numbers and analyze numerical concepts and the perceived importance of listening skills. 
Business classes on the more verbal side of the continuum include courses in Management (MGMT) and especially Marketing (MKTG). Instructors acknowledge the amount of culture which is part of these classes at both levels, and admit that this is a difficult factor for international students. Engineering classes on the more verbal side include some Civil Engineering (CE) theory classes, a few Mechanical Engineering (ME) industrial design classes, and particularly the Engineering Management Program (EMP), a graduate program which bridges the gap between engineering skills and marketing concepts. One ME professor explains the problems international students have with language in these classes, "The engineering classes in manufacturing processes involve cultural-intensive symbols. This hinders their [international students'] performance."

Analyses of survey results show that for those classes in which culturally-embedded language plays a part, reading and writing become the predominantly important language skills. Writing tasks differ in importance based on courses which manipulate numbers more than language in both business and engineering. Those courses prefer essay answers as a frequently used function of writing and term papers as an infrequently used function. Those who teach qualitative courses of language manipulation prefer reports. For speaking tasks, formulating questions increases as a necessary skill use with the importance of analysis and mumerical concepts to course content, whereas, class discussion increases with the importance of cultural- and languageintensive concepts.

No patterns were found with listening tasks. Taking notes is ranked extremely high by the most verbal courses in engineering and the lease verbal courses in business. Conversely, close to the same percentage of faculty from 
the less verbal courses of engineering and the more verbal courses of buisness choose understanding and restating materials as the most important use of the listening skill.

\section{FACULTY ASSESSMENTS}

The following open-ended questions were designed to give faculty an opportunity to describe their classes and discuss the academic performance of international students as compared with native-speaking students. It provides context to the assessment of the importance of language skills and their uses against the background of the amount of culturally-embedded language and the degree of interacting with either instructor or other students required by each class.

Question 1 What is the relationship between communicative tasks (interaction with others) versus independent tasks (listening to lectures, working alone) in classes in your discipline?

In ISQA and ACTG business classes, where the emphasis is on design analysis and data base, responses averaged 10\% communicative task to $90 \%$ independent task. This ratio is contrasted with the high end of the continuum used in one graduate marketing class, where the ratio is $70 \%$ communicative to $30 \%$ independent. A MKTG instructor said,

In these classes[MKTG], students have to manipulate concepts. They can't just feed them back. And they have to do that in context with other students. That's difficult for many Asians.

Responses from undergraduate faculty EE, CMPS, CE and ME are predominantly $10 \%$ communicative to $90 \%$ independent. The shift to interaction with others comes with graduate classes and is highest $(60 / 40)$ in 
the EMP program, which uses highly interactive strategies including team projects, defense of ideas, case discussions, and oral presentations.

Question 2. Compared with native-speaking students, how do international students perform in your classes?

Faculty descriptions of students' academic performances follow similar lines of the quantitative/qualitative or less verbal/more verbal continuum for both disciplines. Opinions about academic success are clear: students, especially Chinese graduate students, do extremely well manipulating numbers. They do very poorly manipulating language.

Many faculty, especially in the school of Business Administration, drew distinctions between European and Asian students. One such observation is offered by a lower division instructor:

There are definite cultural barriers and differences. The German, Russian, Swedish, and Norwegian students are hard workers. The Chinese, Vietnamese, and Japanese rely on a network. They are cliquish. They know everything about every class before they enroll.

Business instructors in ISQA and ACTG say international students reflect the general spectrum of performance They add that many international students have better academic skills and do better than native students. One professor who teaches graduate students in international research explains,

Because of the nature of the courses, International students are equally as good. They have more exposure to international research. They are more technical. These classes demand less reading. They are more manipulative and involve calculation skills.

Some engineering faculty repeat this opinion. One CE instructor says, "There's no discernible difference today. They reflect the broad spectrum of good, bad and average students." An EE instructor says they do as well or better than native speakers. A graduate EE professor says, "They do equal or 
better. It makes no difference if they have good comprehension." And from one ME instructor comes this assessment:

Today, the quality of American students has declined in math. The international students, especially the Chinese, are better qualified. In our classes, symbols speak for themselves. We have a common language in math.

Understandably, many MKTG and MGMT business instructors' opinions contradict this assessment. The nature of their material requires more conceptual language skills used productively. Analysis of material often involves contextual, culturally intensive background information which foreign students do not bring automatically to class as do native speaking students. Responses from MKTG and MGMT include, "They are more likely to have problems than native learners. Many have difficulty participating." "Some do well, others aren't prepared. English skills make the difference. They can't transfer cultural milieu into written concepts."

Engineering faculty from the more verbal end of the spectrum agree $\mathrm{A}$ frequently heard comment was this one from an undergraduate ME professor: ".. language is a handicap for international students." This assessment is from the graduate EMP program:

They have difficulties in the beginning [first quarter]. They're good at book-related concepts, but they have difficulty expressing their ideas. They have difficulty understanding non-mathematical concepts.

Question 3. Are there any areas that tend to be problematic for international students in your classes?

It is interesting to look at this answer by comparing the less verbal/more verbal perspectives. From ISQA and ACTG in business come some "positive" responses:

I don't notice problems as a cultural difference. It's more individual. 
There are small language problems. The cultural content of words is sometimes a problem.

Accounting is a language by itself. Students who have English as a first language also have problems.

Forming teams is a problem. American students weren't initially reaching out to make them feel comfortable. Their written work doesn't show any difficulty.

And some "negative" ones:

.. writing, presentations, assertiveness [lack of], group leadership, participation.

English skills are not very good in general. There's a decline in study skills, attitude. They seem to be here for a good time.

In grading, targeting the average impacts the total quality of education. It pulls it down. It takes a great deal of time. Most of my office hour time is spent with international students. They're not afraid to ask questions in class. I find Asian students very aggressive.

There is less range of comment from the more verbal side of the continuum in business. Many MKTG and MGMT comments are quite negative. The strongest remarks were from instructors teaching at the lowest levels:

Many have difficulty participating. They'd rather be seen and not heard in a cultural perspective. They have speaking and writing problems.

The written essay is the biggest problem. In class, case-studies are done independently, so they can't have friends help them. Students don't participate in class. They are very uncomfortable speaking in class.

Writing [is the biggest problem]. Understanding U.S. approaches to learning. They are confused by how to extract knowledge from class discussions. Many Asian students are poor at presentation skills.

Marketing is culturally centered. Asian students have trouble with marketing classes. They culturally don't want to participate in class.

Problems run across the board. They don't know the language. Some use speaking translators in class. Not enough language skills. 
Asian females have little self-confidence. They revert to plagiarism. I understand that they understand what's not acceptable.

They are heavy-handed when it comes to responsibility for late papers. Some Asian students are embarrassed to turn in papers so they suffer late grades.

They don't take advantage of office hours to discuss problems with professors. They are afraid to approach for help.

The following engineering faculty remarks need to be read in the context of the high number of foreign-born instructors coupled with the large number of foreign students in some classes. Instructors estimated that nonnative speakers comprise approximately $30 \%$ of the graduate students in EMP and $\mathrm{CE}$, over $50 \%$ in $\mathrm{EE}$, and over $75 \%$ in ME and CMPS. When such high percentages of second-language learners dominate the class population, accommodations are sometimes made without introspection about linguistic "deficiencies." International students can be appreciated more for their analytical contributions than evaluated on their linguistic shortcomings.

The same distinctions between the less verbal and more verbal courses in business exist in engineering. However, since the entire discipline is weighted toward the analytical, numerical-based use of language, less range of comment is found. These comments are from CE.

Slang is a problem. They are missing information in the finer areas of language skills with shades of meaning and body language.

Communication between teacher and student is a problem area. Students are hesitant to clear up misconceptions. This is particularly true for Pacific-rim students.

They are hesitant to take the initiative. They are handicapped according to doing things on their own. They have difficulty finding information. When they have to look things up on their own, they don't know where to go. They lack independence on optional tasks. 
Sometimes, two professors in the same department see things quite differently. From a non-native speaking instructor in EE:

I haven't encountered any students whose language skills would negatively impact their academic success.

From an American-born instructor in EE:

In the masters' program, they exhibit tense communication. I don't care what their English sounds like as long as we communicate.

And sometimes, as in the case of this non-native speaking instructor, the professors' own "accent" may get in the way of communication:

Chinese students ask me to write everything. After three years it is still a problem.

An interesting cultural, rather than linguistic, deficit is discussed by an

ME instructor:

Aside from language skills, which are problematic, they have little application experience. No hands on, no lab, no fabrication experience. It's all theory. Remember, there aren't an abundance of cars and lawnmowers in China to tinker with.

Remarks from the EMP program are very insightful when discussing international students' lack of creativity:

Their communication skills are lacking. [also] the ability to define the problem, find a solution, and elaborate. They can't go beyond the boundaries defined by the book. They have general problems with creativity. They are not used to challenges that are brought into the classroom They are used to digesting the professor's materials, not having to participate. They come from a cultural paradigm of taking what's presented in class as gospel. It is intimidating to foreign students who lack work experience to compete with ... men in their 40s and 50s with many years experience.

Question 4. Describe any incidents involving non-native students' misunderstanding of orally-presented material.

This question was designed to elicit observations of listening skill deficits.

For some faculty, however, it became a discussion of culture-based versus 
language-based misunderstandings of material. Overall, business faculties' remarks about behavior which varied from their own cultural expectations were more "prescriptive" than "descriptive" when compared with engineering faculties' remarks. Business instructors more frequently talked about how behavior "ought" to be; engineering instructors more frequently described how it "was." Their remarks attribute misunderstandings more to cultural differences than language deficiencies.

One factor contributing to this difference could be the nature of the classes. "Critical incidents", verbal signals of misunderstanding of material, would be less noticeable in a discipline where the predominant language skills used by professors are receptive skills, reading and listening, such as the discipline of Engineering and Applied Science. Business Administration classes more frequently challenge the productive skills, writing and speaking. Here, "critical incidents" would be observable.

Another factor might be the higher percentage of foreign-born instructors in engineering, $73 \%$, over business, $6 \%$. It is possible that instructors who, in their own academic backgrounds, have experienced learning content at the university level in a different language and culture may have more empathy for and less judgment about second-language learners.

Looking first at business classes, faculty responses to this question follow the previous split along the continuum of degree of language manipulation and cultural materials. Instructors from the quantitative, less verbal, courses cite only a few critical incidents attributed to language. For instance, from lower division ISQA: "Test scores are indicative of misunderstanding of classroom materials. Explaining is hard." And from ACTG, an example of one of the two 
instructors citing "no incidents": "No problems come to mind. Only cultureembedded words are confusing."

But comments about culture are frequent, as these remarks from an upper division systems course instructor reveal:

There are no critical incidents to indicate language is a barrier. There was an instance of perception of cultural discrimination by a Pakistani student working in a small group. One student had biases towards anyone not from her culture or anyone who wasn't white. She was a mediocre student. Also, recently two Malaysian students were upset by results on an exam. They came to see me about their poor performance. They got 68 and 69 out of 70 . They thought that the scores were based on a scale of 100 and didn't realize that they had actually gotten the highest scores of the class.

Another remark about cultural "difference":

A student asked to take a test early. It was a timed test. I had asked a colleague to collect the test and this student took advantage totally by not turning it in on time and then saying he didn't understand. Their ethics are different. My colleagues agree.

A few examples of language misunderstanding come from the qualitative, more verbal, courses, as this MGMT instructor reports: "Recently when two German students were working together as a group, I asked for reports to come as a result of their work. They misunderstood and I got one report rather than three."

But a culture-based difference is evident in this MGMT comment:

Asian women in my international business class don't take notes. They generally don't understand the value of classroom interaction. At the end of a discussion of business points, when I ask them to summarize, they repeat one of the original points. Of the students who fail undergraduate classes, most are international students. I recommend they go back to ESL classes.

The strongest, most judgmental remark of all the interviews comes from this MKTG instructor: "I don't get along with Arab students because their culture is based on casual feelings about time and deceit." 
The above remark notwithstanding, a few business instructors are aware of and understanding about the added dimensions imposed on the academic environment by differences in cultural expectations. An excellent example of how some instructors recognize the difference between culturebased and language-based misunderstandings comes from this MGMT instructor's story:

There have been many incidents of misunderstanding. Concepts of motivation are a problem. Recently, I asked in an exam, 'What situation would you create (as a manager) to motivate people?' The Asian students just don't understand (culturally) why you would need to consider this point of view.

One MKTG instructor says he recognizes the problems created for international students by a shift in their cultural paradigm and tries to counteract this: "One undergraduate assignment was an experiential project: an ethnographic interview. Asian students had a hard time understanding the project."

Because of the MBA program's highly verbal content, non-native students often face added academic hurdles. Their productive language skills of writing and speaking are regularly challenged by class discussions and small group projects. This professor summarizes the challenges of the program and the deficits of the students:

In team projects, students are required to give reports. Predictably, international students lack the following abilities: to present well-written papers, to participate in class, and to appear to other students to carry their own weight in the team project.

Compared with business faculty attitudes, engineering comments about "incidents of misunderstanding" are more "descriptive" (this is how it is) than "prescriptive" (this is how it should be). It is interesting to look at responses to this question from a perspective other than the qualitative/ quantitative degree 
of language in the course content. Instead, faculty remarks from native speakers differed importantly from non-native speakers. The latter group seems more sympathetic about "misunderstandings" and less apt to apply cultural judgments to incidents than native speaking instructors appear. For instance, five engineering faculty (33\% of the responses) report the absence of any critical incidents at all. All five are non-native speakers. Business faculty cite only two "no incidents" ( $12 \%$ of the responses).

Overall, comments from engineering faculty reflect a non judgmental acknowledgment of the possibility of misunderstanding. This response from a non-native speaking EE instructor mirrors the attitude present in many remarks: "It does happen. They do occasionally misunderstand." This acknowledgment is echoed by a non-native speaking EMP professor: "Several have answered questions that weren't really asked during an exam. This has not been limited to international students, however."

An American ME instructor whose classes have little culture-intensive language shares his frustrations, at students' misunderstanding of materials:

It's a common phenomenon. In graduate class, for example, I have one Asian student who is shy. He doesn't ask questions. What he does, he does well, but he often does the wrong problems. I notice this primarily with Far East Students: Korean, Chinese, Taiwanese, Vietnamese, Thai; not European or Indian.

A non-native speaking ME instructor whose graduate work was recently completed in the U.S. has a slightly different perspective to this question. He admits that although it was difficult for him to adjust to learning in a second language, his expectations for his own classes are very high:

Many claim that [language] is the reason for not understanding. I adjust my lectures to match their understanding. I remove subtle statements. 
Faculty answers to the question about student misunderstandings exemplify descriptions, evaluations, and judgments. From a non-native speaking $\mathrm{CE}$ professor, a description of the problem:

It happens every day. I explain and re-explain. Students get only 75$80 \%$. The finer ways of communication pop in. It's like the difference between legal language and everyday speech. For someone who is a novice, chances are the student will misinterpret, especially for a logical or technical statement, a parenthetical expression, or a restrictive clause.

From a native-speaking ME instructor, an intuition about the problem:

I have a feeling about it rather than any critical incidents to report. Judgments, ethics, subtleties are more difficult to teach to non-native speakers. U.S. textbooks don't do as good a job as U.K. textbooks. They've dealt with a broadened view of others for a longer time because of their colonial orientation.

And from a non-native speaking EE instructor, a judgment about the problem:

Class differences create frustrations. Many students leave one status and enter another created by their lack of language skills. This creates emotional problems.

Comments about incidents of misunderstanding vary, even within departments. First, this evaluation of the problem of misunderstanding comes from a recently hired, non-native speaking CMPS instructor: "Only minor problems exist in exams. Students will come in later and say they didn't understand. It happens infrequently."

This story, also from a non-native speaking CMPS professor referring to a problem at PSU about ten years ago, adds a cultural interpretation and judgment to the incident:

The honor code is foreign to some students. They feel it is their duty to help fellow students. They copy work and say 'I had to help him. He's a friend of mine.' I once had five Vietnamese students in a final. One sent a copy to the other four students. An American student noticed it and mentioned it, calling it unfair. I gave an " $F$ " to all five. The poorest student offered to withdraw to save face for the other four. I've had the same thing happen with Indian students. I now always explain expectations at the beginning of class. 
The following remark, from an American CMPS instructor, is a generalized observation of behavior with an attached conclusion and value judgment rather than a specific description of an incident:

Academic dishonesty among international students is at a higher percentage. Take home exams are shared. It is more language-related than culture-related.

To summarize the remarks about understanding orally-presented material, business faculties' comments differ by degree of qualitative language used in the course. They cite more examples of culture-based misunderstandings than language-based problems. They make more judgments about misunderstanding

Engineering faculties' remarks differ by degree of personal experience with learning academic content in primary or secondary language. They cite fewer incidents of misunderstanding. They offer more descriptions of behavior. They cite more language-based than culture-based problems.

Question 5. Does a student's "foreign accent" impact academic success in your discipline?

Most faculty in both disciplines acknowledged that international speakers were "accented." Few were judgmental in their remarks. Most gave descriptions of the problem. No patterns between quantitative and qualitative courses were noted. It was observed, from this small sample of faculty, that individuals deal personally with students' "accents" in various ways.

Business faculty from quantitative classes in ISQA and ACTG respond as follows:

During presentations in class, international students often read their materials. It's a security thing. They're not comfortable with their language skills.

Accent doesn't impact their success. The ability to speak and write does, however. 
No effect.

It takes longer to understand them. It frustrates them not to be understood immediately. Their peers don't react negatively, though.

Some won't talk in class because of it. They can just sit there. Class doesn't depend on their participation.

Not often. Only if it totally prevents communication.

Faculty from qualitative MGMT classes offer a slightly different, but still uncritical, perspective:

The ability for the hearer to understand is diminished. The more difficulty a professor has in understanding, the more difficult it is to judge the content of the material.

Foreign accent doesn't affect them orally. I ask them to repeat if I don't understand. Only once has an American student come to complain about accent-interference as an issue when working in a small group.

It depends on the accent. Not much impact. Business is business. People who have good analytical skills are respected. When the accent interferes with understanding what they're saying, then it impacts.

Four MKTG instructors offer the same comments as their colleagues, and two say simply that accent does not impact academic success:

Accent doesn't impact their success. I tell them accent doesn't matter. It interferes when they have to use double dictionaries. Arab students use this technique to cheat in class by putting post-it notes in their dictionaries.

Their English is not clear when they speak. Some women speak so softly I can't hear them. I ask them to repeat.

Occasionally, S.E. Asian accents are a problem.

If you can understand the student then there's no problem. However, they don't get full benefit for their thinking. Part of their grade is based on good communication. 
Engineering responses to this question relate to faculties' perception of the eventual degree of professional use of language required by the discipline. Faculty from EE routinely describe their classes as primarily quantitative with little use of culture-intensive language. Listening scored highest among these instructors. All say that accent does not impact success in their discipline.

CMPS instructors describe their classes as largely theoretical, which use individual-based assignments with little communication between students. Faculty report accent does not impact success.

ME faculty say "symbols are more important than language. They speak for themselves." Value is placed on the skill of speaking for certain classes. An undergraduate instructor says, "In mechanical engineering, the senior presentation is $30-50 \%$ of the grade in design classes." Responses from this group say accent does not impact success, although one instructor says accent impacts some American students who often do not want to work with international students in groups.

CE faculty describe their classes as theoretical with a moderate use of culturally-embedded language. One non-native instructor says accent has "Not much impact." A good analysis of the eventual utilization of a civil engineers' professional skills comes from this native-English speaking CE instructor:

[Accent has] No impact on academic career. So much is analytical. They can rely on written statements. . .learn code of practice and rely on it. Professionally, they [international students] are weak on marketing their skills to business peers and clients. Of all the engineers, civil engineers are in frequent contact with the public--at hearings, with people, in cities. Environmental engineering is a civil engineering function. It is under the scrutiny of the public. We discuss these issues in design class.

From many instructors, the question elicited responses about students' reluctance to speak in class. This non-native $\mathrm{CE}$ instructor used the question to describe behavior beyond problems with accented speech: 
Not a lot [impact success]. They have difficulty understanding, but they are hesitant to ask questions. They don't participate in class discussions. They try to see me privately. Some try to resolve problems on their own. It hinders them. They are afraid to make mistakes.

Finally, from EMP, the graduate program that transitions students from analytical skills to marketing skills:

It doesn't impact on their academic success. It does impact on their career path development. Not the accent per se, but their visa status is a problem. The other thing that impacts their success is the self-selection process, U.S. students tend to be better at marketing; foreign students tend to be better at analytical skills.

The survey did not uncover strong biases against accented speakers' success in business classes. More than engineering faculty, business instructors acknowledge the difficulty they have giving full credit to international students' thinking and the content of their speech when accent interferes with communication. No faculty mention the impact of accent on eventual professional life.

Engineering faculty acknowledge accent impact as it relates to the marketing of their skills with peers and business clients.

Question 6. In addition to language skills, what social skills do you believe would be most helpful to non-native students' academic success in your discipline?

This question asks faculty to separate language-based "problems" from culture-based behavior. It was designed to explore faculty cultural awareness in both disciplines. It is a transition question to the discussion of the implications of the study for teachers of ESL. Responses to the question are similar across levels, disciplines, and within the range of continuum of quantitative and qualitative courses. 
Following are sample comments from business administration, arranged from less verbal to more verbal courses. The degree to which descriptions of behavior become more "critical" than "descriptive" seems to increase toward the farthest end of the culture-intensive continuum:

I believe that learning should be fun. International students have a more formal orientation to teachers. Culturally, they don't understand you can have fun while learning and this will enhance their learning.

Group interaction. How to work with people not from their own background. They need to understand the grapevine here. If they don't work well with their peers, it gets around. Need to learn nonverbal gestures, distance parameters, and English slang.

Nature of classes don't require social skills.

They don't have work experience. It handicaps them against American students. Don't have as much life experience to bring to the table. Eastern European students are disadvantaged by not having a background in capitalism. Even though this is a quantitative class, it is still culture-based in response to our business climate. [Also] group dynamics are different. It would be helpful if they integrated themselves more into class. Domestic students would benefit from interactions with these students.

Not aware of any skills they need. Overseas students find at first that they and American students are talking on different wave lengths. Their attitudes are very different. They come from different perspectives. I feel that American students don't appreciate the difference. Europeans feel they have a more serious, disciplined approach to classroom work.

They could have a better understanding of the role of active participation in class. They could develop an understanding of the business culture in America.

They need to work in groups. They need to have communicative skills.

They should understand the level of expectation from the university system. That includes work in groups and work done independently. Issues such as timeliness and quality of work. In general, their social skills should include contributions to overall classroom discussions.

Some of them can be abrupt in terms of their communication style. This makes [American] students uncomfortable. When they say 'That's not right. ..' instead of something less direct, they run into difficulty in fitting 
in with American students in their group interactions. This is a culturebased problem. Students react negatively to those who tend to be abrupt.

It's a matter of European versus Asian. The former don't have as many problems as the latter. Asians don't seem to have assertiveness or the ability to make friends. It would be helpful if they were outgoing in the American sense of the word. They also need small group discussion skills.

Asking questions. Students need to get used to asking questions in class.

They need to understand that in this country professors are approachable.

Developing the ability to feel comfortable talking to classmates is important for marketing classes. It builds community in the classroom.

The sampling of remarks from engineering faculty is arranged in the same manner, from less verbal to more verbal courses. Native speakers are identified by $(\mathrm{N})$. All non-marked comments are from non-native speakers. It seems that "less critical" remarks are from non-native speakers, as the first two examples discussing "cheating" indicate:

(N) They need to understand the American perception of what cheating is. S.E. Asians help one another when they shouldn't. They don't appreciate the difference in our culture.

Understanding honor code.

Interacting with groups. Non-natives are no different.

(N) Sometimes there is evidence that international students don't understand how to interact with shared-computer time. Occasionally abuses occur with some students. There is a different perspective of shared time between foreign and American students. When they are competing for shared time, sometimes conflict arises.

Explain the system of grading. Cultural perspective of cooperative learning asks them to cooperate.

(N) They don't feel comfortable. They seek clarification. Not comfortable with chit chat. Chinese students intimidated by power and even other students. 
They don't suffer from lack of social skills. No differences noticed.

(N) They are badly served by their selectively grouping themselves by language. They need a willingness to say 'I don't understand.' Instead, they just smile and nod.

They need to interact with native-speaking students more after class.

[Social skills] have no bearing. I encourage them to be part of the student organizations.

(N) Teamwork. Comprehending that everyone benefits if they contribute their efforts. Language is a cultural barrier to the team, but social skills also are cultural.

They look at a professor in a different light. They don't establish a relationship, don't get to know them or feel at ease.

This is part of communication. Linkage, networking, the tendency of foreign students to group. If that process is modified, they benefit. Their perspectives get broadened.

\section{SUMMARY}

Faculty perceptions of international students' academic performance are impacted by several factors. First, for each discipline, there is a range of less verbal to more verbal courses. The more qualitative, culturally-embedded, contextually-relevant language demanded by the course, the more difficulties faculty observed in non-native speakers' performances.

Second, the higher the degree of visibility of non-native speakers' productive skills, the greater the opportunity to recognize, judge and perceive the "thinking" of students as faulty.

Third, the degree to which faculty experienced their own secondlanguage learning seems to impact their "descriptive" versus "prescriptive" observations of international students' academic performance. 
Finally, the analytical skills of non-native speakers, especially the Asian students, seem to be highly regarded by faculty from the less verbal end of each discipline's continuum. 


\section{CHAPTER VI}

\section{CONCLUSIONS}

This chapter will discuss findings from the questionnaire and interviews, factors relating to the analysis of findings, implications of the analysis of the interviews, limitations of the study, and recommendations for the teaching of academic ESL.

\section{PURPOSE OF THE STUDY}

The purpose of the study was to conduct a needs analysis of international students' language skills at Portland State University. The study's focus was a survey of faculty opinions from the schools of Business Administration and Engineering and Applied Science. The survey asked professors two major questions: first, which of four language skills--reading, writing, speaking, or listening-- did they believe were most important to academic success in their classes at PSU; and second, what were the most important uses for each of the four skills.

This study's research is based on assumptions that English proficiency alone does not equate with academic success; that success in both the disciplines of business and engineering rests on specific skills of reading, listening, and writing; and that reading and listening are considered the most important language skills for academic success by both levels in both disciplines. 
The survey's research questions were designed to elicit specific information from PSU. faculty that would be helpful to teachers of ESL who are preparing students to enter two major schools of interest: Business Administration, and Engineering and Applied Science.

\section{CULTURAL FACTORS OF LANGUAGE}

Factors contributing to language skill adjustment for international students in academic classes vary. One of the most predictable factors identified by this survey is the relationship of culturally-contextual materials to numerically-based materials in the curricula of both business and engineering classes.

Studies disagree about how to group disciplines according to more verbal and less verbal categories of course content. Light, Xu, and Mossop (1987), in a study of international students' academic performance, group science, math and business together. Another method of organizing the data is not to look at business and engineering as distinctly less or more verbal in themselves. But rather to look at both disciplines as a continuum of less verbal to more verbal content-based courses. The terms quantitative and qualitative courses more aptly describe the types of classes which both disciplines offer. Simply put, quantitative courses manipulate numbers; qualitative courses manipulate language. According to instructors' remarks during the interviews, international students did best academically when they relied on their quantitative, mathematical skills and did not have to react to materials which contained culturally-embedded vocabulary and concepts. 
This finding is supported by research done by Light, $\mathrm{Xu}$, and Mossup who measured factors that determine international students' academic success. They analyzed records of 376 international graduate students at the State University of New York at Albany for relationships among TOEFL score, grade point average, graduate credits earned, and academic major. They found a stronger correlation and relationship between academic performance and language skills for humanities, arts, and social science students than for those majoring in science, math, or business. The former set of classes would naturally contain a heavier concentration of culturally-embedded materials than the latter.

Classes within both disciplines fall along lines of a continuum for verbal interaction. The less verbal end of the continuum for Business Administration includes courses in Accounting (ACTG) and Information Systems and Quantitative Analysis (ISQA). Less verbal classes for Engineering and Applied Science include courses in Computer Science (CMPS), Electrical Engineering (EE), as well as lab classes in both Civil Engineering (CE) and Mechanical Engineering (ME).

Classes on the more verbal side of the continuum in the school of Business Administration include courses in Management (MGMT) and Marketing (MKTG) In the school of Engineering and Applied Science, they include some (CE) theory classes, a few (ME) industrial design classes, and the Engineering Management Program (EMP), a graduate program which marries engineering skills with marketing strategies. All discussion pertaining to language skill and language skill use preferences in this chapter will take into account the degree to which international students are required by the nature of the class to manipulate culturally-intensive language or concepts. 


\section{ANSWERS TO RESEARCHQUESTIONS}

The following research questions were posed in Chapter I.

1. a. Which of the four language skills, reading, writing, listening and speaking, are considered most important by faculty in the schools of Business Administration and Engineering and Applied Science?

Results from Chapter IV show that reading was the overall most important skill across disciplines and levels. Listening was highly valued as the second-most important skill. Writing was considered third-most important, but only half as important as reading. Speaking was the least important skill.

$b$. Is there a difference in how these skills are ranked between the two divisions?

Reading was ranked higher by Engineering and Applied Science (67\%) than by Business Administration (57\%). Listening was ranked twice as high by Engineering and Applied Science (59\%) than Business Administration (32\%). Writing was ranked more than twice as important by Business Administration (28\%) than Engineering and Applied Science (11\%). Speaking was ranked last by all faculty, but rated higher by Business Administration than Engineering and Applied Science.

The perceived difference in importance of individual language skills-reading, writing, speaking, listening--follows the previous discussion of more verbal and less verbal classes, rather than discipline or level.

\section{Reading and Listening:}

Overall survey results for faculty show that reading is considered the "most important" language skill for academic success. And yet, individual interviews with instructors who teach the less verbal classes in both disciplines 
reveal a strong preference for listening. For example, $50 \%$ of the first rankings from business's ACTG and ISQA instructors are listening and 33\% are reading.

This result is amplified when data from engineering's CMPS and EE faculty show that $86 \%$ view listening and reading as equally important. The increased importance of listening to the school of Engineering is apparent from the Johns (1981) and Powers (1986) studies and this survey's results.

As important as this skill is thought to be, however, it is rarely mentioned by faculty as a deficit skill for foreign students. Some faculty seem unaware of their students' possible listening comprehension problems; but a few, like this ISQA instructor, offer a good description of the problem of evaluating a receptive versus a productive skill deficit:

Many are shy and afraid to speak up. I talk fast and they have trouble keeping up with me. Their listening skills don't match my pace. It's hard to know if they're having trouble when they're reluctant to tell you.

An instructor at the lowest level of EE observes that listening is often a stumbling block: "Getting students to respond to English is difficult. They have trouble following directions."

\section{Writing:}

The findings outlined in chapter IV reveal that writing received midrange rankings, but generally higher from business than engineering. The overall faculty average is $20 \%$ and the highest ranking is undergraduate business' $31 \%$. Yet an examination of scores on the continuum of more or less verbal shows $55 \%$ from more verbal business classes, MKTG and MGMT, and 16\% from less verbal ACTG and ISQA. 
Again, the same continuum is evident within the school of Engineering. Almost one-third of EMP, CE and ME instructors rank writing most important, while EE and CMPS give no "most important" rankings for either undergraduate or graduate levels.

Even though few instructors said that writing was the most important language skill for academic success in their classes, many expressed strong comments about international students' writing skill deficits. It is understandable that most critical comments from faculty are focused on the productive rather than receptive language skills. Reading and listening, receptive skills, are less open to inspection and observation and, therefore, less easy to evaluate than are the productive skills of writing and speaking. Thus, most problematic areas cited by faculty emphasize international students' deficient productive language skills, writing and speaking.

First, comments from engineering faculty: "In the Ph.D. program, Chinese students have the biggest difficulty in writing." From CMPS: "Comprehending the written assignment is difficult. For example, in short answer essay questions, non-native speakers are at a disadvantage. During evaluations, it shows up."

And these strong words from EE professors: "Thesis writing is difficult. Basically, their thesis advisor translates for publication. They are handicapped." And, "Every masters' thesis has to be rewritten at least five times. The Chinese students have problems in writing. Whatever you can do to help writing skills is very important."

Critical comments come also from business faculty. From ACTG:

For undergraduate students, the research paper is a problem. I get a lot of plagiarism. When they can't speak a complete sentence, I know they 
can't write. I have informed them about the writing lab, but I still get unreadable papers.

Sometimes students themselves recognize the need for peer instruction and support, as reported by an ACTG instructor in the MBA program: "A Thai student asked to be removed to another group with higher level students with better writing skills."

From the MBA program: "Asian students' writing [is a problem]. Grammar. Tenses are important. It drives me crazy to read their writing when the tenses aren't correct." From MGMT: "Asian students have more problems [with writing]. Essay tests in graduate class are problems." And from a MGMT instructor who teaches lower division organization and behavior classes:

The written essay is the biggest problem. Many international students do not have a good command of the language. They lack basic skills of sentence construction. Although I ask for no names on the papers, only social security numbers, I can still tell they're international students by their writing. I do a lot of accommodating of my teaching techniques to fit their needs.

\section{Speaking:}

Speaking was consistently ranked lowest of all major language skills. However, business faculty ranked it higher than engineering faculty. The highest ranking speaking received was three "second-most important" scores from MGMT instructors. All three professors teach MBA management classes which are culturally embedded with either a global or a United States perspective. All use a high ratio of communicative to independent tasks, meaning that classes are more interactive than lecture-based. Interestingly, of all faculty surveyed in either discipline, these three instructors have the highest ratio of communicative tasks to independent tasks Speaking received no first 
rankings from any faculty, other than the few who ranked all four language skills "most important."

In engineering no one ranked speaking "most important" and only one instructor, from ME, ranked it "second-most important." Although many of his classes are primarily theoretical, he stresses student interaction within his design and lab classes.

Nearly all faculty commented that most international students are reluctant to speak in class. Adamson (1990) says the reluctance in his study had three causes:

... the students' cultural backgrounds, their fear of being laughed at because of imperfect English, and their fear of divulging a lack of knowledge about the subject matter. (p. 74)

Difference between U.S. teaching styles and students' home countries is also a major contributing factor to their lack of oral participation in class. Differences in cultural expectations contribute to misunderstandings between some faculty and students. Asking questions in class is considered disrespectful by some Asian students, yet is a prerequisite to showing "interest in the subject" as expressed by some PSU faculty members. One graduate professor in MGMT summarized the concerns of many others I heard, "In their oral performance in classes, the international students perform less well. They are less talkative and quantity is part of the judgment of their academic performances."

Some students experience embarrassment at the hands of either faculty or peers when they do speak. In a study by Funston and Funston (1985) of graduate programs for foreign students at three law schools, student perceptions of their language-based difficulties differed from faculty and administrator perceptions. The most commonly reported problems were with speaking skills. One Spanish-speaking woman with eleven years experience 
as a practicing attorney, reported feeling "ridiculized" after volunteering to speak in class. She stopped participating in class discussions.

Similarly, a Korean woman student at PSU reported her humiliation at being called " lazy and dishonest " by a business professor when she had misunderstood an assignment due date. Later conversations with that professor revealed that some male Asian students previously had accused him of being prejudiced in his teaching style. He admitted strong biases against Middle Eastern students, but denied any "racist" feelings about Asians.

Although this was the strongest response received during the interviews, many faculty agreed with the findings of the Funston and Funston study that international students "take a lot of time." Most said that they spend many hours counseling students in their offices with academic and nonacademic assistance.

c. Is there a difference in how these skills are ranked between undergraduate and graduate levels?

Reading was ranked most consistently the same between levels for both disciplines (56\% / 58\% Business to $71 \% / 62 \%$ Engineering). In the first case, the importance of reading is lower with undergraduate faculty. In the second case, the importance is higher with undergraduate faculty. For Business Administration, the shift to non-textbooks, presentations, and case analyses as learning strategies for graduate students may signal the move toward more reading at the higher level. For Engineering and Applied Science students, the move is toward design projects at the graduate level with less emphasis on classroom lectures and tests.

Listening was ranked similarly by both levels in both disciplines. Little difference is noted between levels. ( $31 \% / 33 \%$ Business and 57\%/62\% 
Engineering). The obvious difference for this skill is between disciplines, not levels.

Writing shows slightly more difference in rankings between levels than the previous two language skills. The divisional difference shows that business $(31 \% / 25 \%)$ values the skill nearly twice as much as engineering $(7 \% / 15 \%)$, but graduate engineering (15\%) values it twice as much as undergraduate engineering (7\%). The large difference between lower and upper levels can be accounted for by the thesis requirement for graduate engineers.

Speaking differences between levels are not dramatic in engineering $(7 \% / 8 \%)$. They are more so for business $(25 \% / 42 \%)$. Some of the strongest criticism of international students' verbal reticence came from graduate business faculty, especially from instructors whose classes are at the farthest end of the more verbal spectrum. In some cases, cultural awareness can play a role in the evaluation of international students' academic performance, as shown by these two examples. Both comments come from MKTG faculty; the first from an American instructor, the second, an Asian:

[They need to develop ] Self-confidence, outgoing, assertiveness. If you're in a business meeting, you can't be quiet in a room with your hands over your mouth. Every teacher in business school stresses participation. Still, I have to pull teeth to get them to speak.

It depends on the country of origin. Students from Asian countries are more passive. They have to be able to go out of their way to talk to people. They have to overcome both language and cultural barriers to do this. As a result of their language deficiencies, they often settle for something other than what they want to say. They tend to be straight forward and put their foot in their mouth because they lack sophistication of language, the nuances. American students have complained a little about this. 
2. a. For what functions are reading, writing, listening and speaking actually used.

This research question was addressed in the survey by questionnaire items B through E. [see Appendix B]. Faculty were offered choices of preestablished activities. For the most part, responses fell within the suggested subsets of skills.

Two categories were provided for answers that fell outside the preestablished functions. Non-applicable (NA) was the response category possible for any activity that did not apply to either course content or teaching style. Other was the response category designed to solicit alternative functions for the language skills. The small percentage of responses in Other suggests that most faculty use the activities outlined on the questionnaire.

Average scores of all faculty show the following language skill functions to be considered most important: for reading-textbooks; for listening--taking notes in class; for writing--essay answers and reports (equally important); and for speaking--class discussions. [see Appendix $\mathrm{H}$ for percentages].

b. Are these skills used similarly by both the schools of Business Administration and Engineering and Applied Science?

Reading:

How do business classes generally use reading skills? The responses addressing skill uses are the best clues to the question. The average score for textbooks as the preferred use of reading skills by faculty in the business department is $70 \%$. Average scores for materials such as journals and papers, categorized as non-textbooks is $30 \%$, and for the little-used examination forms (multiple choice and essay) it is $6 \%$ each. One MBA professor said he was moving 
away from textbooks altogether toward more non-traditional sources that put more emphasis on "dialogue."

Engineering faculty chose textbooks by $77 \%$ as the most necessary use of reading, and non-textbooks by $34 \%$, only slightly different than business. Examinations (multiple choice and essay) were used more frequently; $8 \%$ chose multiple choice and $30 \%$ chose essay. Their testing methods, however, were less reading and discussing materials and more solving problems. The preferred reading skills for engineering were numerically-based problems that required critical thinking skills, done in and out of class.

Writing:

Both business and engineering use the same percentage of reports as a preferred writing skill, but the content focus is different. The analytical skills for the former are language-concept skills; for engineering and for the lessverbal ISQA and ACTG classes of business, the focus is quantitative skills.

Business classes put nearly twice as much emphasis on essay answers as engineering, and nearly one-third more emphasis on term papers. Short critiques were not used by anyone. Business faculty said course summaries, small group report analyses, case assessments, case analyses were the writing activities their students needed to do in class.

Engineering faculty said it was important for their students to write clearly, spell, use grammar coherently, write correctly. The writing activities mentioned were lab report, journal publication, homework problem-solving, writing " $E$ " mail. The focus for writing was on analysis and execution of a problem, and the importance of "clarity of presentation" was viewed from that perspective. This remark summarizes a position which was expressed often: 
Concentrate on writing. They can't improve this skill on their own once they leave the classroom environment. Reading, listening and speaking skills can all improve on their own. Structure paragraphs. Use of articles, subject-verb agreement. English grammar.

\section{Speaking:}

Both business (65\%) and engineering (41\%) said class discussions were the most necessary skill for speaking. Both departments had identical scores (26\%) for formulating questions. The interesting difference between disciplines is in the increased importance of oral reports by engineering (26\%) over business (7\%). Pronunciation was ranked last by both disciplines, but considered twice as important by business as engineering faculty.

The category Other provides some examinations into the differences in the use of the speaking skill in each disciplines Business faculty offered alternatives such as ability to stay on track and further the discussion, ability to participate in group discussion, and the ability to participate in small groups. The only engineering alternative was the ability to communicate in groups.

A relevant remark to this discipline comes from a CMPS instructor who commented on the lack of importance she places on the speaking skills of international students: "To be academically successful here you only need a 2,000 word vocabulary!"

\section{Listening}

Taking notes in class was more highly valued by engineering $(60 \% / 46 \%)$. Restating orally-presented classroom material, the second-most important use, was more highly favored by business $(44 \% / 30 \%)$. Understanding student talk was valued more by business (22\%) than engineering (0\%); while following directions was more highly valued by engineering (26\%) than business (4\%). 
The dramatic picture painted by these statistics is in the importance of participation. An international business school student, even in the less verbal courses of the program, will be more required to understand lectures, synthesize the material, participate with peers, and be held accountable for that part of the grade which judges content of thought by participation in class than a peer in the school of engineering.

c. Are these skills used similarly by both undergraduate and graduate levels?

\section{Reading:}

The preference of using textbooks (undergraduate) and non-textbooks (graduate) as the first choice for reading skills shows an obvious shared similarity between levels in both fields. This would seem a natural growth from a generalized to a specific use of materials in professional fields of study. No similarity exists for the other reading skill uses.

\section{Writing:}

More reports are preferred by graduate faculty in both disciplines than undergraduate. Essay answers are also more important to undergraduate faculty in both fields. No pattern is present for term papers or short critiques.

\section{Speaking}

Participating in class discussion is slightly more important to graduate faculty than to undergraduate in both fields. Even though pronunciation was ranked last in importance of the speaking skill uses, it is still considered slightly more important at the graduate than undergraduate level. No similar pattern exists for formulating questions or oral reports. 


\section{Listening}

Restating orally-presented class materials, the skill requiring the ability to synthesize information, is considered more necessary for graduate students than for undergraduate. As the focus in business and engineering classes shifts from lectures to group projects, the opportunity to demonstrate competent synthesizing abilities through productive skills increases. This increased importance is reflected by the differential in scores between levels in both disciplines.

No other activities have patterns of similarity between levels. While understanding and taking class lecture notes is the most important use to three levels, only graduate business faculty rank another use higher, restating class materials.

Not enough specific information was derived from the surveys to establish patterns of skill use differences between levels.

\section{IMPLICATIONS OF THE STUDY}

The last three questions serve as an introduction to the implications portion of this study. The questions ask faculty to discuss their familiarity with ESL classes at PSU, their advice to language professionals, and their biggest concern about international students' academic performances.

Question 7. Are you familiar with the language skills taught in academic ESL classes at Portland State University.

Responses to this and other questions are directed to faculty about all international students. For the most part, faculty in university classes are not aware of which students have come to their classes directly from their home 
countries and which ones have had specialized academic English preparation in ESL classes. This question sought to establish a reference point of evaluation for all survey questions. The goals of Portland State University's ESL program are found in Appendix I.

There are unstated questions embedded in question 7 . In effect, the question asks if instructors are aware of the type of specialized training provided to international students in reading, writing, speaking and listening. Specifically, it asks if they know that many of their concerns about writing skills, small group discussions skills, oral presentations skills, and general classroom participation are addressed in ESL classes by language professionals who hope that non-native students will be able to compete effectively with native-speaking students to realize their personal academic goals in content courses.

The overwhelming answer from faculty to this question was "I am not at all familiar with ESL." One instructor from engineering said, "[I'm] fairly familiar. They're doing a good job." Two instructors said they were favorably impressed during their brief encounters with the department. One from business said the same thing. The implication for ESL professionals is that lines of communication need to be opened with all faculty to acknowledge our understanding of the problems and our willingness to prepare students linguistically and culturally for successful transition to university classes.

\section{IMPLICATIONS FOR TEACHERS OF ESL}

The implication for teachers preparing second-language learners to enter university classes in business and engineering is to look beyond the obvious 
divisional stereotypes of how language is used by each school. Instead, students need to be prepared to handle language skills according to how they will manipulate language and concepts--quantitatively or qualitatively. They need to know how to analyze, write critical interpretations, evaluate ideas in terms of their cultural context, and participate in class discussions. All are important to success in each discipline. Engineering students need to be prepared for non-mathematical encounters with reading and writing. Business students need to be able to expand their thinking globally through reading non-textbooks and applying their own creative thinking to management and marketing concepts.

The best advice on this subject comes from the faculty in these two disciplines in their answer to the following question:

Question 8 .What advice would you give to language professionals who are preparing international students for academic success in your classes.

Remarks from business are arranged from ISQA and ACTG (quantitative) through MGMT and MKTG (qualitative). The emphasis at the less verbal end of the scale is on listening. At the more verbal end, it is on speaking. Writing is frequently mentioned, but reading only infrequently, even though it was unanimously chosen as the "most important language skill for success."

- Learn to take notes. Emphasize how to listen for key points.

Recognize the diversity of our communication styles in America. Not every thing is presented as $A, B, C$. Styles, dictions, pace all differ from person to person. Teach them to recognize regionalized listening styles. Introduce them to guest speakers with different styles. Then ask 'What were the key points this person was making?'

-Listening skills are very important. Also critical thinking skills. Teach them to ask [questions]. 
-Listening skills. Paraphrasing, perception checking. Practice outlining skills when reading textbooks. Practice speaking coherently in front of large and small groups. Leaning how to write solid answers to essay questions.

-Speaking and writing. Do 'in class' writing assignments. Hands on work with sentence structure. Their reading comprehension is o.k. Learn to work with groups with techniques such as brainstorming.

- Help them with presentation skills. 'What points do I want to make.' Teach the same strategy for essay answers in exams.

- Need basic written skills. The students who struggle are from southeast Asia: Korea, Cambodia, Thailand, Vietnam, China and Taiwan.

- Teach them to write, speak, and understand what it means to be a student in the University system. Understand American culture Have a holistic approach to communication that includes understanding and speaking.

- Have more interaction with professors. Improve social skills. I can see a difference as the anxiety level decreases. Work on teaching students how to write answers to essay questions.

-I would suggest that someone 'run them through toastmasters.' They would be forced to think in this language. Give them one minute to talk on a spontaneous topic.

-Assure that foreign students don't room together. Spend a lot of time reading aloud in front of groups to break down their fear of doing this. Understand the culture of America. Speaking out is o.k. Perfection is not required.

Engineering faculties' remarks are similar. Arranged in the same format as the responses from business, they reveal the most concern with writing and speaking, but there are many comments on the need for general communication skills.

- The department $[\mathrm{EE}]$ doesn't need to pay attention to verbal skills. Math skills are important. I would like to see more flexibility in the TOEFL rules that would allow some outstanding candidates, who don't need to score high verbally for our program, be admitted. When students get into professional work they will produce a written product. Therefore, you should stress writing. 
-Write in class. This is a good test of their actual level of skills.

- Emphasize clear speaking to graduate students for their job searches. It doesn't matter for academic careers. Stress speaking ability. Get them to speak and be active in class. Graduate students need writing skills.

-For graduate classes, reading and comprehension are most important. Improve their written and oral communication skills. Their writing skills are not very good.

- Some people are shy and intimidated. They need to improve their presentation skills. They need to learn communication skills. Take research, make transparencies, answer questions on their research. Write scientific paper or report. They don't pay attention to transitions between sources.

-It goes beyond the language. Culture is involved. Pair or associate students with native speakers. It only reinforces poor English by grouping them by themselves. Immerse them with Americans.

-Writing skills are needed. In advising students, I find the ability to present topics clearly is important. I suggest they write short summaries of activities during the past week.

-More writing and speaking, especially writing. They need the ability to comprehend complex statements both in listening and reading.

-Students need to develop skills [listening and responding] on openended questions. Professional growth will make more demands on their language growth.

Some faculty expressed a desire for increased socialization and communication skills:

- It seems to me that you need to Americanize them. Teach them to understand slang, joking, inflections.

-Work on more conversation on a basic level, not technical interpretation of information. Communication about understanding-personal, interpersonal. Have a good feel for communicative nuances.

Finally, this advice is aimed at teachers preparing graduate students for the EMP:

If you want to prepare students for success, prepare them for communication other than reading and writing; particularly formulation 
of ideas, topic identification, and definition and mode of information transfer.

Question 9. What have I not asked you that seems important regarding this problem?

This "catch-all" question was designed to give faculty a chance to emphasize a previously made point, and/or express a concern not addressed by the survey. It was an indication of faculty interest in continuing the conversation or reviewing the problem. Eleven instructors said they had nothing to add; three requested copies of the study. Most said they were very interested in the subject and that many issues, such as grading policies for international students, required further study by the university.

Concerns about writing were often expressed:

-Students need to learn to write simple, concise language. There's a deficiency in writing analytically. The handicap of most students is writing, both native and non-native. PSU. should look at writing across the curriculum.

- They have the most trouble with grammar, tenses, sentence structure. In their writing, the tenses are choppy.

Faculty in both disciplines have advice about how best to learn a new language.

-Don't hang around too much and speak only with others of their own language group.

- Get them early on to practice and get involved with Americanspeaking people and think in English. Use the usual practices of learning a new language: look up words, correct pronunciation. Students cluster in their own ethnic groups. They should avoid this practice. If they're here to learn new skills in English, they have to eat, breathe, think in the new language. Tell them to just do it. There are no short cuts!

Some offer advice on orientation to the university process. One ME instructor said a two-hour orientation would be a good idea. A MGMT 
instructor said international students needed a two-week orientation that included intensive language and cultural work.

Some business instructors used this question to discuss their concerns about cultural differences in classroom expectations, both critically:

-I often get requests for more time on assignments from international students. It's troublesome for me. I allow them to bring in dictionaries, but I have to check them for cheat notes. If they're here they need to operate within the system.

-The essential problem is that you cannot graduate a foreign student, particularly in a profession, who does not have the ability to communicate almost as easily as a non-native speaker. To me, it's the same thing as taking [athletes] who play basketball for you for four years but can't read or write. I think it's unethical! We give them competitive skills but not the ability to work in American society. How do they get to me like this? The ability to communicate will be more important in the future than even now. We are moving away from specialists toward teams.

And sympathetically:

-International students are hesitant to make oral contributions. They have a richness of experiences that could add to the class. I ask them to, but they hesitate to because of their reluctance to embarrass themselves.

- Language is context related. Translation doesn't get at the whole meaning. Students don't have a history of the emotion that is attached to words. This hinders their ability to use language.

-The demand of choosing words to put into sentences is great. It's often a trade-off for foreign students. Either content or how it's presented or understood. Because of that they may behave differently than in their own country. This phenomenon can cause personality change. They behave differently and communicate differently.

And at the heart of this last response lies the reason for undertaking this survey in the first place. In this business instructor's questions, one sees a genuine concern for the problems inherent in international students' adjustments to American university classrooms: 
The biggest issue for me is what can we do to facilitate their learning. What kind of feedback do we get from students that indicates they didn't understand? Sometimes I can tell that they haven't understood because of the vocabulary they use or when they can't synthesize the answer.

\section{LIMITATIONS}

Serious limitations exist in doing survey research. Respondents are not always truthful, candid, or accurate in their answers. Their responses may reflect what they think they do rather than what they actually do. Or, they may simply tell the researcher what she wants to hear. The interviewer attempted to achieve respondent truthfulness by conducting the interviews in person, by assuring faculty of their anonymity, and by reflecting concern for the dimension of the academic adjustments encountered by both faculty and international students.

It is difficult to measure to what extent ethnocentric biases might skew faculty reactions to non-native speakers' verbal interactions in classes. Interview questions which mention "foreign accent" could raise concerns from faculty members and create an unwillingness either to continue the interview or to discuss their perceptions of international students' actual performance. No tests were factored into the survey to measure respondent bias.

The accuracy of survey research is weighed against protecting confidentiality and therefore encouraging openness in responses. Tape recording the interviewees' remarks guarantees accurateness. Note-taking encourages openness. The choice was made to use the latter approach, so responses to questions 1 through 9 are a combination of paraphrases and direct quotations based on the limitations of the transcriber. 
As noted earlier, it is easier to observe and judge students' product skills than their receptive skills. Therefore, comments tended to reflect more observation and criticism of students' deficiencies in writing and speaking than reading and listening. The idea of analyzing listening activities may have been unfamiliar to some faculty, whose academic focus is different from the focus of language-related disciplines. Non-language oriented faculty may have had a tendency to attribute lack of participation in class as due to culture-based problems rather than listening-based weaknesses.

Class size may have been a factor in discussing and analyzing listening deficit behaviors. Large undergraduate engineering classes may have been less available to observing the results of possible misunderstandings of lectures and assignments than the generally smaller business classes.

Many of the limitations inherent in survey research, such as confusion or uncertainty about items on the questionnaire, were addressed by the one-onone nature of the interviews in which questions could be paraphrased and amplified to help elicit information.

\section{CONCLUSION}

What does this study mean for the direction of future curricula in the academic ESL classroom? Results of studies by Ostler, Johns, and Powers and this survey raise questions about the emphasis on communicative competence as the focus of an academic ESL program. The emphasis on the skills necessary for success in an academic environment as opposed to social language skills needed for communication is a critical step toward guaranteeing academic progress for second-language learners. Students preparing for university 
programs in a second language need to focus on skills which emphasize the ability to abstract, generalize, and synthesize.

Implications for curriculum development should include the necessary emphasis on those skills which are considered most important by the academic faculty--reading and listening, followed closely by writing and then speaking-using authentic, content-based materials.

Reading strategies should be emphasized. Saville-Troike (1976) says "reading is probably the single most important skill for survival in our educational system." (p. 86) Ostler (1980) found that students' "greatest needs overall were the abilities to read text books $(90 \%)$, take notes in class $(84 \%)$, and ask questions in class (68\%) (p. 492). Reading instructors should prepare curricula using real texts and real problems from academic English.

The systematic teaching of listening to lectures and note-taking should be an integral part of activity in all classrooms. Students could view video tapes of academic lectures, participate in class discussions about what skills they view as necessary to survive those lectures, and practice the skills that they have identified.

Writing could involve the paraphrase or summary of reading materials or the organization and rewriting of lecture notes. Speaking instruction could include response to readings or lectures or, for business engineering class preparation, the practice of group work in analyzing and presenting conclusions to "case studies" and oral presentations, rather than the preparation of dialogues. An oral skills class for engineering management students could satisfy the concerns expressed by faculty about weaknesses in class presentations. 
Two key concepts in second language learning are motivation and relevance. Both concepts translate to the basic questions: why do you want to learn English and what will you do with it? Future curricula planning should include research on both faculty expectations for success and student perceptions of academic needs. As much as possible, students should be made active participants in establishing the curriculum that they perceive they need for their own professional development. As is the case with any learnercentered curriculum, ESL professionals need to equip students with the skills necessary to achieve the stated goals and perceived needs of their students. Based on the results of previous academic skills surveys, academic reading, listening strategy, and note-taking instruction should be part of every student's arsenal of survival techniques they take from the sheltered ESL classroom to university-level content courses.

Certainly, academic ESL programs at the university level should prepare students to compete on an equal basis with American students. Therefore, research on university professors' assessments of success-producing language skills for international students is beyond useful; it is essential.

\section{RECOMMENDATIONS}

This study can shed light on a question for future research: Do current academic ESL classes at Portland State University focus on teaching the necessary skills to help international students maximize their second-language learning potential in these and other university-level courses? This study was 
one step in an overall assessment of university ESL students' academic language skills. It was the faculty assessment portion of a study.

One of the major limitations of survey research about international students is in asking professors to assess performance of diverse groups within a certain population without adequate information about that population. Without asking students to discuss their university-admitted status, faculty would not know whether individuals have been accepted directly into PSU from their home countries; have spent time in academic ESL classes prior to university admittance; or have spent some part of their academic careers in secondary or even elementary public schools in the United States.

An additional source of information pertinent to this study would be an international students' needs assessment. With faculty permission, the same questionnaire (without the interview portion) asking what skills students thought were important in classes, could be handed out, completed by international students, and collected in class. Answers could be tabulated in the same manner as the faculty questionnaires. Other parts of this study could include native-speakers' assessments of international students' success in classes, and administrations' assessment of the interaction and interplay of the international student within the university's network of support. Future research could also focus on more detailed descriptions of programs within both the schools of Business Administration and Engineering and Applied Science. Larger samples of faculty could be surveyed with questions about how language skills are used within each discipline.

All aspects of student needs are widely assessed, evaluated, considered and respected within the pedagogy of second-language instruction. The skill set that is addressed by teachers of second-language students is research-based 
and dynamic rather than static. If language professionals can continue to adapt to the growing and changing demands of content-based, university classrooms, the profession and its students will be even stronger in tomorrow's university. To prepare university students for their future second-language study in content classes, language professisonals must concentrate on those skills which are considered most important by the academic faculty. 


\section{BIBLIOGRAPHY}

Adamson, H.D. (1990). ESL students' use of academic skills in content courses. English for Specific Purposes, 9 67-87.

Anderson-Mejias, P. L. (1986). English for academic listening: Teaching the skills associated with listening to extended discourse. Foreign Language Annals, 19 391-398.

Apodaca, R. (1985, March). How we educate non-English speaking students successfully. The high intensity language training program description. Paper presented at the annual convention of the National Association of School Boards Association. Anaheim, CA. (ED261532).

Block, Ellen. (1986). The comprehension strategies of second language readers. TESOL Quarterly, 20, 463-494.

Bridgeman, B. \& Carson, S.B. (1984). Survey of academic writing tasks. Written Communication, I, 247-280.

Brown, H. D. (1987). Principles of language learning and teaching (2nd ed.). New Jersey: Prentice Hall.

Carrell, P., Pharis, B. \& Liberto, J. (1989). Metacognitive strategy training for ESL reading. TESOL Quarterly, 23, 647-678.

Crawford-Lange, L. (1987). Curricular alternatives for second-language learning. In M. Long \& , J. Richards (Ed), Methodology in TESOL (pp. 45-60). New York: Newbury House.

Cummins, J. (1980). The cross-lingual dimensions of language proficiency. TESOL Quarterly, 14, 175-187.

Cummins, J. (1983). Language proficiency and academic achievement. In J. Oller (Ed.), Issues in language testing research (pp. 108-129). Rowley, MA: Newbury House.

DeCarrico, J. \& Nattinger, J. (1988). Lexical phrases for the comprehension of academic lectures. English for Specific Purposes, $7,91-102$.

Feyten, C. (1989). Listening ability: an overlooked dimension of foreign language acquisition. Paper presented at annual meeting of the Eastern Educational Research Association. Savannah, GA. (ED 304002). 
Funston, J. \& Funston, R. (1985). ESL and the MCL: a study of "language"based problems faced by candidates for the degree of Master of Comparative Law in American law schools. Paper presented at the Eastern Michigan University Conference on Languages for Business and the Professions. Dearborn, MI. (ED271995).

Graham, J. (1987). English language proficiency and the prediction of academic success. TESOL Quarterly, 21, 505-521.

Horowitz, D. M. (1986). What professors actually require: academic tasks for the ESL classroom. TESOL Quarterly, 20, (3) 445-462.

Johns, A. (1981). Necessary English: a different story. TESOL Quarterly 15 51-57.

Lebauer, R. S. (1984). Using lecture transcripts in EAP lecture comprehension courses. TESOL Quarterly, 18, 41-54.

Light, R. L. , Xu, M. \& Mossop, J. (1987). English proficiency and academic performance of international students. TESOL Quarterly 21 (2), 251-261.

O'Malley, J., Chamot, A., Stewner-Manzaneres, G.,Russo,R \& Kupper, L. (1985). Learning strategy applications with students of English as a second language. TESOL Quarterly 19 , 557-584.

Ostler, S.E. (1980). A survey of academic needs for advanced ESL. TESOL Quarterly 14, 489-502.

Peyton, J., Staton, J., Richardson, G., \& Wolfram, W. (1990). The influence of writing task on ESL students' written production. Research in the Teaching of English, 24, 142-171.

Powers, D. (1986). Academic demands related to listening skills. Language Testing, $\underline{3}, 1-38$.

Richards, J. C. (1983). Listening comprehension: approach, design, procedure. TESOL Quarterly 17, 219-240.

Santos, T. (1986). Professor's reactions to the academic writing of non-nativespeaking students. Paper presented at the annual meeting of the Teachers of English to Speakers of Other Languages. Anaheim, CA. (ED285380).

Saville-Troike, M. (1976). Foundations for teaching English as a second language. N.J.: Prentice Hall. 
Saville-Troike, M. (1984). What really matters in second language learning for academic purposes? TESOL Quarterly 18 , 199-219.

Snow, M.A. \& Brinton, D. (1988). Content-based language instruction: Investigating the effectiveness of the adjunct model. TESOL Quarterly, $\underline{22}, 553-574$.

Stewner-Manzanares, G. (1985). Learning strategies in English as a second language instruction: a teacher's guide. Rosslyn, Va.: Inter-America Research Assoc.

Tarvin, William and Ali Yahya Al-Arishi. (1991). Rethinking communicative language teaching: reflection and the EFL classroom. TESOL Quarterly, $25,9-27$.

Taylor, B. (1987) Teaching ESL: incorporating a communicative, studentcentered component. In M. Long, \& J. Richards (Ed), Methodology in TESOL, (pp. 45-60). New York: Newbury House.

U.S. Department of Commerce. (1993). Statistical abstract of the United States. Washington, DC: U.S. Government Printing Office.

Vann, R.. \& Abraham, R. (1990). Strategies of unsuccessful language learners. TESOL Quarterly, 24, 177-197.

Wan, T. Y., Chapman, D., \& Biggs, D. (1992). Academic stress of international students attending U.S. universities. Research in Higher Education, 33, (5), 607-623.

Xu, M. (1991). The impact of English-language proficiency on international graduate students' perceived academic difficulty. Research in Higher Education, 32, (5), 557-570. 
APPENDIX A 
February 9, 1994

Dear fellow Portland State University faculty member:

Ms. Carol Sloan, a graduate student in the Applied Linguistics department, will contact you by phone within the next five working days to participate in survey research which is in partial fulfillment of a masters' degree in TESOL (Teaching English to Speakers of Other Languages).

The research consists of a needs assessment of international students' language skills. It will be given to thirty selected faculty members from the departments of business and engineering. Your participation is requested because of your contact with international students.

The interview is designed to last thirty minutes and your responses will become part of the confidential data which will form the body of Ms. Sloan's work. Your name will not be used.

Your participation would add to the understanding of the body of knowledge pertinent to the teaching of academic English as a Second Language. I hope Ms. Sloan may count on your help.

Thank you for your consideration to this matter.

Sincerely,

Marjorie Terdal

Associate Professor of Applied Linguistics

725-4142 
I, agree to take part in this research project on faculty assessment of language skills of non-native speakers.

I understand that the study is a needs assessment survey of language skills of non-native speakers in my classes and that I will be asked to evaluate the importance of reading, writing, speaking and listening to the academic success of those students.

I understand that there is no risk or hazard and minimum inconvenience because of this study.

Carol Sloan has told me that the purpose of the study is to learn which language skills are considered most important by faculty in my discipline.

I may not receive any direct benefit from taking part in this study. But the study may help to increase knowledge that may influence Portland State University's English as a Second Language curricular decisions in the future.

Carol Sloan has offered to answer any questions I have about the study and what I am expected to do.

She has promised that all the information I give will be kept confidential to the extent permitted by law, and that the names of all people in the study will remain anonymous.

I understand that I do not have to take part in this study, and that this will not affect my relationship with Portland State University.

I have read and understand the above information and agree to take part in this study.

Date: Signature:

If you have concerns or questions about this study, please contact the Chair of the Human Subjects Research Review Committee, Office of Research and Sponsored Projects, 105 Neuberger Hall, Portland State University, 503/725-3417. 
APPENDIX B 
Please rank order the following questions on a scale of 1 to 4 : (1 most and 4 least important) Undergraduate

Graduate

A. Of the four major skill categories, which are most essential to success in your classes?

Reading (texts)

Writing (reports, papers)

Speaking (oral reports, discussion)

Listening (lectures)

B. Which reading skills are most necessary?

Textbooks

Examination questions (mult. choice)

Examination questions (essay)

Non textbook assignments

(i.e., journals, papers)
Reading (texts)

Writing( reports, papers)

Speaking (oral reports, disc.)

Listening (lectures)

Other

C. Which writing skills are most necessary?

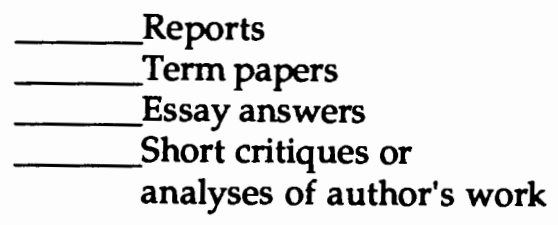

Other

D. Which speaking skills are most essential?

Ability to participate in class discussion

Ability to formulate questions

Ability to organize and present

an oral report

Ability to pronounce words clearly

Other

E. Which listening skills are most important?

Other

\section{Ability to follow spoken directions
Ability to understand and restate
orally-presented classroom materia
Ability to understand and take
adequate notes on lectures
Ability to understand student talk \\ Ability to follow spoken directions
Ability to understand and restate
orally-presented classroom material
Ability to understand and take
adequate notes on lectures
Ability to understand student talk \\ Ability to follow spoken directions
Ability to understand and restate
orally-presented classroom material
Ability to understand and take
adequate notes on lectures
Ability to understand student talk \\ Ability to follow spoken directions
Ability to understand and restate
orally-presented classroom material
Ability to understand and take
adequate notes on lectures
Ability to understand student talk \\ Ability to follow spoken directions
Ability to understand and restate
orally-presented classroom material
Ability to understand and take
adequate notes on lectures
Ability to understand student talk \\ Ability to follow spoken directions
Ability to understand and restate
orally-presented classroom material
Ability to understand and take
adequate notes on lectures
Ability to understand student talk}

Textbooks

Examination questions (m.c.)

Examination questions (essay)

Non textbook assignments

(i.e., journals, papers)

Ability to follow spoken direct

Ability to participate in c. d. Ability to formulate questions Ability to organize and present an oral report Ability to pronounce words cly

Reports

Term papers

Essay answers

Short critiques or

analyses of author's work 
-What is the relationship between communicative tasks versus independent tasks in classes in your discipline?

- Compared with native-speaking students, how do international students perform in your classes?

-Are there any areas that tend to be problematic for international students in your classes?

- Describe any incidents involving non-native students' understanding or misunderstanding of orally-presented material.

-Does a student's "foreign accent" impact academic success in your discipline?

-In addition to language skills, what social skills do you believe would be most helpful to non-native students' academic success in your discipline?

-Are you familiar with the language skills taught in academic ESL classes at Portland State University? 
APPENDIXC 


\begin{tabular}{|ccccc|}
\hline Rankings - \#Responses & & & \\
& 1 & 2 & 3 & 4 \\
Reading & 9 & 3 & 2 & 2 \\
Writing & 5 & 3 & 6 & 2 \\
Listening & 5 & 7 & 3 & 1 \\
Speaking & 1 & 3 & 3 & 9 \\
\hline
\end{tabular}

\begin{tabular}{|ccccc|}
\hline Rankings - Percentage & & & \\
& 1 & 2 & 3 & 4 \\
Reading & $56 \%$ & $19 \%$ & $13 \%$ & $13 \%$ \\
Writing & $31 \%$ & $19 \%$ & $38 \%$ & $13 \%$ \\
Listening & $31 \%$ & $44 \%$ & $19 \%$ & $6 \%$ \\
Speaking & $6 \%$ & $19 \%$ & $19 \%$ & $56 \%$ \\
\hline
\end{tabular}

\section{Comparative Importance of Language Skills for Business Undergraduate Faculty}

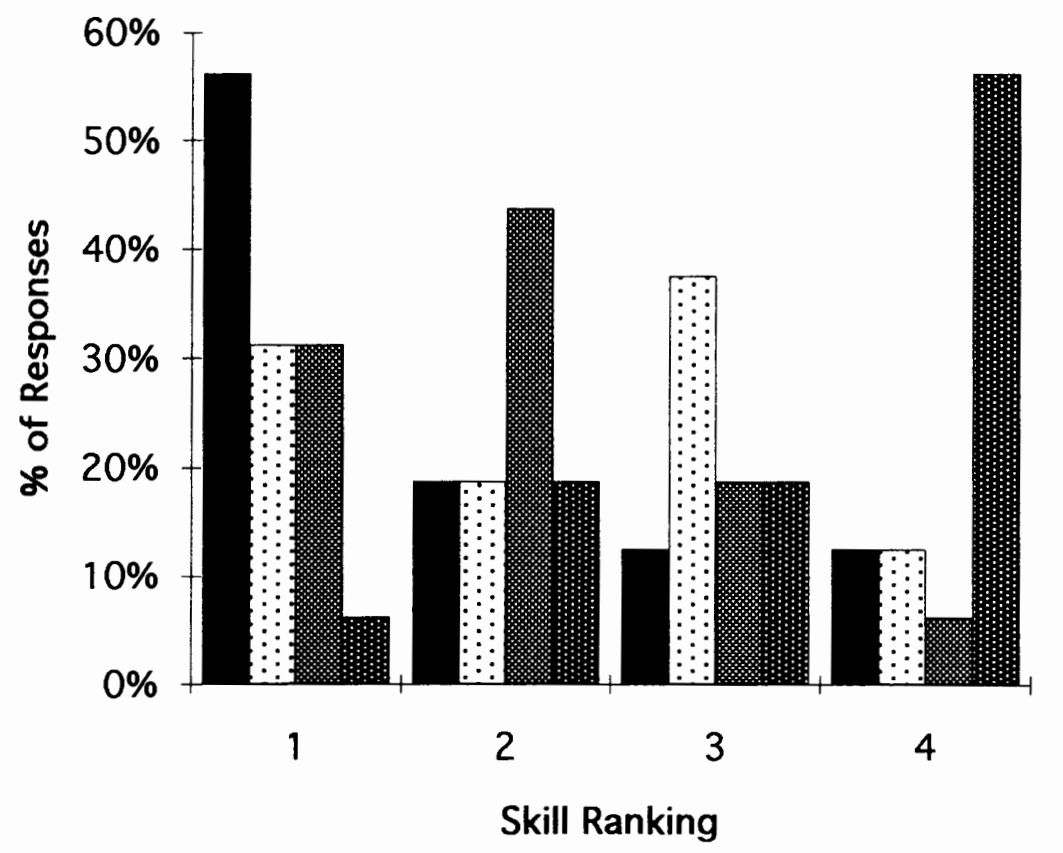

Reading

Writing

Listening

貱 Speaking 
Responses From Business Graduate Faculty

\begin{tabular}{|ccccc|}
\hline Rankings - \#Responses & 1 & 2 & 3 & 4 \\
Reading & 7 & 2 & 2 & 1 \\
Writing & 3 & 4 & 2 & 3 \\
Listening & 4 & 2 & 4 & 2 \\
Speaking & 1 & 4 & 3 & 4 \\
\hline
\end{tabular}

\begin{tabular}{|ccccc|}
\hline Rankings - Percentage & 1 & 2 & 3 & 4 \\
Reading & $58 \%$ & $17 \%$ & $17 \%$ & $8 \%$ \\
Writing & $25 \%$ & $33 \%$ & $17 \%$ & $25 \%$ \\
Listening & $33 \%$ & $17 \%$ & $33 \%$ & $17 \%$ \\
Speaking & $8 \%$ & $33 \%$ & $25 \%$ & $33 \%$ \\
\hline
\end{tabular}

Comparative Importance of Language Skills for

Graduate Business Faculty

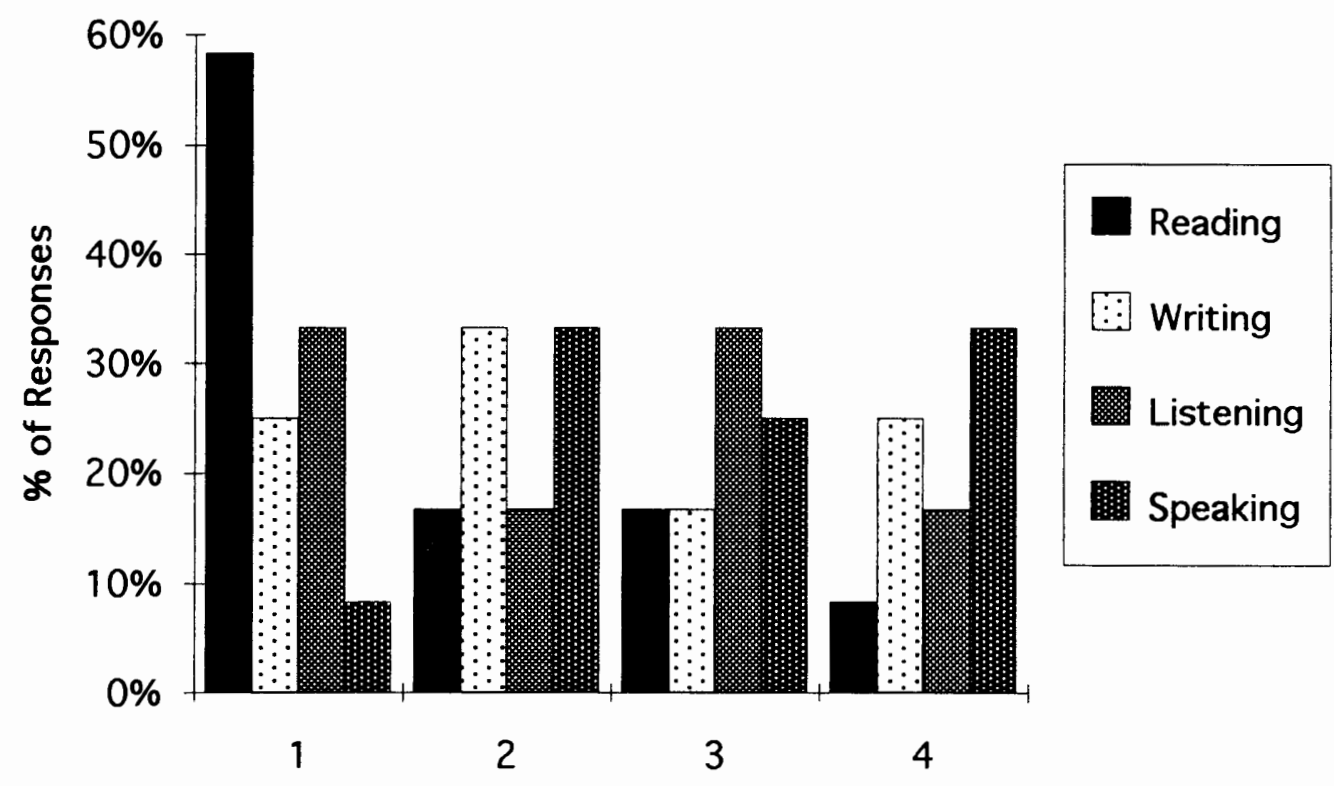

Skill Ranking 
Responses From Engineering Undergraduate Faculty

\begin{tabular}{|c|c|c|c|c|c|}
\hline \multicolumn{6}{|c|}{ Rankings - \#Responses } \\
\hline & 1 & 2 & 3 & 4 & N/A \\
\hline Reading & 10 & 3 & 0 & 1 & 0 \\
\hline Writing & 1 & 4 & 7 & 1 & 1 \\
\hline Listening & 8 & 4 & 1 & 1 & 0 \\
\hline Speaking & 0 & 1 & 5 & 7 & 1 \\
\hline \multicolumn{6}{|c|}{ First Rankings - Percentage } \\
\hline & 1 & 2 & 3 & 4 & N/A \\
\hline Reading & $71 \%$ & $21 \%$ & $0 \%$ & $7 \%$ & $0 \%$ \\
\hline Writing & $7 \%$ & $29 \%$ & $50 \%$ & $7 \%$ & $7 \%$ \\
\hline Listening & $57 \%$ & $29 \%$ & $7 \%$ & $7 \%$ & $0 \%$ \\
\hline Speaking & $0 \%$ & $7 \%$ & $36 \%$ & $50 \%$ & $7 \%$ \\
\hline
\end{tabular}

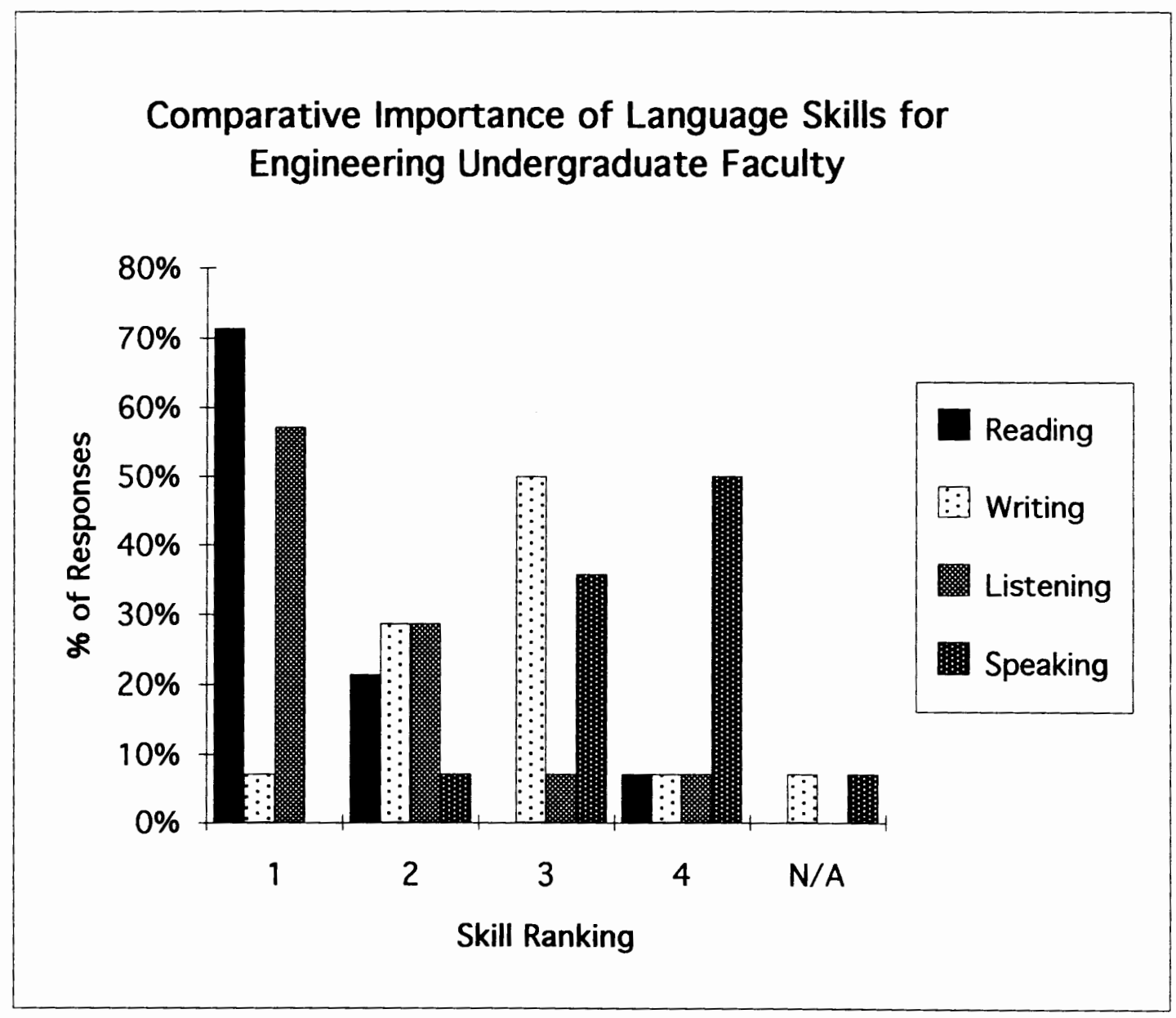


Responses From Graduate Engineering Faculty

\begin{tabular}{|c|c|c|c|c|}
\hline \multicolumn{5}{|c|}{ Rankings - \#Responses } \\
\hline & 1 & 2 & 3 & 4 \\
\hline Reading & 8 & 5 & 0 & 0 \\
\hline Writing & 2 & 4 & 6 & 1 \\
\hline Listening & 8 & 3 & 2 & 0 \\
\hline Speaking & 0 & 1 & 5 & 7 \\
\hline \multicolumn{5}{|c|}{ Rankings - Percentage } \\
\hline & 1 & 2 & 3 & 4 \\
\hline Reading & $62 \%$ & $38 \%$ & $0 \%$ & $0 \%$ \\
\hline Writing & $15 \%$ & $31 \%$ & $46 \%$ & $8 \%$ \\
\hline Listening & $62 \%$ & $23 \%$ & $15 \%$ & $0 \%$ \\
\hline Speaking & $0 \%$ & $8 \%$ & $38 \%$ & $54 \%$ \\
\hline
\end{tabular}

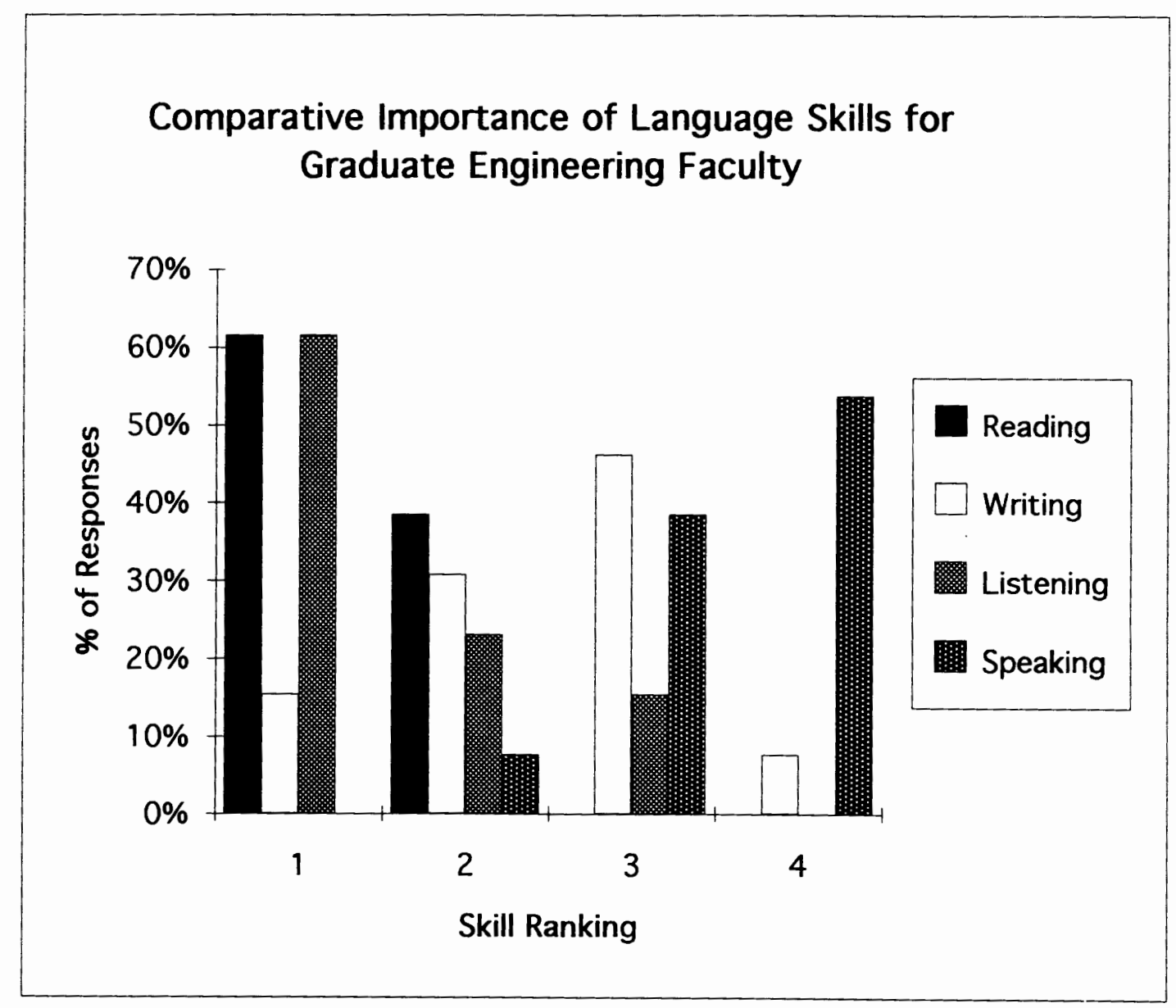




\section{APPENDIXD}


Comparative Rankings of the Reading Skill

\begin{tabular}{|r|ccccc|}
\hline Rankings - \#Responses & 1 & 2 & 3 & 4 & N/A \\
\cline { 2 - 6 } & 9 & 3 & 2 & 2 & 0 \\
Undergrd Biz & 7 & 2 & 2 & 1 & 0 \\
Grad Biz & 10 & 3 & 0 & 1 & 0 \\
Undergrd Eng & 8 & 5 & 0 & 0 & 0 \\
Grad Eng & & & & \\
\hline
\end{tabular}

\begin{tabular}{|r|ccccc|}
\hline Rankings \% & 1 & 2 & 3 & 4 & N/A \\
\cline { 2 - 6 } Undergrd Biz & $56 \%$ & $19 \%$ & $13 \%$ & $13 \%$ & $0 \%$ \\
Grad Biz & $58 \%$ & $17 \%$ & $17 \%$ & $8 \%$ & $0 \%$ \\
Undergrd Eng & $71 \%$ & $21 \%$ & $0 \%$ & $7 \%$ & $0 \%$ \\
Grad Eng & $62 \%$ & $38 \%$ & $0 \%$ & $0 \%$ & $0 \%$ \\
\hline
\end{tabular}

Comparative Ranking of Reading Skills

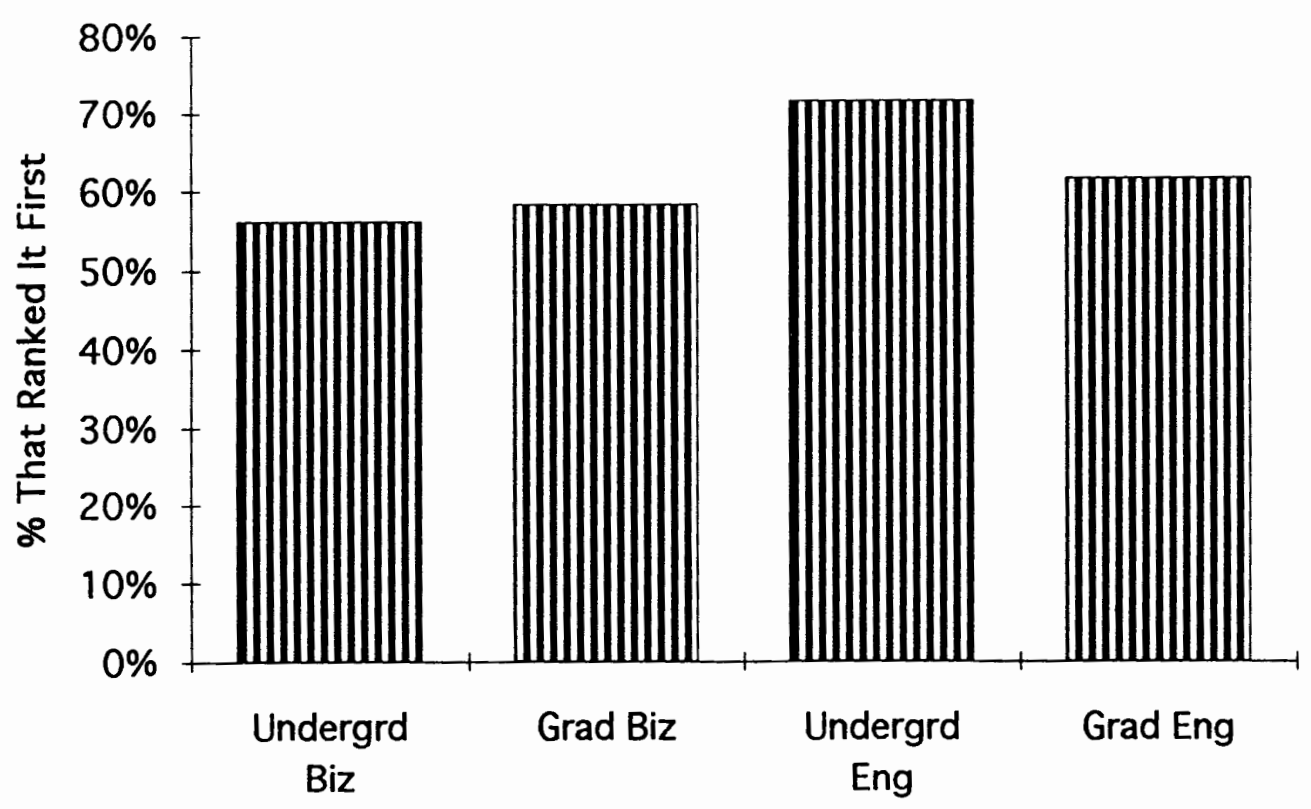

Discipline 
Comparative Rankings of the Writing Skill

\begin{tabular}{|r|ccccc|}
\hline Rankings - \#Responses & 1 & 2 & 3 & 4 & N/A \\
\cline { 2 - 6 } & 5 & 3 & 6 & 2 & 0 \\
Undergrd Biz & 3 & 4 & 2 & 3 & 0 \\
Grad Biz & 1 & 4 & 7 & 1 & 1 \\
Undergrd Eng & 1 & 6 & 1 & 0 \\
Grad Eng & 2 & 4 & 6 & \\
\hline
\end{tabular}

\begin{tabular}{|r|ccccc|}
\hline Rankings \% & 1 & 2 & 3 & 4 & N/A \\
\cline { 2 - 6 } Undergrd Biz & $31 \%$ & $19 \%$ & $38 \%$ & $38 \%$ & $0 \%$ \\
Grad Biz & $25 \%$ & $33 \%$ & $17 \%$ & $17 \%$ & $0 \%$ \\
Undergrd Eng & $7 \%$ & $29 \%$ & $50 \%$ & $50 \%$ & $7 \%$ \\
Grad Eng & $15 \%$ & $31 \%$ & $46 \%$ & $46 \%$ & $0 \%$ \\
\hline
\end{tabular}

Comparative Rankings for Writing Skill

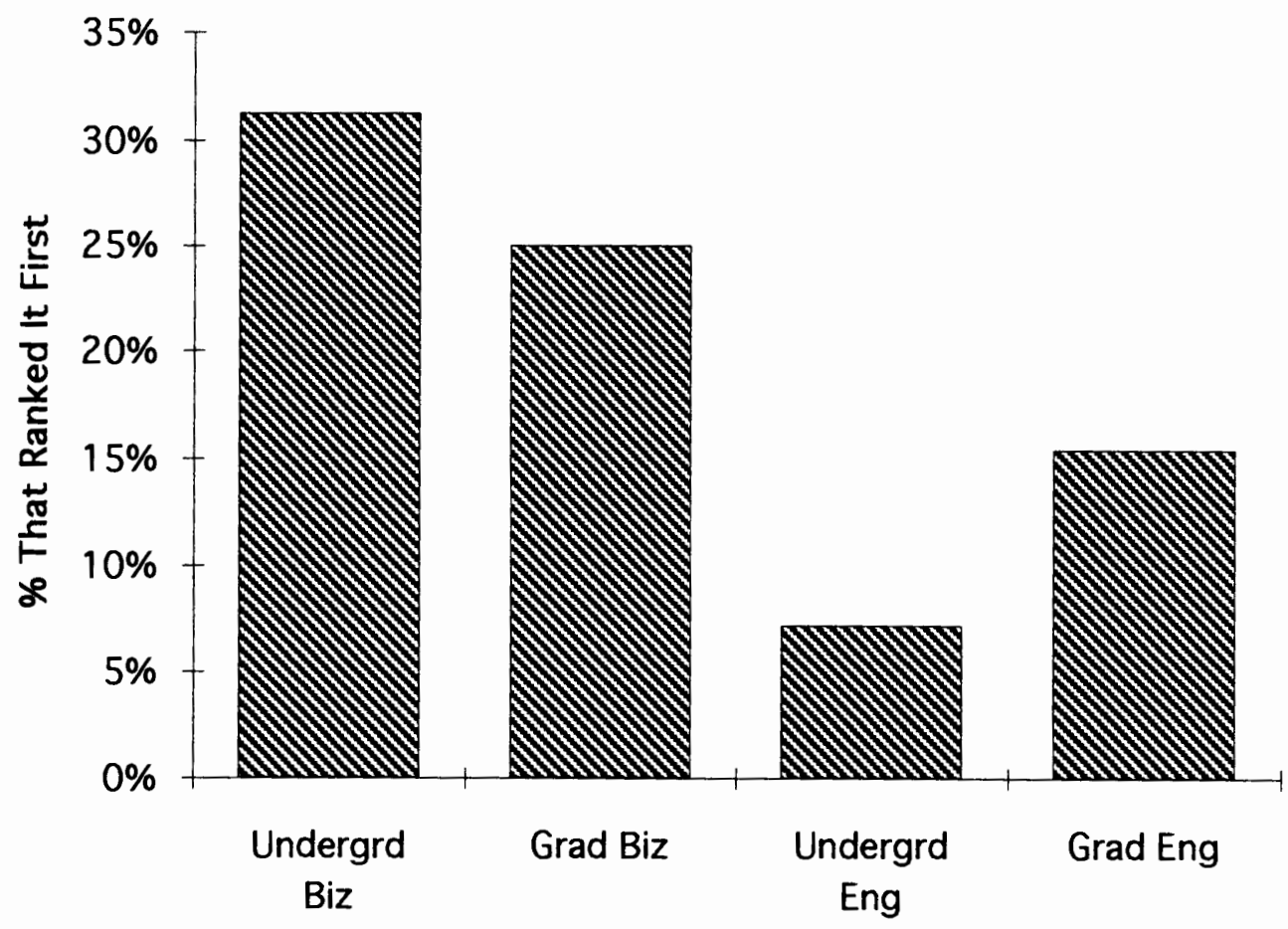

Discipline 
Comparative Rankings of the Speaking Skill

\begin{tabular}{|c|c|c|c|c|c|}
\hline \multicolumn{6}{|c|}{ Rankings - \#Responses } \\
\hline & 1 or 2 & 1 & 2 & 3 & 4 \\
\hline Undergrd Biz & $\overline{4}$ & 1 & 3 & 3 & 9 \\
\hline Grad Biz & 5 & 1 & 4 & 3 & 4 \\
\hline Undergrd Eng & 1 & 0 & 1 & 5 & 7 \\
\hline Grad Eng & 1 & 0 & 1 & 5 & 7 \\
\hline Rankings \% & 1 or 2 & 1 & 2 & 3 & 4 \\
\hline Undergrd Biz & $25 \%$ & $6 \%$ & $19 \%$ & $19 \%$ & $56 \%$ \\
\hline Grad Biz & $42 \%$ & $8 \%$ & $33 \%$ & $25 \%$ & $33 \%$ \\
\hline Undergrd Eng & $7 \%$ & $0 \%$ & $7 \%$ & $36 \%$ & $50 \%$ \\
\hline Grad Eng & $8 \%$ & $0 \%$ & $8 \%$ & $38 \%$ & $54 \%$ \\
\hline
\end{tabular}

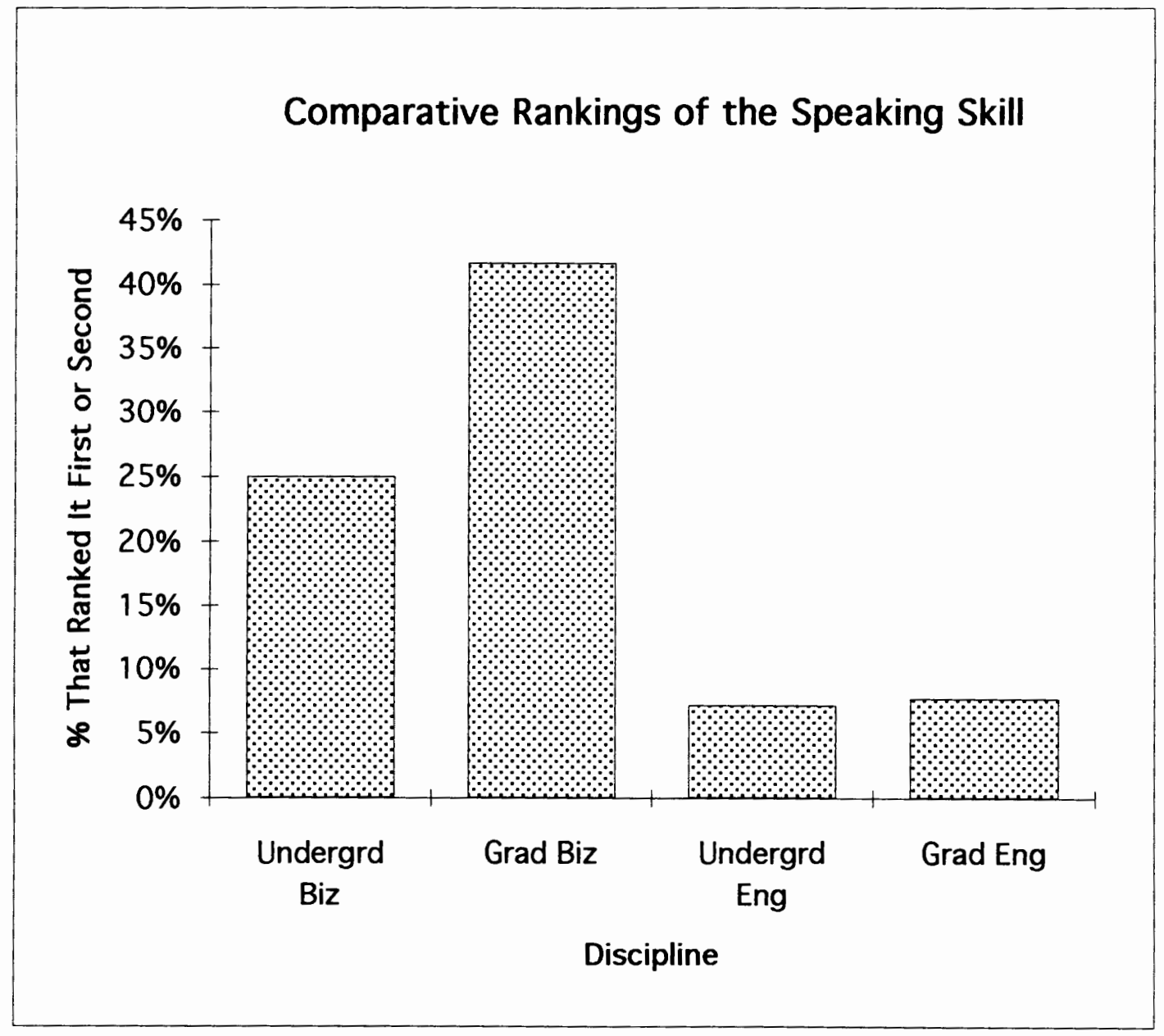


Comparative Rankings of the Listening Skill

\begin{tabular}{|c|c|c|c|c|c|}
\hline \multicolumn{6}{|c|}{ Rankings - \#Responses } \\
\hline & 1 & 2 & 3 & 4 & $N / A$ \\
\hline Undergrd Biz & 5 & 7 & 3 & 1 & 0 \\
\hline Grad Biz & 4 & 2 & 4 & 2 & 0 \\
\hline Undergrd Eng & 8 & 4 & 1 & 1 & 0 \\
\hline Grad Eng & 8 & 3 & 2 & 0 & 0 \\
\hline
\end{tabular}

\begin{tabular}{|r|ccccc|}
\hline Rankings \% & 1 & 2 & 3 & 4 & N/A \\
\cline { 2 - 6 } Undergrd Biz & $31 \%$ & $44 \%$ & $19 \%$ & $19 \%$ & $6 \%$ \\
Grad Biz & $33 \%$ & $17 \%$ & $33 \%$ & $33 \%$ & $17 \%$ \\
Undergrd Eng & $57 \%$ & $29 \%$ & $7 \%$ & $7 \%$ & $7 \%$ \\
Grad Eng & $62 \%$ & $23 \%$ & $15 \%$ & $15 \%$ & $0 \%$ \\
\hline
\end{tabular}

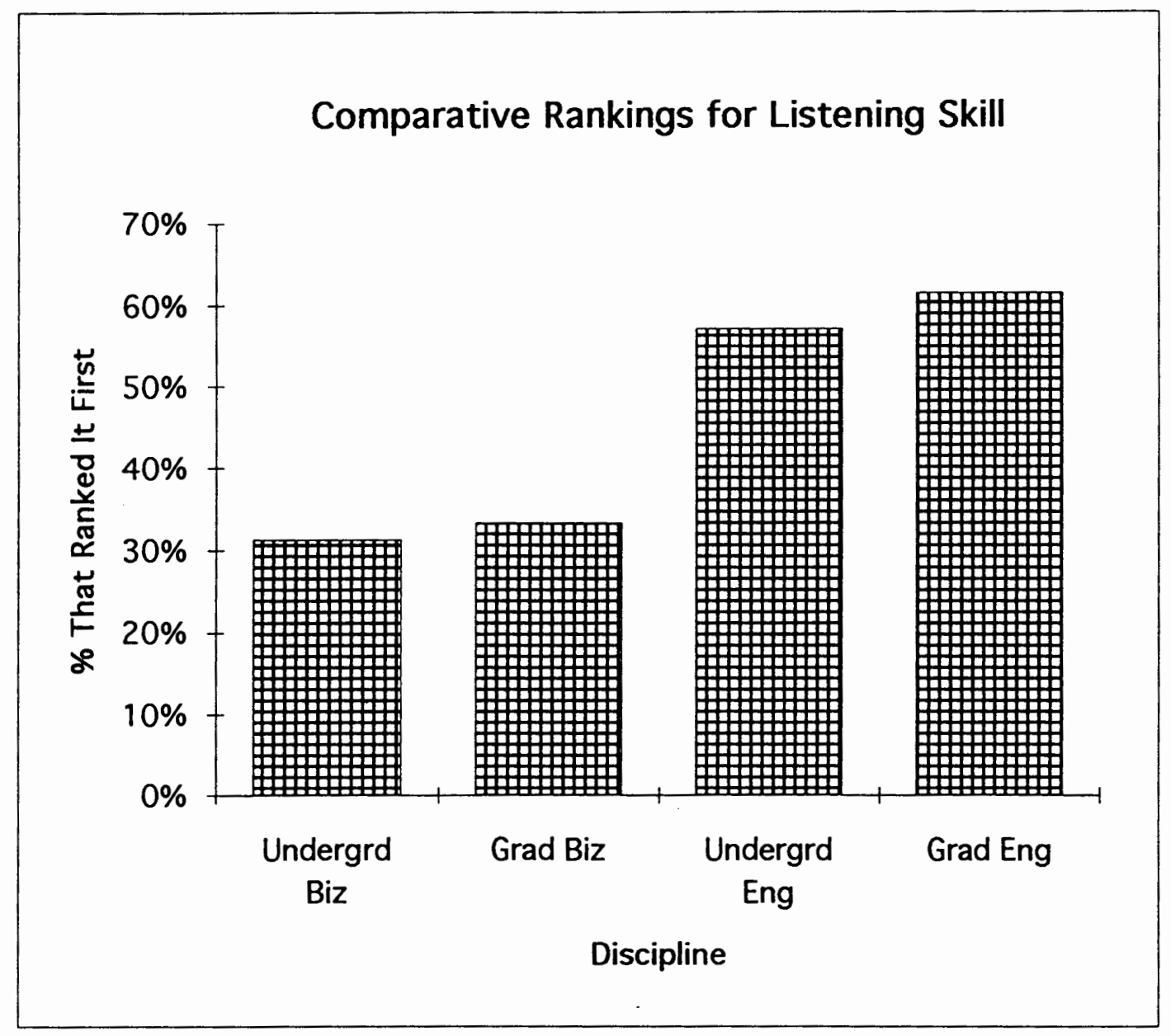


APPENDIXE 
Undergraduate Business Faculty: Reading Skill Uses

\begin{tabular}{|c|c|c|c|c|c|}
\hline \multicolumn{6}{|c|}{ Rankings - \#Responses } \\
\hline & 1 & 2 & 3 & 4 & $N / A$ \\
\hline Textbooks & 13 & 3 & 0 & 0 & 0 \\
\hline $\mathrm{Exam} / \mathrm{MC}$ & 2 & 7 & 3 & 1 & 3 \\
\hline Exam/essay & 2 & 2 & 7 & 3 & 2 \\
\hline Nontextbook & 3 & 3 & 3 & 7 & 0 \\
\hline
\end{tabular}

\begin{tabular}{|c|c|c|c|c|c|}
\hline \multicolumn{6}{|c|}{ Rankings - Percentage } \\
\hline & 1 & 2 & 3 & 4 & $N / A$ \\
\hline Textbooks & $81 \%$ & $19 \%$ & $0 \%$ & $0 \%$ & $0 \%$ \\
\hline Exam/MC & $13 \%$ & $44 \%$ & $19 \%$ & $6 \%$ & $19 \%$ \\
\hline Exam/essay & $13 \%$ & $13 \%$ & $44 \%$ & $19 \%$ & $13 \%$ \\
\hline Nontextbook & $19 \%$ & $19 \%$ & $19 \%$ & $44 \%$ & $0 \%$ \\
\hline
\end{tabular}




Graduate Business Faculty: Reading Skill Uses

\begin{tabular}{|c|c|c|c|c|c|}
\hline \multicolumn{6}{|c|}{ Rankings - \#Responses } \\
\hline & 1 & 2 & 3 & 4 & $N / A$ \\
\hline Textbooks & 7 & 3 & 1 & 0 & 1 \\
\hline Exam $/ M C$ & 0 & 2 & 3 & 2 & 5 \\
\hline Exam/essay & 0 & 5 & 4 & 0 & 3 \\
\hline Nontextbook & 5 & 3 & 1 & 3 & 0 \\
\hline
\end{tabular}

\begin{tabular}{|r|ccccc|}
\hline \multicolumn{2}{|l}{ Rankings - Percentage } & \multicolumn{3}{c|}{} & \\
Textbooks & 1 & 2 & 3 & 4 & N/A \\
\cline { 2 - 6 } Exam/MC & $58 \%$ & $25 \%$ & $8 \%$ & $0 \%$ & $8 \%$ \\
Exam/essay & $0 \%$ & $17 \%$ & $25 \%$ & $17 \%$ & $42 \%$ \\
Nontextbook & $0 \%$ & $42 \%$ & $33 \%$ & $0 \%$ & $25 \%$ \\
\hline
\end{tabular}

Graduate Business Faculty: Uses of Reading Skills

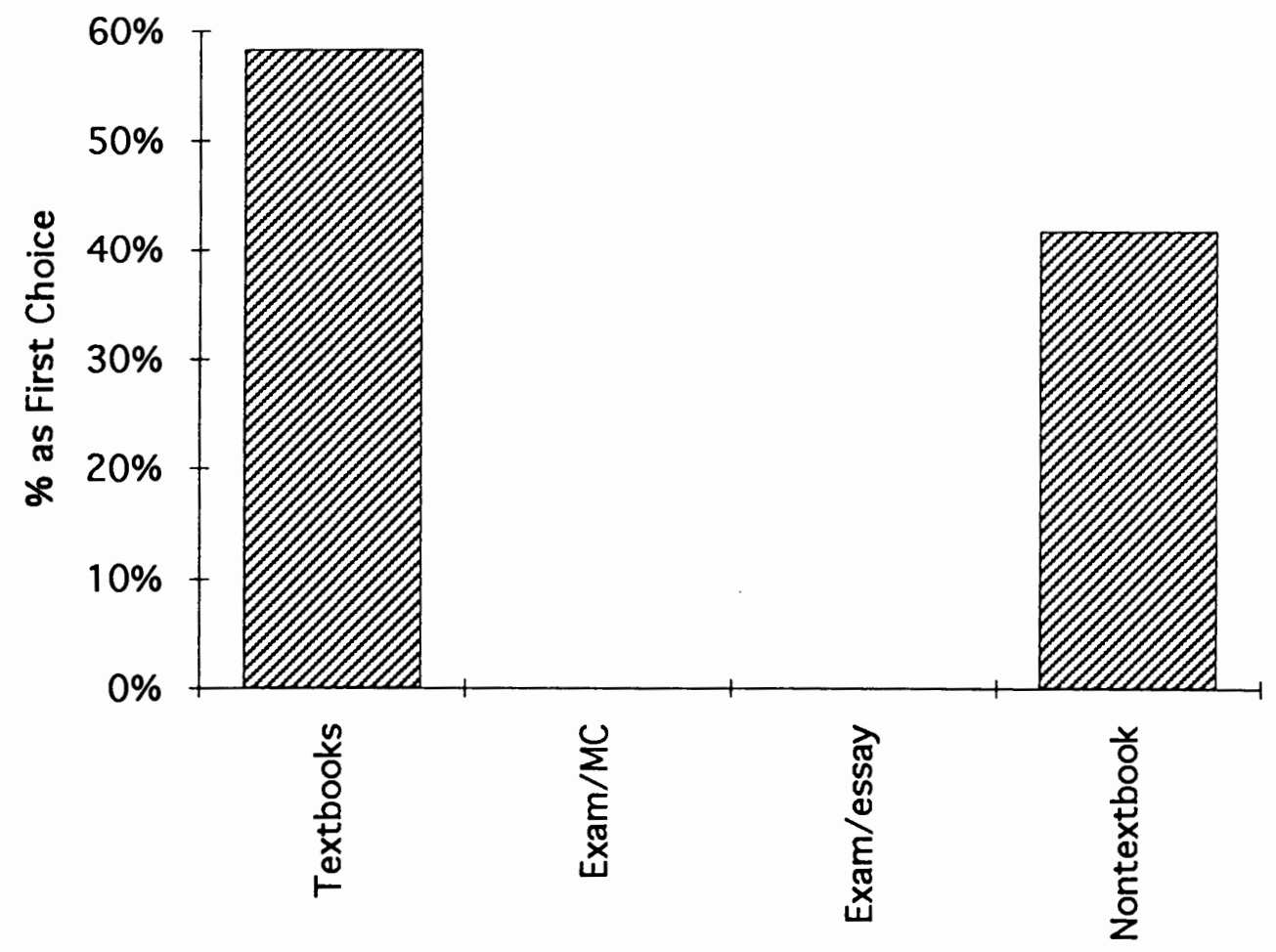

Uses 
Undergraduate Engineering Faculty: Reading Skill Uses

\begin{tabular}{|c|c|c|c|c|c|}
\hline \multicolumn{6}{|c|}{ Rankings - \#Responses } \\
\hline & 1 & 2 & 3 & 4 & $N / A$ \\
\hline Textbooks & 12 & 0 & 2 & 0 & 0 \\
\hline Exam $/ M C$ & 1 & 2 & 2 & 1 & 8 \\
\hline Exam/essay & 4 & 4 & 1 & 1 & 4 \\
\hline Nontextbook & 3 & 4 & 3 & 3 & 1 \\
\hline Other & 0 & 1 & 1 & 0 & \\
\hline Rankings \% & 1 & 2 & 3 & 4 & $N / A$ \\
\hline Textbooks & $86 \%$ & $0 \%$ & $14 \%$ & $0 \%$ & $0 \%$ \\
\hline Exam/MC & $7 \%$ & $14 \%$ & $14 \%$ & $7 \%$ & $57 \%$ \\
\hline Exam/essay & $29 \%$ & $29 \%$ & $7 \%$ & $7 \%$ & $29 \%$ \\
\hline Nontextbook & $21 \%$ & $29 \%$ & $21 \%$ & $21 \%$ & $7 \%$ \\
\hline Other & $0 \%$ & $7 \%$ & $7 \%$ & $0 \%$ & $0 \%$ \\
\hline
\end{tabular}

Undergraduate Engineering Faculty: Uses of Reading Skills

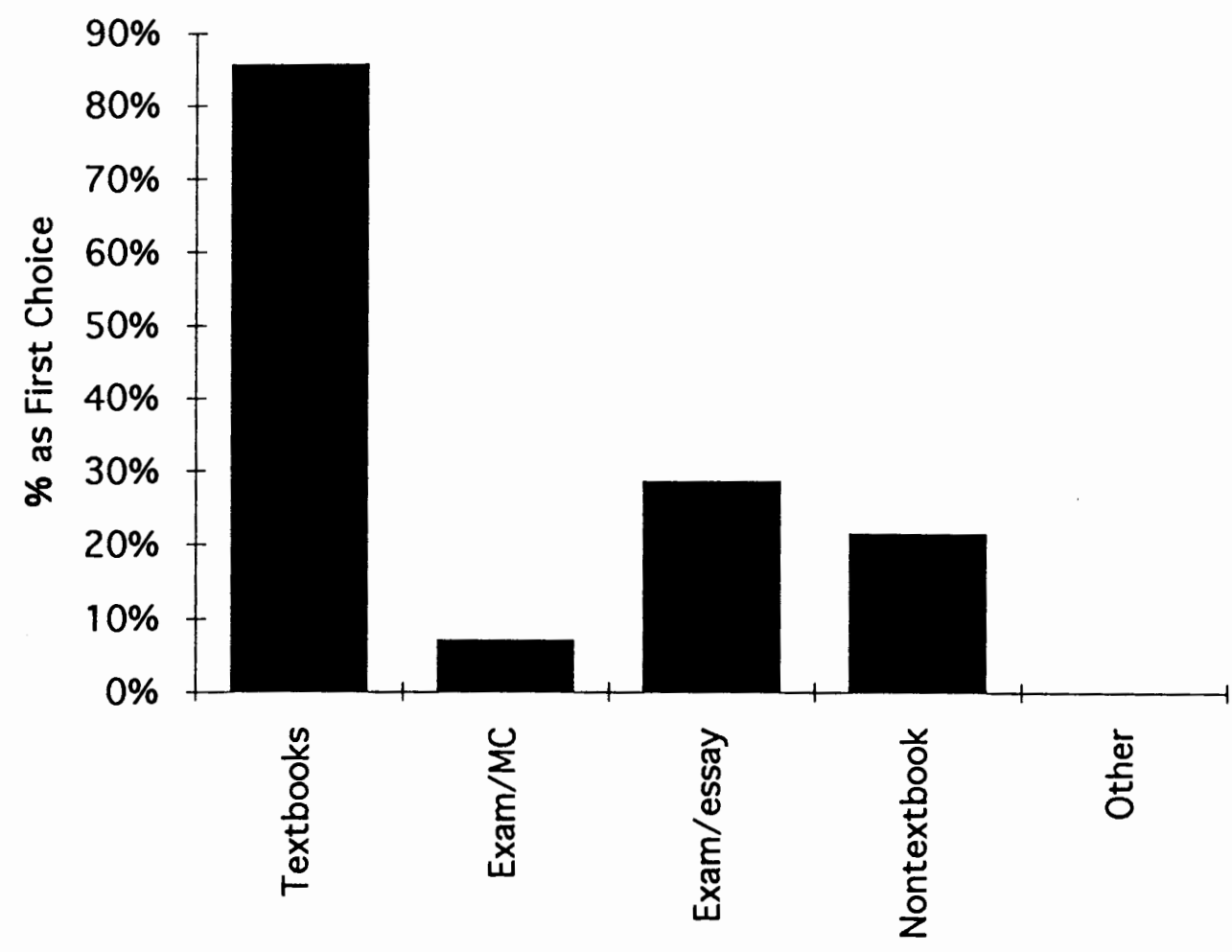

Uses 
Graduate Engineering Faculty: Reading Skill Uses

\begin{tabular}{|c|c|c|c|c|c|}
\hline \multicolumn{6}{|c|}{ Rankings - \#Responses } \\
\hline & 1 & 2 & 3 & 4 & $N / A$ \\
\hline Textbooks & 9 & 2 & 1 & 1 & 0 \\
\hline Exam $/ M C$ & 1 & 1 & 1 & 2 & 8 \\
\hline Exam/essay & 3 & 2 & 6 & 1 & 1 \\
\hline Nontextbook & 6 & 7 & 0 & 0 & 0 \\
\hline Other & 1 & 1 & 0 & 0 & 0 \\
\hline Rank \% & 7 & 2 & 3 & 4 & $N / A$ \\
\hline Textbooks & $69 \%$ & $15 \%$ & $8 \%$ & $8 \%$ & $0 \%$ \\
\hline Exam $/ M C$ & $8 \%$ & $8 \%$ & $8 \%$ & $15 \%$ & $62 \%$ \\
\hline Exam/essay & $23 \%$ & $15 \%$ & $46 \%$ & $8 \%$ & $8 \%$ \\
\hline Nontextbook & $46 \%$ & $54 \%$ & $0 \%$ & $0 \%$ & $0 \%$ \\
\hline Other & $8 \%$ & $8 \%$ & $0 \%$ & $0 \%$ & $0 \%$ \\
\hline
\end{tabular}

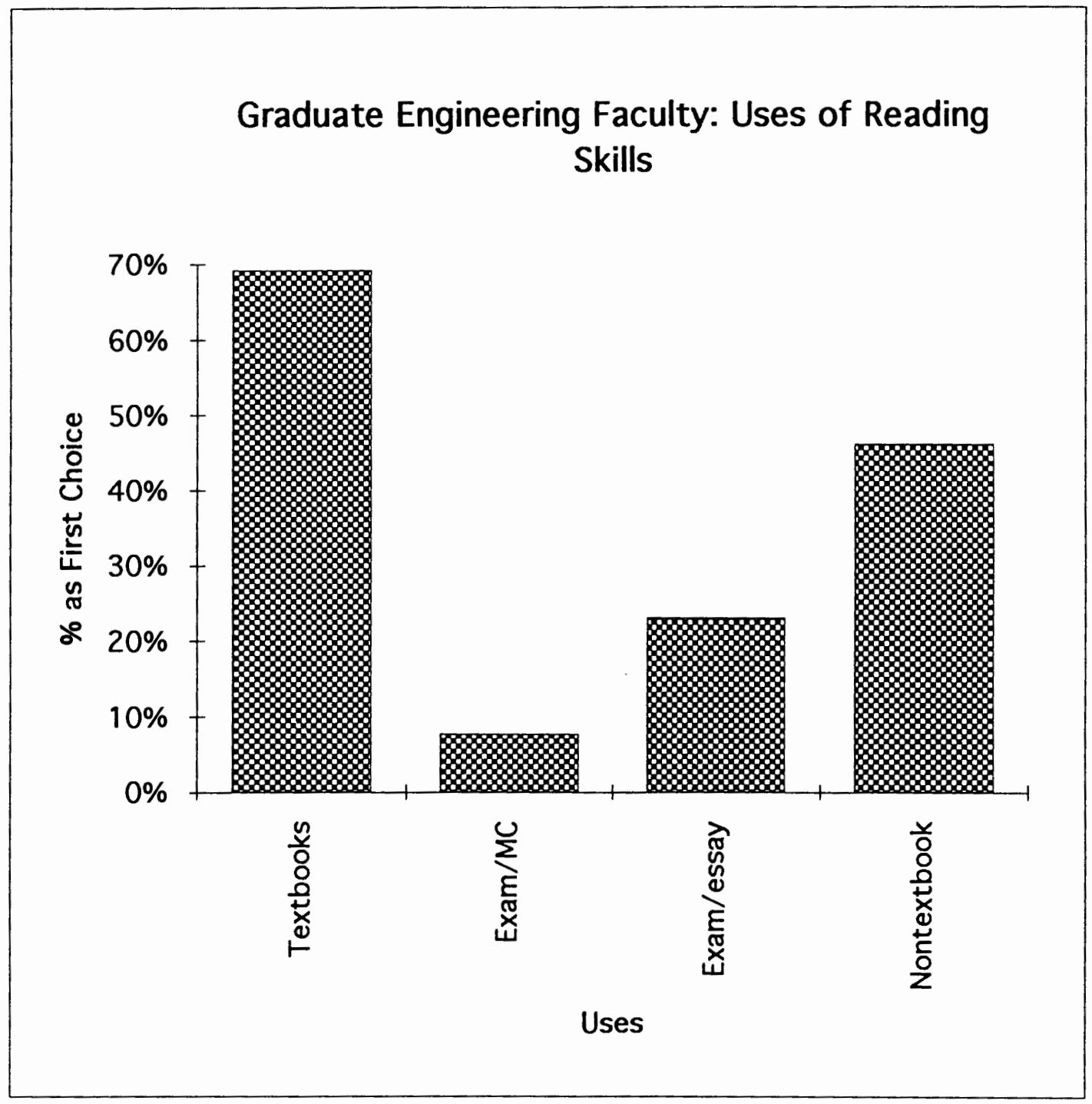


Undergraduate Business Faculty: Writing Skill Uses

\begin{tabular}{|c|c|c|c|c|c|}
\hline \multicolumn{6}{|c|}{ Rankings - \#Responses } \\
\hline & 1 & 2 & 3 & 4 & $N / A$ \\
\hline Reports & 5 & 5 & 4 & 0 & 2 \\
\hline Term papers & 7 & 4 & 3 & 1 & 1 \\
\hline ssay answers & 8 & 4 & 2 & 0 & 2 \\
\hline hort critiques & 1 & 0 & 2 & 2 & 11 \\
\hline Other & 0 & 2 & 1 & 1 & 0 \\
\hline
\end{tabular}

\begin{tabular}{|c|c|c|c|c|c|}
\hline \\
\hline \multicolumn{6}{|c|}{$\begin{array}{r}\text { Rankıngs - Percentage } \\
1\end{array}$} \\
\hline Reports & $31 \%$ & $31 \%$ & $25 \%$ & $0 \%$ & $13 \%$ \\
\hline Term papers & $44 \%$ & $25 \%$ & $19 \%$ & $6 \%$ & $6 \%$ \\
\hline ssay answers & $50 \%$ & $25 \%$ & $13 \%$ & $0 \%$ & $13 \%$ \\
\hline hort critiques & $6 \%$ & $0 \%$ & $13 \%$ & $13 \%$ & $69 \%$ \\
\hline Other & $0 \%$ & $13 \%$ & $6 \%$ & $6 \%$ & $0 \%$ \\
\hline
\end{tabular}

Undergraduate Business Faculty: Uses of Writing

Skills

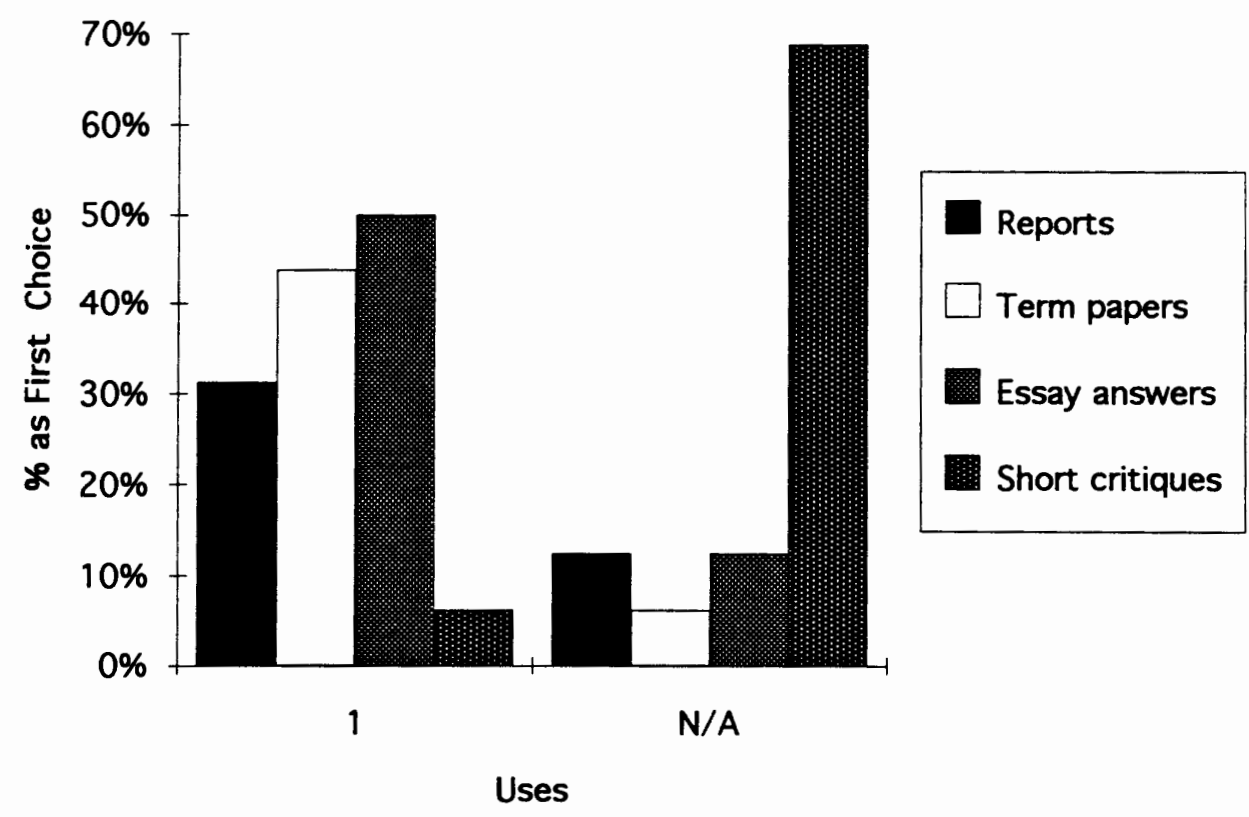


Graduate Business Faculty: Writing Skill Uses

\begin{tabular}{|c|c|c|c|c|c|}
\hline \multicolumn{6}{|c|}{ Rankings - \#Responses } \\
\hline & 1 & 2 & 3 & 4 & $N / A$ \\
\hline Reports & 6 & 3 & 3 & 0 & 0 \\
\hline Term papers & 3 & 5 & 2 & 1 & 1 \\
\hline ssay answers & 4 & 3 & 2 & 0 & 3 \\
\hline port critiques & 1 & 0 & 2 & 1 & 8 \\
\hline \multicolumn{6}{|c|}{ Rankings - Percentage } \\
\hline & 1 & 2 & 3 & 4 & $N / A$ \\
\hline Reports & $50 \%$ & $25 \%$ & $25 \%$ & $0 \%$ & $0 \%$ \\
\hline Term papers & $25 \%$ & $42 \%$ & $17 \%$ & $8 \%$ & $8 \%$ \\
\hline ssay answers & $33 \%$ & $25 \%$ & $17 \%$ & $0 \%$ & $25 \%$ \\
\hline hort critiques & $8 \%$ & $0 \%$ & $17 \%$ & $8 \%$ & $67 \%$ \\
\hline
\end{tabular}

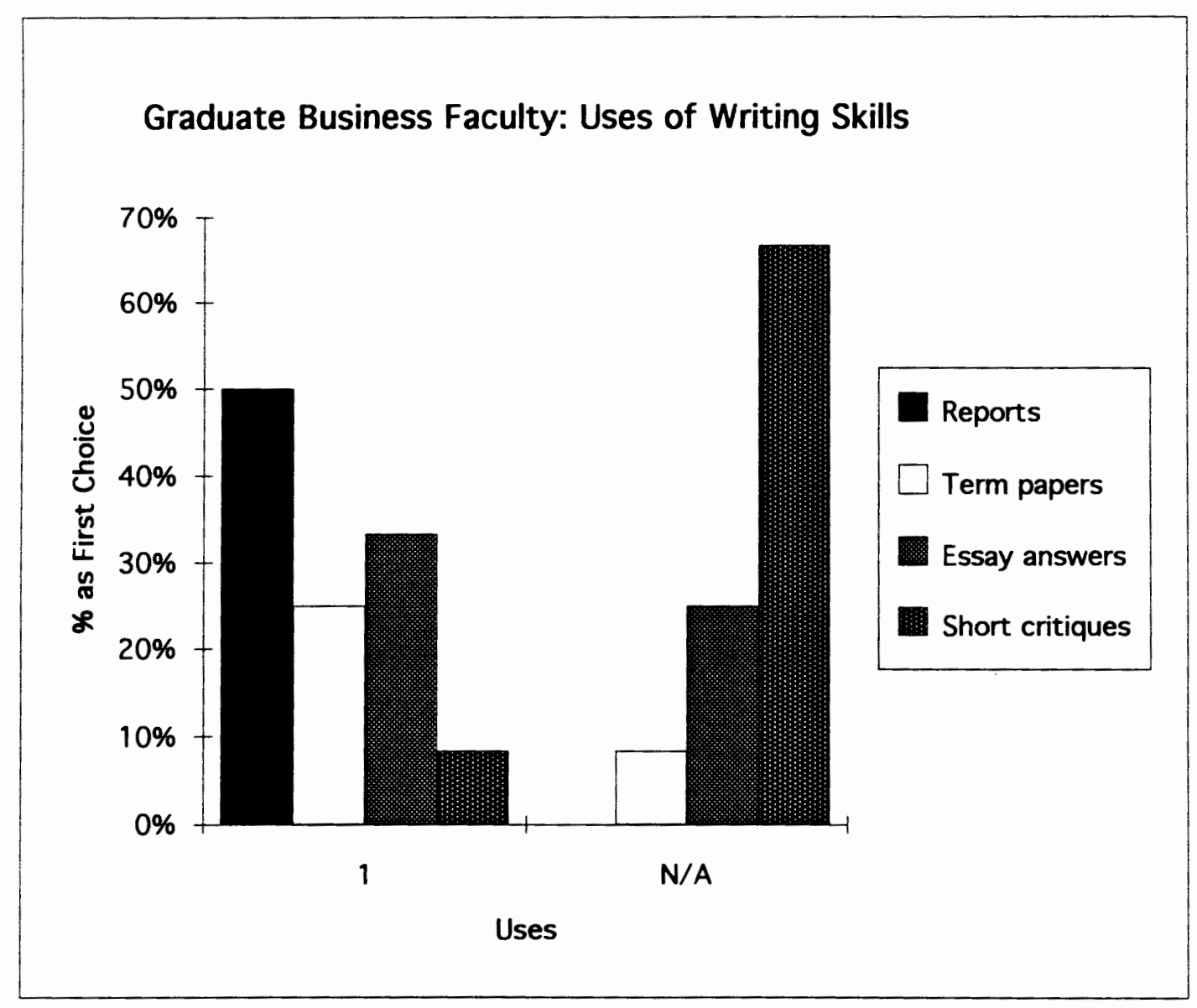


Undergraduate Engineering Faculty: Writing Skill Uses

\begin{tabular}{|c|c|c|c|c|c|}
\hline \multicolumn{6}{|c|}{ Rankings - \#Responses } \\
\hline & 1 & 2 & 3 & 4 & $N / A$ \\
\hline Reports & 5 & 8 & 0 & 0 & 1 \\
\hline Term papers & 3 & 3 & 2 & 1 & 5 \\
\hline ssay answers & 4 & 2 & 3 & 1 & 4 \\
\hline hort critiques & 0 & 0 & 4 & 2 & 8 \\
\hline Other & 3 & 1 & 0 & 0 & 1 \\
\hline Rankings \% & 1 & 2 & 3 & 4 & $N / A$ \\
\hline Reports & $36 \%$ & $57 \%$ & $0 \%$ & $0 \%$ & $7 \%$ \\
\hline Term papers & $21 \%$ & $21 \%$ & $14 \%$ & $7 \%$ & $36 \%$ \\
\hline ssay answers & $29 \%$ & $14 \%$ & $21 \%$ & $7 \%$ & $29 \%$ \\
\hline hort critiques & $0 \%$ & $0 \%$ & $29 \%$ & $14 \%$ & $57 \%$ \\
\hline Other & $21 \%$ & $7 \%$ & $0 \%$ & $0 \%$ & $7 \%$ \\
\hline
\end{tabular}

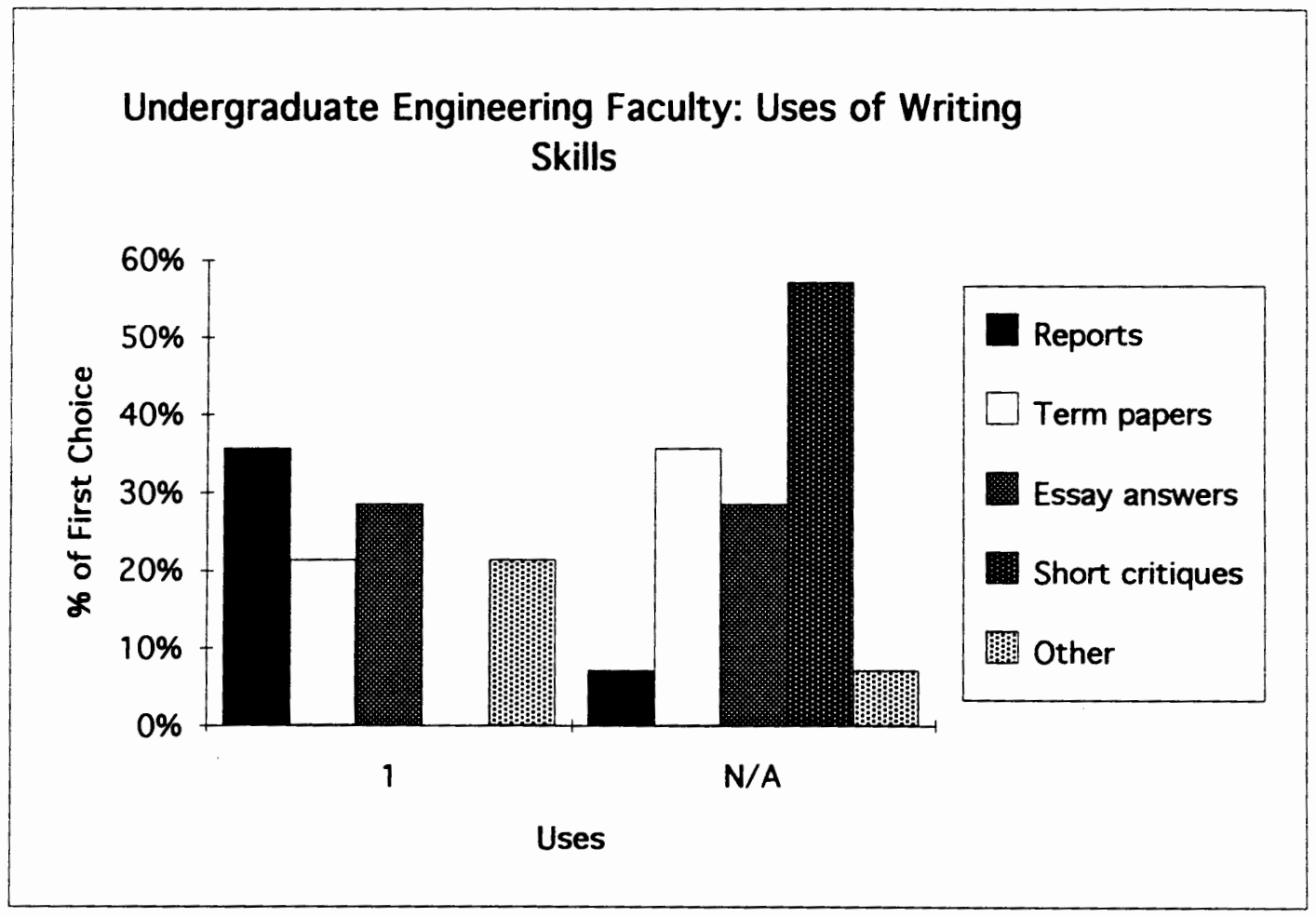


Graduate Engineering Faculty: Writing Skill Uses

\begin{tabular}{|c|c|c|c|c|c|}
\hline \multicolumn{6}{|c|}{ Rankings - \#Responses } \\
\hline & 1 & 2 & 3 & 4 & $N / A$ \\
\hline Reports & 6 & 3 & 3 & 1 & 0 \\
\hline Term papers & 4 & 6 & 2 & 0 & 1 \\
\hline ssay answers & 3 & 4 & 3 & 1 & 2 \\
\hline hort critiques & 0 & 0 & 4 & 3 & 6 \\
\hline Other & 0 & 2 & 3 & 1 & 0 \\
\hline Rankings \% & 1 & 2 & 3 & 4 & $N / A$ \\
\hline Reports & $46 \%$ & $23 \%$ & $23 \%$ & $8 \%$ & $0 \%$ \\
\hline Term papers & $31 \%$ & $46 \%$ & $15 \%$ & $0 \%$ & $8 \%$ \\
\hline ssay answers & $23 \%$ & $31 \%$ & $23 \%$ & $8 \%$ & $15 \%$ \\
\hline hort critiques & $0 \%$ & $0 \%$ & $31 \%$ & $23 \%$ & $46 \%$ \\
\hline Other & $0 \%$ & $14 \%$ & $21 \%$ & $7 \%$ & $0 \%$ \\
\hline
\end{tabular}

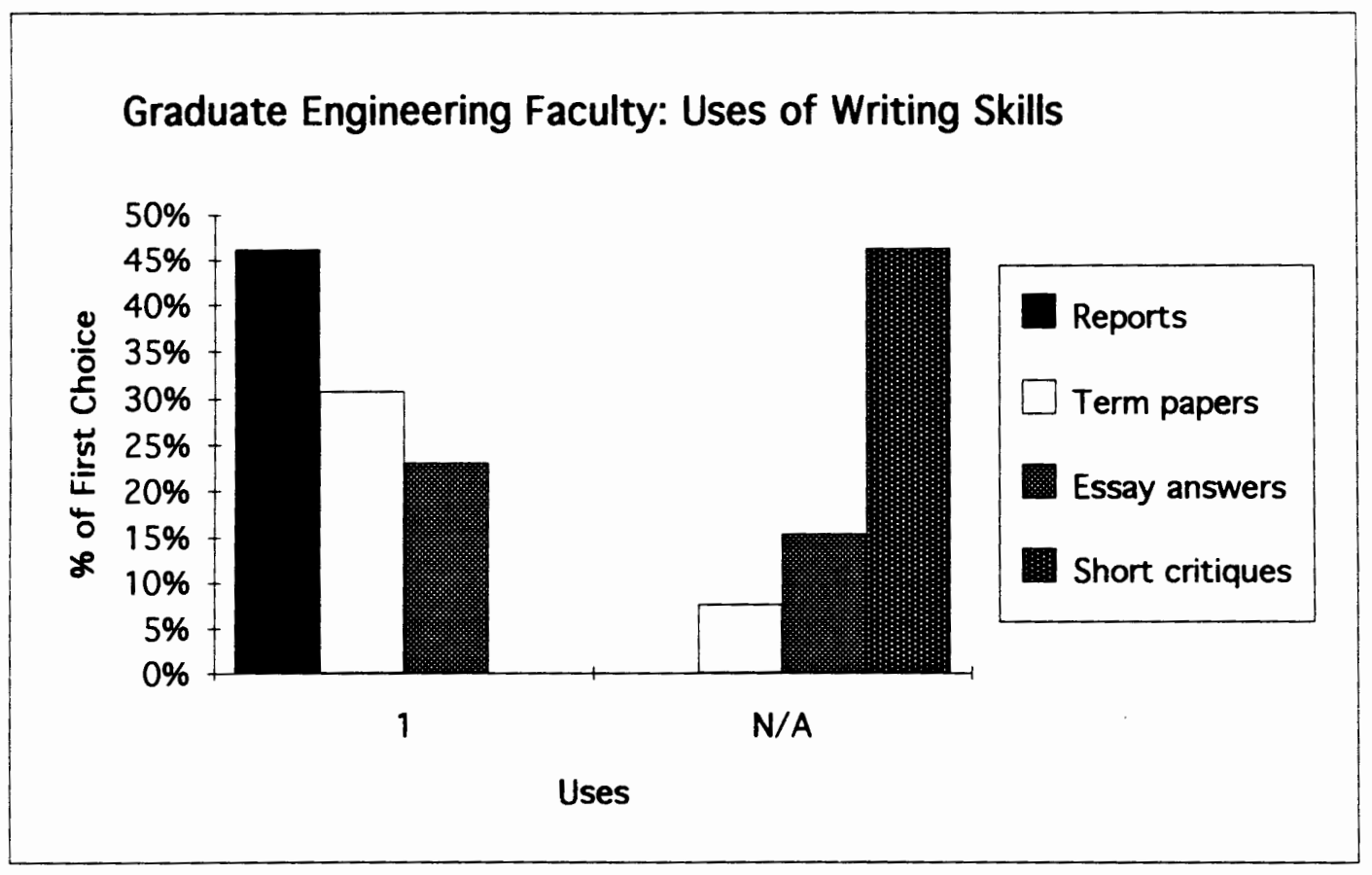


Undergraduate Business Faculty: Speaking Skill Uses

\begin{tabular}{|r|ccccc|}
\hline Rankings - \#Responses & 1 & 2 & 3 & 4 & N/A \\
\cline { 2 - 6 } ss discussion & 10 & 5 & 0 & 1 & 0 \\
Questions & 4 & 7 & 4 & 1 & 0 \\
Oral reports & 2 & 3 & 6 & 3 & 2 \\
Pronunciation & 2 & 3 & 2 & 6 & 3 \\
Other & 0 & 1 & 0 & 1 & 0 \\
\hline
\end{tabular}

\begin{tabular}{|r|c|c|c|c|c|}
\hline Rankings \% & 1 & 2 & 3 & 4 & N/A \\
\cline { 2 - 7 } ss discussion & $63 \%$ & $31 \%$ & $0 \%$ & $6 \%$ & $0 \%$ \\
Questions & $25 \%$ & $44 \%$ & $25 \%$ & $6 \%$ & $0 \%$ \\
Oral reports & $13 \%$ & $19 \%$ & $38 \%$ & $19 \%$ & $13 \%$ \\
pronunciation & $13 \%$ & $19 \%$ & $13 \%$ & $38 \%$ & $19 \%$ \\
Other & $0 \%$ & $6 \%$ & $0 \%$ & $6 \%$ & $0 \%$ \\
\hline
\end{tabular}

Undergraduate Business Faculty: Uses of Speaking

Skills

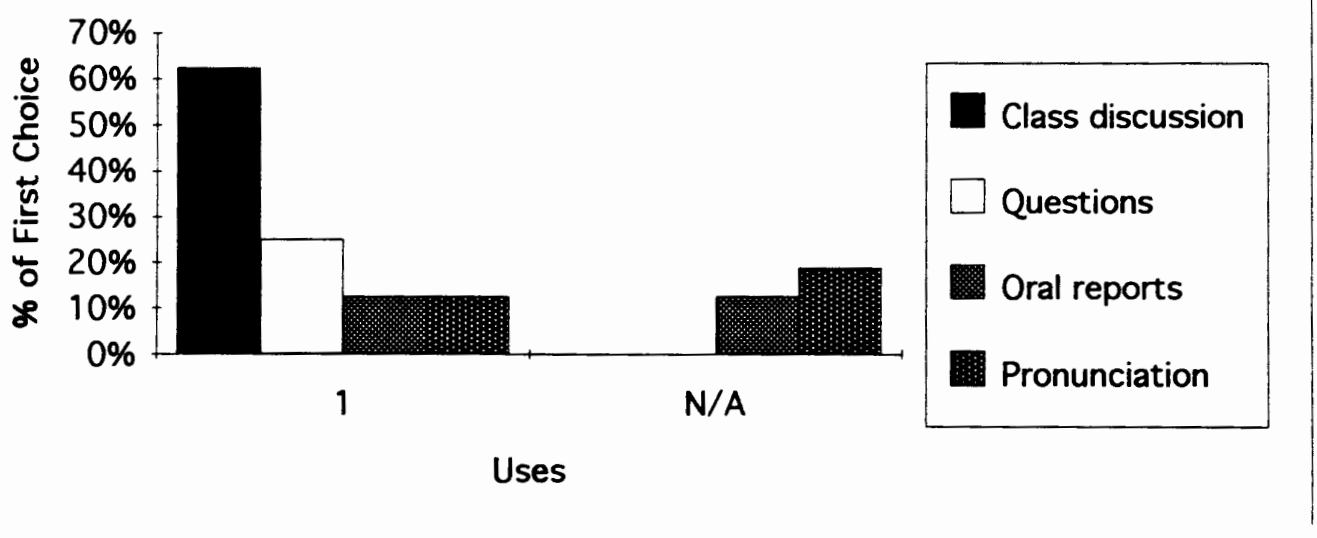


Graduate Business Faculty: Speaking Skill Uses

\begin{tabular}{|c|c|c|c|c|c|}
\hline \multicolumn{6}{|c|}{ Rankings - \#Responses } \\
\hline & 1 & 2 & 3 & 4 & $N / A$ \\
\hline ss discussion & 8 & 3 & 0 & 1 & 0 \\
\hline Questions & 4 & 5 & 2 & 1 & 0 \\
\hline Oral reports & 0 & 2 & 6 & 3 & 1 \\
\hline Pronunciation & 2 & 2 & 2 & 4 & 2 \\
\hline Other & 0 & 1 & 0 & 1 & 0 \\
\hline Rankings \% & 1 & 2 & 3 & 4 & $N / A$ \\
\hline ss discussion & $67 \%$ & $25 \%$ & $0 \%$ & $8 \%$ & $0 \%$ \\
\hline Questions & $33 \%$ & $42 \%$ & $17 \%$ & $8 \%$ & $0 \%$ \\
\hline Oral reports & $0 \%$ & $17 \%$ & $50 \%$ & $25 \%$ & $8 \%$ \\
\hline Pronunciation & $17 \%$ & $17 \%$ & $17 \%$ & $33 \%$ & $17 \%$ \\
\hline Other & $0 \%$ & $8 \%$ & $0 \%$ & $8 \%$ & $0 \%$ \\
\hline
\end{tabular}

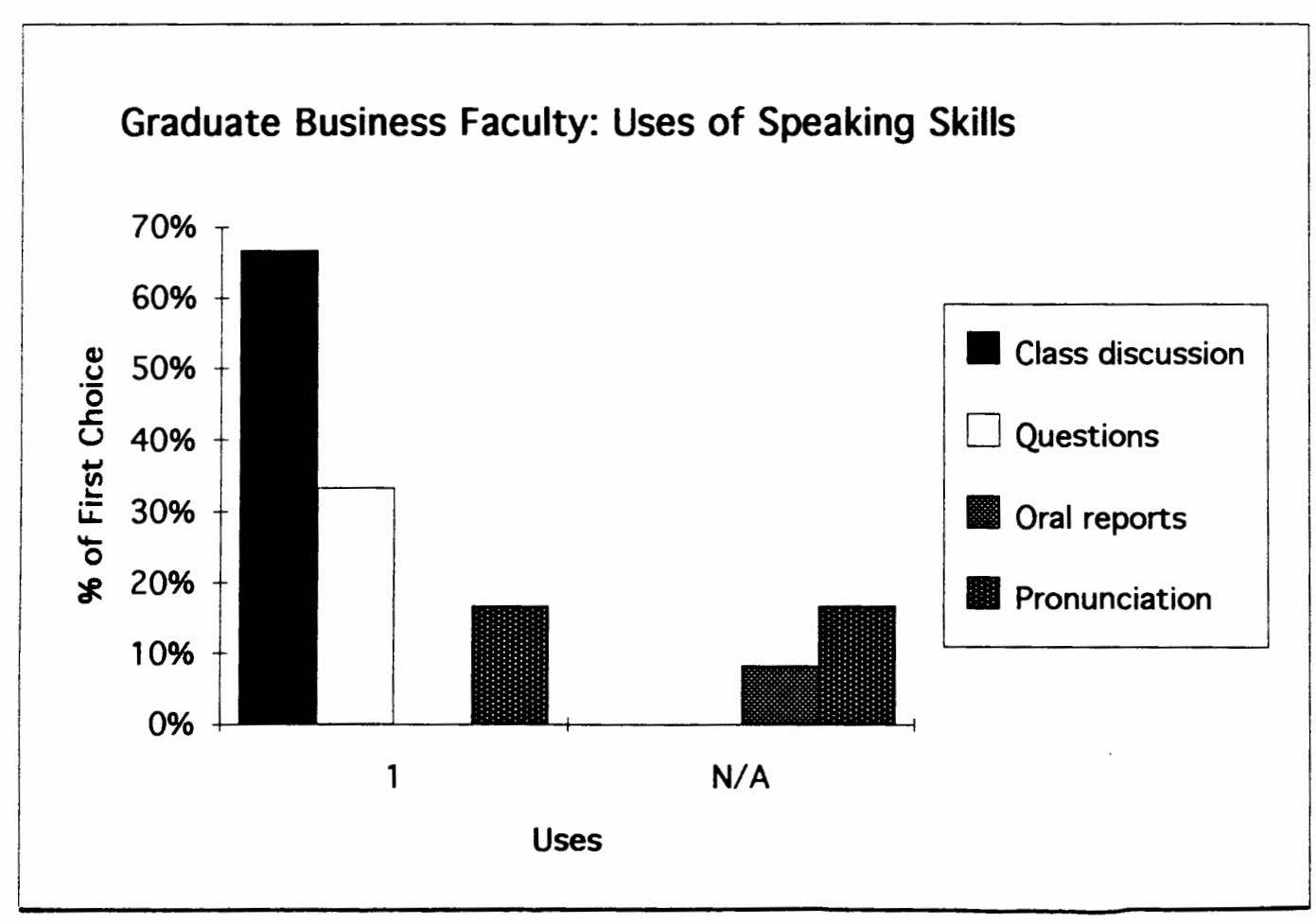


Undergraduate Engineering Faculty: Speaking Skill Uses

\begin{tabular}{|c|c|c|c|c|c|}
\hline \multicolumn{6}{|c|}{ Rankings - \#Responses } \\
\hline & 1 & 2 & 3 & 4 & $N / A$ \\
\hline ss discussion & 5 & 5 & 3 & 1 & 0 \\
\hline Questions & 5 & 7 & 2 & 0 & 0 \\
\hline Oral reports & 3 & 3 & 3 & 2 & 3 \\
\hline Pronunciation & 1 & 1 & 3 & 9 & 0 \\
\hline Other & 1 & 0 & 0 & 0 & 0 \\
\hline Rankings \% & 1 & 2 & 3 & 4 & $N / A$ \\
\hline ss discussion & $36 \%$ & $36 \%$ & $21 \%$ & $7 \%$ & $0 \%$ \\
\hline Questions & $36 \%$ & $50 \%$ & $14 \%$ & $0 \%$ & $0 \%$ \\
\hline Oral reports & $21 \%$ & $21 \%$ & $21 \%$ & $14 \%$ & $21 \%$ \\
\hline Pronunciation & $7 \%$ & $7 \%$ & $21 \%$ & $64 \%$ & $0 \%$ \\
\hline Other & $7 \%$ & $0 \%$ & $0 \%$ & $0 \%$ & $0 \%$ \\
\hline
\end{tabular}

Undergraduate Engineering Faculty: Uses of Speaking

Skills

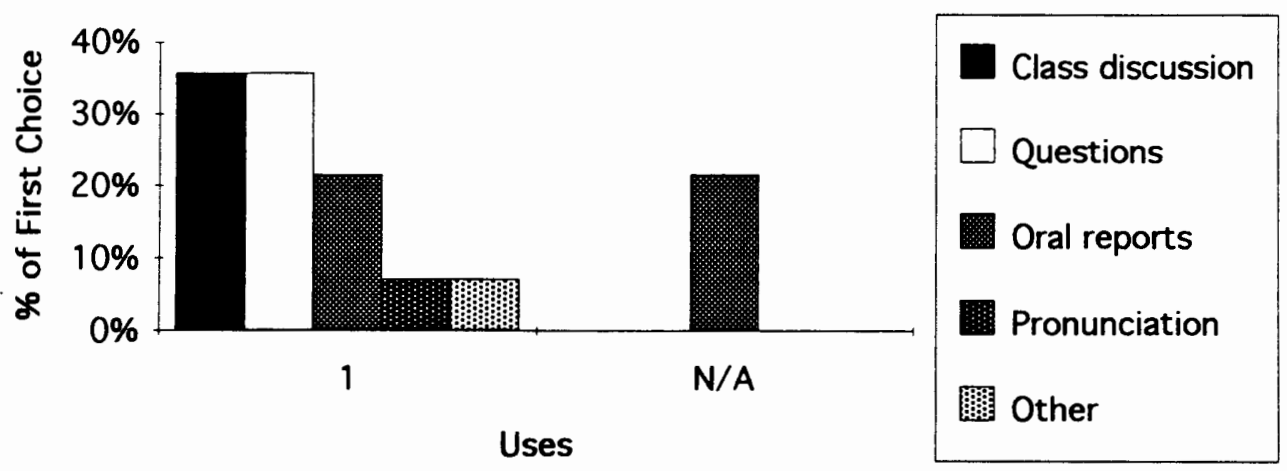


Graduate Engineering Faculty: Speaking Skill Uses

\begin{tabular}{|c|c|c|c|c|c|}
\hline \multicolumn{6}{|c|}{ Rankings - \#Responses } \\
\hline & 1 & 2 & 3 & 4 & $N / A$ \\
\hline ss discussion & 6 & 5 & 2 & 0 & 0 \\
\hline Questions & 3 & 3 & 7 & 0 & 0 \\
\hline Oral reports & 4 & 6 & 0 & 1 & 2 \\
\hline Pronunciation & 1 & 0 & 3 & 8 & 1 \\
\hline Rankings \% & 1 & 2 & 3 & 4 & $N / A$ \\
\hline ss discussion & $46 \%$ & $38 \%$ & $15 \%$ & $0 \%$ & $0 \%$ \\
\hline Questions & $23 \%$ & $23 \%$ & $54 \%$ & $0 \%$ & $0 \%$ \\
\hline Oral reports & $31 \%$ & $46 \%$ & $0 \%$ & $8 \%$ & $15 \%$ \\
\hline Pronunciation & $8 \%$ & $0 \%$ & $25 \%$ & $67 \%$ & $8 \%$ \\
\hline
\end{tabular}

\section{Graduate Engineering Faculty: Uses of Speaking Skills}

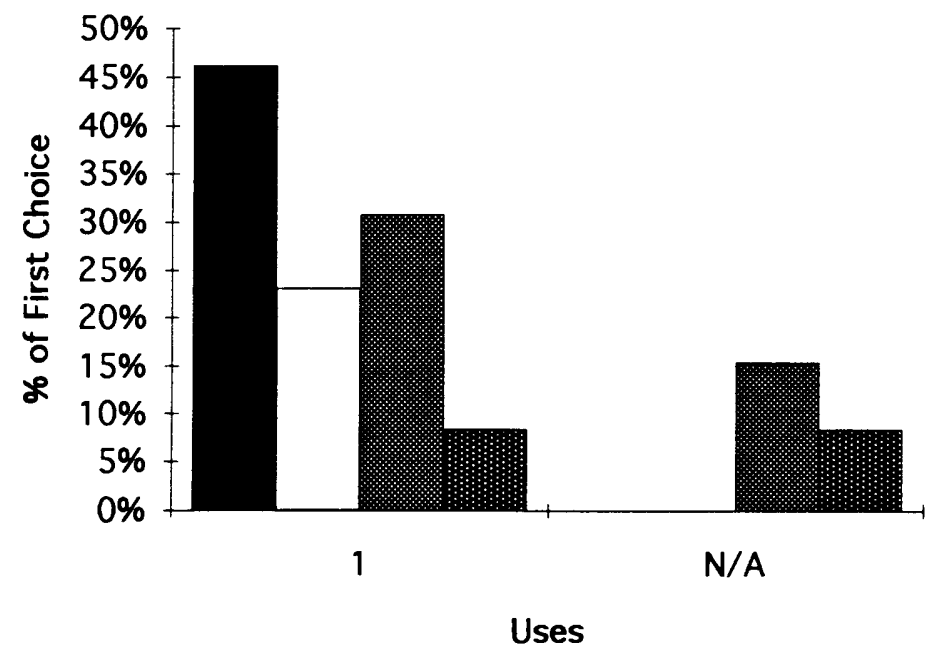

Class discussion

$\square$ Questions

Oral reports

雨 Pronunciation 
Undergraduate Business Faculty: Listening Skill Uses

\begin{tabular}{|c|c|c|c|c|c|}
\hline \multicolumn{6}{|c|}{ Rankings - \#Responses } \\
\hline & 1 & 2 & 3 & 4 & $N / A$ \\
\hline How direction & 0 & 5 & 9 & 2 & 0 \\
\hline state mater. & 6 & 6 & 2 & 2 & 0 \\
\hline Take notes & 8 & 4 & 2 & 2 & 0 \\
\hline Student talk & 3 & 2 & 2 & 9 & 0 \\
\hline
\end{tabular}




Graduate Business Faculty: Listening Skill Uses

\begin{tabular}{|c|c|c|c|c|c|}
\hline \multicolumn{6}{|c|}{ Rankings - \#Responses } \\
\hline & 1 & 2 & 3 & 4 & $N / A$ \\
\hline low direction & 1 & 1 & 6 & 3 & 1 \\
\hline state mater. & 6 & 4 & 1 & 1 & 0 \\
\hline Take notes & 5 & 3 & 2 & 1 & 1 \\
\hline Student talk & 3 & 3 & 1 & 5 & 0 \\
\hline \begin{tabular}{|l|} 
Rankings \% \\
\end{tabular} & 7 & 2 & 3 & 4 & $N / A$ \\
\hline low direction & $8 \%$ & $8 \%$ & $50 \%$ & $25 \%$ & $8 \%$ \\
\hline state mater. & $50 \%$ & $33 \%$ & $8 \%$ & $8 \%$ & $0 \%$ \\
\hline Take notes & $42 \%$ & $25 \%$ & $17 \%$ & $8 \%$ & $8 \%$ \\
\hline Student talk & $25 \%$ & $25 \%$ & $8 \%$ & $42 \%$ & $0 \%$ \\
\hline
\end{tabular}

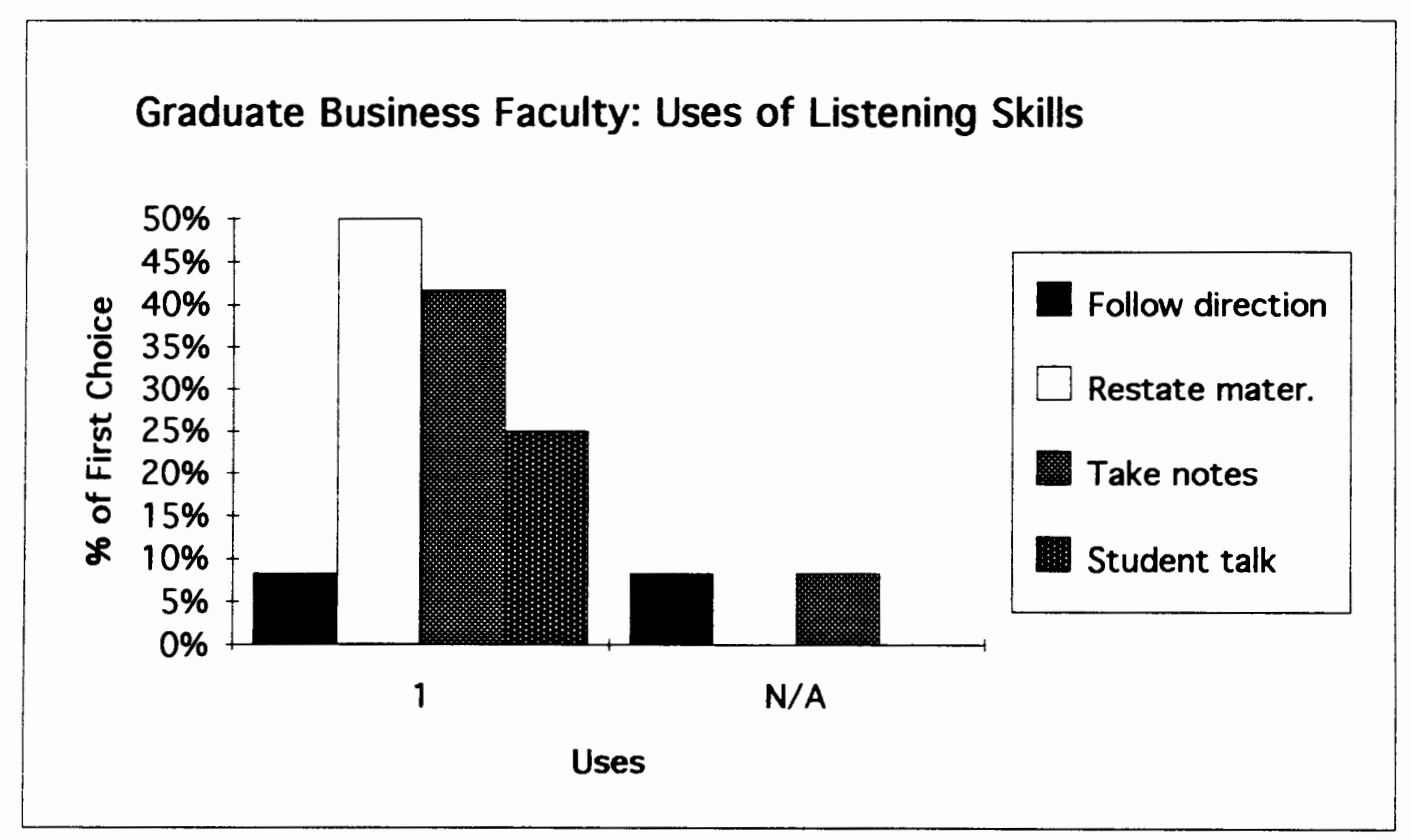


Undergraduate Engineering Faculty: Listening Skill Uses

\begin{tabular}{|l|ccccc|}
\hline \multicolumn{1}{|l}{ Rankings - \#Responses } & 1 & 2 & 3 & 4 & N/A \\
\cline { 2 - 7 } & 4 & 3 & 3 & 3 & 1 \\
How direction & 4 & 2 & 5 & 2 & 1 \\
state mater. & 8 & 6 & 0 & 0 & 0 \\
Take notes & 8 & 3 & 6 & 4 & 1 \\
Student talk & 0 & & & &
\end{tabular}

\begin{tabular}{|r|ccccc|}
\hline Rankings \% & 1 & 2 & 3 & 4 & N/A \\
\cline { 2 - 6 } How direction & $29 \%$ & $21 \%$ & $21 \%$ & $21 \%$ & $7 \%$ \\
state mater. & $29 \%$ & $14 \%$ & $36 \%$ & $14 \%$ & $7 \%$ \\
Take notes & $57 \%$ & $43 \%$ & $0 \%$ & $0 \%$ & $0 \%$ \\
Student talk & $0 \%$ & $21 \%$ & $43 \%$ & $29 \%$ & $7 \%$
\end{tabular}

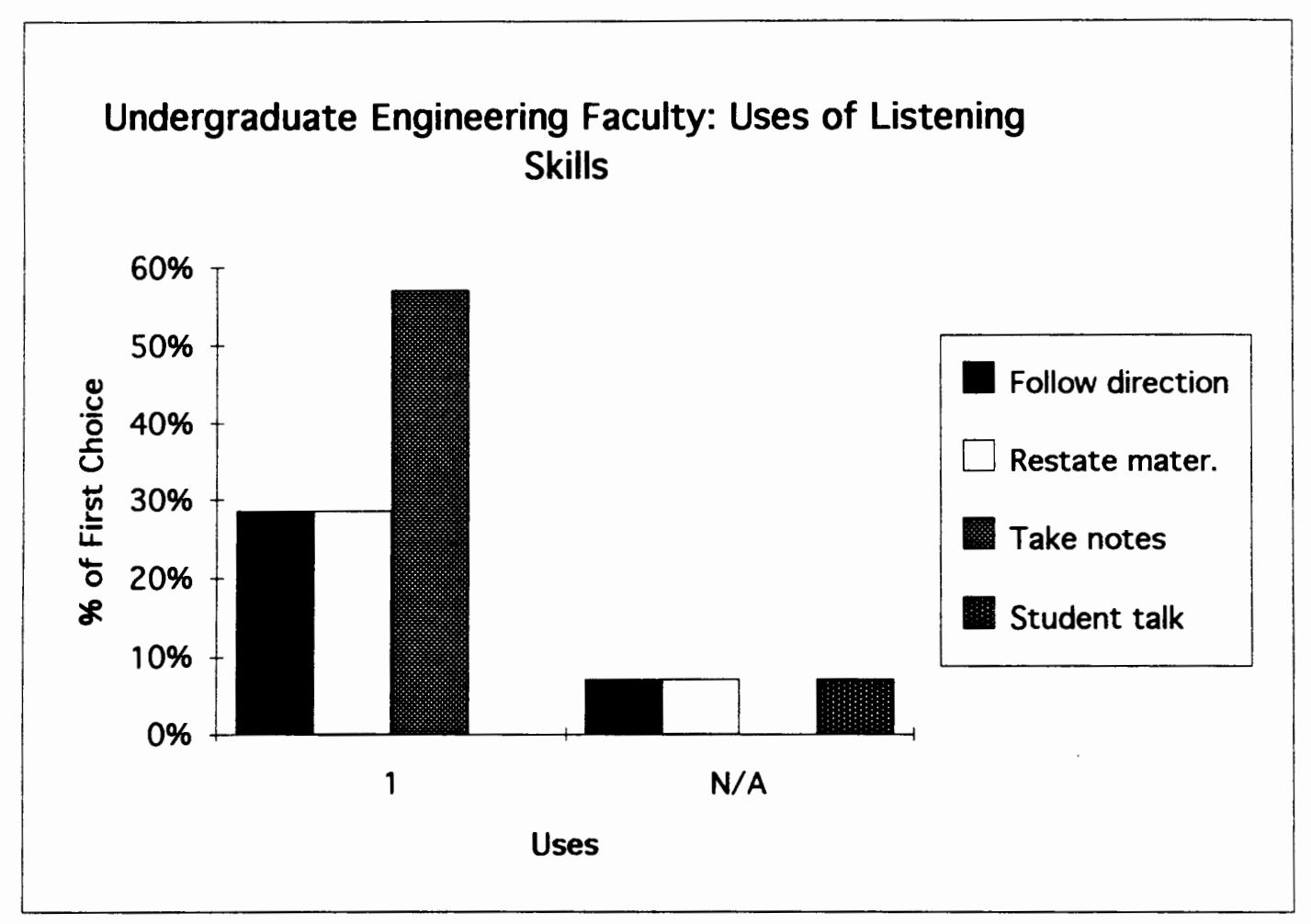


Graduate Engineering Faculty: Listening Skill Uses

\begin{tabular}{|c|c|c|c|c|c|}
\hline \multicolumn{6}{|c|}{ Rankings - \#Responses } \\
\hline & 1 & 2 & 3 & 4 & $N / A$ \\
\hline \multirow{4}{*}{$\begin{array}{l}\text { low direction } \\
\text { state mater. } \\
\text { Take notes } \\
\text { Student talk }\end{array}$} & 3 & 2 & 4 & 4 & 0 \\
\hline & 4 & 4 & 3 & 2 & 0 \\
\hline & 8 & 5 & 0 & 0 & 0 \\
\hline & 0 & 2 & 7 & 3 & 1 \\
\hline Rankings \% & 1 & 2 & 3 & 4 & $N / A$ \\
\hline llow direction & $23 \%$ & $15 \%$ & $31 \%$ & $31 \%$ & $0 \%$ \\
\hline estate mater. & $31 \%$ & $31 \%$ & $23 \%$ & $15 \%$ & $0 \%$ \\
\hline Take notes & $62 \%$ & $38 \%$ & $0 \%$ & $0 \%$ & $0 \%$ \\
\hline Student talk & $0 \%$ & $15 \%$ & $54 \%$ & $23 \%$ & $8 \%$ \\
\hline
\end{tabular}

\section{Graduate Engineering Faculty: Uses of Listening Skills}

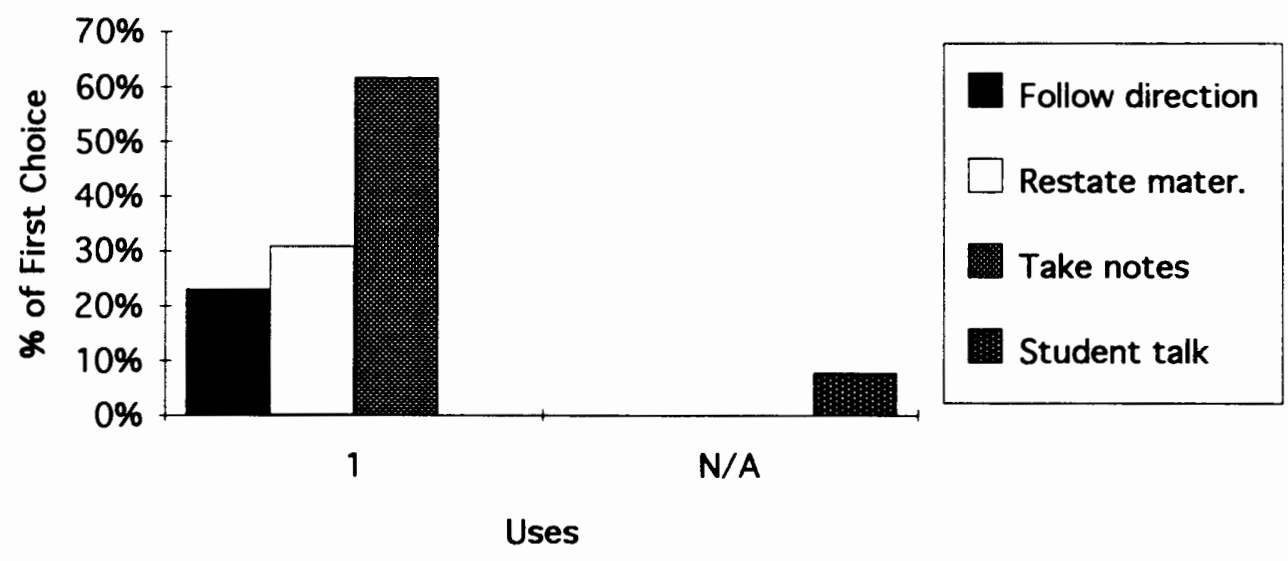




\section{APPENDIX F}

HIGHEST RANKINGS FOR LANGUAGE SKILLS

BY DISCIPLINE AND LEVEL

\begin{tabular}{|c|c|c|c|c|}
\hline Lang. Skill & Reading & Listening & Writing & Speaking \\
\hline Level & Undergraduate & Graduate & Undergraduate & Graduate \\
\hline $\begin{array}{c}\text { Discipline } \\
\text { Engineering }\end{array}$ & Engineering & Business & Business \\
\hline $\begin{array}{c}\% \text { of Faculty } \\
\text { important" }\end{array}$ & $71 \%$ & $62 \%$ & $31 \%$ & $42 \%$ \\
\hline
\end{tabular}

LOWEST RANKINGS FOR LANGUAGE SKILLS BY DISCIPLINE AND LEVEL

\begin{tabular}{|c|c|c|c|c|}
\hline Lang. Skill & Speaking & Writing & Listening & Reading \\
\hline Level & Undergraduate & Undergraduate & Undergraduate & Undergraduate \\
\hline $\begin{array}{c}\text { Discipline } \\
\text { E of Faculty } \\
\text { ranking"most } \\
\text { important" }\end{array}$ & $7 \%$ & $7 \%$ & $31 \%$ & Business \\
\hline
\end{tabular}




\section{HIGHEST RANKINGS FOR LANGUAGE SKILL USES \\ BY DISCIPLINE AND LEVEL}

\begin{tabular}{|c|c|c|c|c|c|}
\hline Skill Subset & Reading Uses & \multicolumn{2}{|c|}{ Writing Uses } & Speaking Uses & Listening Uses \\
\hline $\begin{array}{c}\text { Most } \\
\text { Important Use } \\
\text { of Skill }\end{array}$ & Textbooks & Essay Answers & Reports & Class Discuss & Take notes \\
\hline Level & Undergraduate & Undergraduate & Graduate & Graduate & Graduate \\
\hline $\begin{array}{c}\text { Discipline } \\
\text { \% of Faculty } \\
\text { ranking"most } \\
\text { important" }\end{array}$ & Engineering & Business & Business & Business & Engineering \\
\hline
\end{tabular}

\section{LOWEST RANKINGS FOR LANGUAGE SKILL USES BY DISCIPLINE AND LEVEL}

\begin{tabular}{|c|c|c|c|c|c|}
\hline Skill Subset & Reading Uses & Writing Uses & Speaking Uses & \multicolumn{2}{|c|}{ Listening Uses } \\
\hline Skill Use & $\begin{array}{c}\text { Multiple } \\
\text { Choice/ } \\
\text { essay exam }\end{array}$ & Short Critiques & Oral Reports & Student talk & $\begin{array}{c}\text { Follow } \\
\text { directions }\end{array}$ \\
\hline Level & Graduate & $\begin{array}{c}\text { Graduate/ } \\
\text { Undergraduate }\end{array}$ & Graduate & $\begin{array}{c}\text { Graduate/ } \\
\text { Undergraduate }\end{array}$ & Undergraduate \\
\hline $\begin{array}{c}\text { Discipline } \\
\text { \%of Faculty } \\
\text { ranking"most } \\
\text { important" }\end{array}$ & Business & Engineering & Business & Engineering & Business \\
\hline
\end{tabular}


COMPARISON OF "MOST IMPORTANT"

LANGUAGE SKILLS BY AVERAGE SCORE OF ALL FACULTY

\begin{tabular}{|c|c|c|c|c|}
\hline Lang. Skill & Reading & Listening & Speaking & Writing \\
\hline Average Score & $62 \%$ & $46 \%$ & $21 \%$ & $20 \%$ \\
\hline
\end{tabular}

COMPARISON OF "MOST IMPORTANT"

LANGUAGE SKILL USES BY AVERAGE SCORE OF ALL FACULTY

\begin{tabular}{|l|c|c|c|c|}
\hline B. READING & Textbooks & Non-textbooks & Exam/Essay & Exam/MC \\
\hline Average Score & $74 \%$ & $32 \%$ & $17 \%$ & $7 \%$ \\
\hline
\end{tabular}

\begin{tabular}{|c|c|c|c|c|}
\hline C. WRITING & Reports & Essay Answers & Term Papers & Short Critique \\
\hline Average Score & $41 \%$ & $34 \%$ & $31 \%$ & $4 \%$ \\
\hline
\end{tabular}

\begin{tabular}{|l|c|c|c|c|}
\hline D. SPEAKING & Class discuss. & Questions & Oral Reports & Pronunciation \\
\hline Average Score & $53 \%$ & $30 \%$ & $16 \%$ & $11 \%$ \\
\hline
\end{tabular}

\begin{tabular}{|l|c|c|c|c|}
\hline E. LISTENING & Take Notes & Restate Mater. & Follow Direct. & Student Talk \\
\hline Average Score & $53 \%$ & $37 \%$ & $15 \%$ & $11 \%$ \\
\hline
\end{tabular}




\section{GOALS OF PORTLAND STATE UNIVERSITY'S ENGLISH AS A SECOND LANGUAGE PROGRAM}

In 1964, Intensive English classes were established at PSU to assist students from Saudi Arabia in their English acquisition. The ESL program falls under the auspices of the Department of Applied Linguistics. Originally, the program had four levels (I-beginning, II-low intermediate, III-intermediate, and IV-advanced), each of which consisted of four components: grammar, reading, writing, and speaking/listening. The program no longer has a beginning level. Until 1989, there were also other classes offered: vocabulary, pronunciation, library, study skills, and cultural orientation. These functions are now included within the three main segments.

Currently, the program consists of three levels: lower intermediate, upper intermediate, and advanced classes. In addition to grammar, reading, writing, and speaking/listening, there is a preparatory class for the Test of English as a Foreign Language (TOEFL) for advanced students and a class to assist international graduate teaching assistants with their pronunciation, stress, intonation, and classroom teaching skills.

PSU requires undergraduate students from countries where English is not the primary language to achieve a minimum score on the TOEFL prior to beginning academic study. Students who fall between a score of 425 and 525 are tested using the Michigan Test of English Language Proficiency, the Comprehensive English Language Test, and an in-house writing test and placed in appropriate levels of ESL classes. An undergraduate who has attended and passed at least the highest level (Level IV) of ESL classes maybe allowed to 
begin academic courses with a TOEFL score of 500 and the permission of the ESL coordinator. 